Paula Jaqueline de Moura

\title{
CONTRIBUIÇÕES PARA O ESTUDO DA MEMÓRIA DE RECONHECIMENTO SOCIAL EM RATOS
}


PAULA JAQUELINE DE MOURA

\section{CONTRIBUIÇÕES PARA O ESTUDO DA MEMÓRIA DE RECONHECIMENTO SOCIAL EM RATOS}

Tese apresentada ao Instituto de Biociências da Universidade de São Paulo, para a obtenção de Título de Doutor em Ciências, na Área de Fisiologia Geral.

Orientador: Gilberto Fernando Xavier 
Moura, Paula Jaqueline de

M 929c Contribuição para o estudo da memória de reconhecimento social em ratos / Paula Jaqueline de Moura. -- São Paulo : P. J. M, 2008

176 pág

p.: il.

Tese (Doutorado) - Instituto de Biociências da Universidade de São Paulo. Departamento de Fisiologia, 2008.

1. Memória de reconhecimento social 2. Memória de longa duração 3. Comportamento social - Animal I.Universidade de São Paulo. Instituto de Biociências. Departamento de Fisiologia. II. Título. 
Paula Jaqueline de Moura

Contribuições para o estudo da memória de reconhecimento social em ratos

Tese apresentada ao Instituto de Biociências da Universidade de São Paulo, para a obtenção de Título de Doutor em Ciências, na Área de Fisiologia Geral.

\section{Comissão Julgadora}

Prof(a). Dr(a).

$\operatorname{Prof}(a) . \operatorname{Dr}(a)$.

Prof(a). Dr(a).

Prof(a). Dr(a).

Prof. Dr. Gilberto Fernando Xavier

Orientador 
Dedico este trabalho à toda minha família que contribuiu para que eu continuasse em busca dos meus ideais superando a distância que nos separa. E a Deus por estar sempre presente em todos os momentos difíceis da minha trajetória. 
"Um homem precisa viajar.

Por sua conta, não por meio de histórias, imagens, livros ou tv.

Precisa viajar por si, com seus olhos e pés, para entender o que é seu.

Para um dia plantar as suas próprias árvores e dar-lhes valor.

Conhecer o frio para desfrutar do calor. E o oposto.

Sentir a distância e o desabrigo para estar bem sob o próprio teto. Um homem precisa viajar para lugares que não conhece para quebrar essa arrogância que nos faz ver o mundo como o imaginamos, e não simplesmente como é ou pode ser; que nos faz professores e doutores do que não vimos, quando deveríamos ser alunos, e simplesmente ir ver".

Amyr Klink

"The future belongs to those who believe in the beauty of their dreams" Eleanor Roosevelt 
À Deus pela presença e conforto durante todos os momentos difícieis enfrentados nesta jornada.

À CAPES pelos 3 anos de apoio financeiro para o desenvolvimento de pesquisa no Brasil, e também por mais 1 ano de financiamento no Child Study Center da Yale University, EUA.

À CNPq e FAPESP que indiretamente contribuiram para a realização deste trabalho pelo financiamente de materiais e também animais para o uso no Laboratório de Neurociências e Comportamento.

Ao Prof. Dr. Gilberto Fernando Xavier por sua prontidão para discutir desenhos experimentais, resultados e suas interpretações sempre que solicitado. Por respeitar a individualidade de cada um de seus alunos. Obrigada pelas contribuições científicas e acadêmicas singulares que foram preponderantes na confecção deste trabalho que aconteciam não só em discussões em sua sala, mas também na hora do café. E claro, por suas habilidades únicas em construir equipamentos para testagem de comportamentos animais de qualquer tipo, programação de sistemas que controlem esses equipamentos que são, indubitavelmente, geniais.

Ao Prof. Dr. Marcos Tomanik Mercadante pelo apoio concedido ao longo desses anos. Por seu otimismo contagioso, por nunca exitar em dividir seus conhecimentos e ainda por incentivar novos pesquisadores à trilharem seus próprios caminhos.

To Prof. Dr. Paul J. Lombroso I would like to express my sincere gratitude for the opportunity to integrate with his research team. Paul has an extrodinary gift of being able to explain complicated things very simply and made the understanding of molecular biology fun. I would like to thank all the good friends I made at Yale who made my stay there plesant. To Prof. James Leckman I would like to thank for the invaluable advice about grant proposals and his unique and efficient way of discussing issues related to psychiatric disorders.

À Prof. Dra. Mirian Marques e pelo Prof. Dr. Menna-Barreto pelos ensinamentos dos princípios básicos de cronobiologia e sugestões pertinentes.

À Dra. Verónica Sandra Valentinuzzi pela convivência durante parte de seu pósdoutoramento no laboratório de Neurociências e Comportamento. Por apresentar-me à cronobiologia de um forma tão singular que de uma maneira irrefutável me vi pensando em 
todos os experimentos em uma perspectiva cronobiológica. Pelo exemplo de pesquisadora, mulher e Mãe.

À Dra. Lotte Renault pela motivação e seus ensinamentos teóricos mesmo estando à $16.000 \mathrm{~km}$ de distância. Representação de superação, inteligência impar e amizade acima de tudo. Sinto falta dos experimentos de final de semana, das conversas durante a corrida ou de volta pra casa, e claro discussões sobre todos os assuntos possíveis e imagináveis.

To Dr. Deepa Venkitaramani I would like to express my appreciation for her enthusiasm and inspiration in discussing with me all issues, from Vincent van Cogh to Immunoflourescence Microscopy. Also, I want to thank her for the wonderful times spent together inside and outside the lab. To Dr. Roman Tashev for his suggestions in some of the behaviorial experiments, for his good mood and for his valuable knoweldge about important deals. Also, Casey Perley, who was a pleasure to work with and also her voluntary assistance with the English language, e. g. the differences in the prounciation of similar words. To Dr Peter Olaussen for phonemnal advice not only related to behavioral neuroscience grant proposals, but also those which integrated behavorial nuroscience and its neurobiology.

To Dr. Paul Lombroso's team at Yale University (Dr. Deepa Venkitaramani, Dr. Roman Tashev, Casey Perly, Dr. Yang Zhan, Dr. Pradeep Kurup, Dr. YoungFang Zhang, Dr. Jian Xu, Li Ding and Cong Huang) for the multi-cultural experience given to me. "Hello!" "Draty!" (Bulgarian), "Ni Hau" (Chinese - mandarim) and "Vanakkam" (Indian - Tamil).

To Ginny, an essential key of Child Study Center, always smilling, great sense of humor and such a great enthusiasm to help portuguese speaking people with the english language! Ginny thank you so much for the Cinque Tierre tip! I would like to thank the animal facility team due to competence, profissionalism, and special attention when some of my animals had health problems (special thank to Rachel Ardito).

Aos amigos Dra. Rosane Gomez, Dra. Fabiana Feitosa e Dr. Thiago Castilho que possuem em comum determinação e competência que devem ser tomadas como exemplo. Dra. Rosane especialmente pela amizade e dicas científicas valiosas. Por estar sempre disposta à abrir sua casa para que pudessemos nos confratenizar à moda brasileira ("pizzada" às sexta anoite e bolo de brigadeiro de sobremessa), pela lavagem de roupa e caminhadas no final de tarde para desestressar. À Dra. Fabiana Feitosa pelo seu bom humor, pela amizade, pelo "seu jeito" de lidar com algumas turbulações com um humor que é só seu. Ao Thiago Castilho pela disposição em ajudar sempre, pela presença nas pizzadas de sexta mesmo que atrasado algumas horas e a culpa era sempre do camundongo. 
Ao João pela amizade, apoio constante, bom humor incomparável e ser humano ímpar. Sempre disposto à contribuir desde a manipulação dos muito mais de 200 animais (e com bom humor durante todo o processo) até nos muitos "despachos" para os diferentes lugares que a neurociência me levou. Por seu exemplo de humildade, perserverança e caráter. Ainda dividimos o "parto" da tese e dissertação ao mesmo tempo! Mas agora vai, conseguimos!

Aos integrantes diretos e indiretos do laboratório de Neurociências e Comportamento: Adriano, André Chagas, André Kanamura, Andréa, Arnaldo, Barbara, Claudia Marote, Claudia Salai, Cyrus, Diego, Edson, Elaine, Felipe, Frazão, Graciele, Ilton, João, Jóice, Leopoldo, Lotte, Mariana Mattos, Marson, Neander, Renata, Rodrigo Colino, Rodrigo Pavão, Sylvinha, Verónica, Viviane e Wataru, pelo convívio, apoio constante, e por sempre estarem dispostos à discussões importantes e claro, confraternizações. Também aos funcionários do Departamento de Fisiologia: Érika, Helder, Roseli, Vera, Gisele, Ricardo, Manoel, Henrique, Dona Irani, Rose e Francisco por sempre estarem dispostos à contribuir.

À minha "teacher" Cida, não só professora de inglês, mas companheira, psicóloga, mãe e acima de tudo amiga. Obrigada por ter aceito um desafio aparentemente impossível, você foi capaz de me guiar pelos caminhos da língua inglesa, da qual devo admitir ter tido aversão por muitos anos, mas com o seu jeitinho não foi tão doloroso assim. Thank you teacher, you are the best!

À Eliane Fujisawa, amiga de todas as horas, que me entende mesmo não entendendo muito que eu faço. Me acompanha desde a faculdade aonde o problema eramos "tirar 7.0" para não ficar de exame. Depois seguimos caminhos distintos, eu na busca da carreira acadêmica e Eliane nos caminhos da reabilitação fisioterapêutica; mesmo assim, isso não foi motivo para que nossas vidas se afastassem. Eliane acompanhou minhas angustias no mestrado bem de perto, e as de doutorado de longe fisicamente, mas sempre presente na forma de um e-mail, conversas no MSN ou telefonemas, sempre com palavras de apoio e incentivo. Minha irmã por escolha, e com ela ganhei uma outra irmã (Elisiane) e também uma outra Mãe (Dona Nena) que sempre me receberam muito bem, e que sei que me querem bem.

À todos os amigos especiais que me acompanharam nessa longa trajetória especialmente Dr. Wanderson Alves pelo incentivo, pelos anos (muitos) anos de amizade que iniciaram-se lá atrás, nos anos das competições de karatê. À Viviane Abreu pelos conselhos na hora certa e por ter sempre uma palavra de apoio, obrigada! À Ticiane Oliveira, amiga de 
sempre, daquelas que mesmo após meses sem nos falar quando nos falamos parece que não foi tanto tempo assim.

À todos os meus familiares (a melhor família do mundo) pelo apoio incondicional. Meus “irmãos” Cláudio (pelos conselhos com precisão cirúrgica e sempre na hora certa), Adilson (pelo exemplo, amizade e por ter aprendido aquela receita de pizza!) e Wagner (pelo bom humor incomparável, não tem como estar com você sem sorrir), suas respectivas "senhoras" Eunice, Krycia e Denise por serem companhias sempre tão agradáveis. Também aos Tios e Tias tão especiais: Antônio, Osmar, Orlando, Raimundo, Maria Dalva, Lucilene, Cida e Suzana. Especialmente à minha Avó Orlinda (in memoriam) exemplo de força e perseverança, saudades Vó.

Ao meu irmão, Délcio Filho, pelo carisma, pela competência e sensibilidade. Por sempre conseguir distrair-me do "meu mundo", e mais, por mostrar-me o mundo de uma outra perspectiva, de uma maneira "artística". Obrigada por sempre estar disposto à ajudar, pelos ensinamentos fotográficos (ainda não consigo fazer o panning, mas ainda chego lá), por ser uma pessoa cativante, e claro, por ser meu irmão! Sucesso!

Às minhas Mães Abadia e Divina por sempre me apoiarem de maneira incondicional, mesmo quando eu ligo dizendo: "Mães estou indo para os EUA por 1 ano". Sei que todos nós pensávamos que eu voltaria pra casa logo após o término da faculdade, mas se vão anos e mais anos... A distância é muito difícil e dolorosa, mas acho que também ela nos ensina a darmos valor à quem se é de direito. Amo muito vocês, duas mulheres batalhadoras que são meu exemplo de vida. Obrigada! Também, ao Délcio, meu "pai"-drasto que está comigo desde que me conheço por gente. Pessoa de caráter admirável, ser humano simples, bondozo e exemplo à ser seguido. Obrigada por tudo! E pelos três terem me ensinado o valor da honestidade, coragem, persistência, e humildade acima de todas as outras virtudes.

To Dan, I would like to thank him for his support, understanding and for making each day better than the last one.

Gostaria de agradecer todas as pessoas que contribuíram direta ou indiretamente no processo de construção deste trabalho.

Paula Moura

São Paulo, Junho/2008 
MOURA, P.J. Contribuições para o estudo da memória de reconhecimento social em ratos. 2008. 176 f. Tese (Doutorado em Fisiologia Geral) - Instituto de Biociências, Universidade de São Paulo, São Paulo, 2008.

O paradigma intruso-residente vem sendo intensamente empregado em estudos para avaliar a memória de reconhecimento social em roedores. Tipicamente, ratos adultos, denominados residentes, são expostos a dois encontros sucessivos, de 5 minutos cada, com um mesmo rato juvenil ou com ratos juvenis diferentes, denominados intrusos; o intervalo de tempo entre encontros é 30 minutos. A quantidade de comportamentos sociais do residente (no segundo encontro) em relação a um intruso familiar é substancialmente menor do que o observado no primeiro encontro, o que não ocorre quando o segundo encontro envolve um juvenil novo; esse resultado caracteriza a memoria de reconhecimento social. Se o intervalo de tempo entre os encontros é aumentado para 60 minutos, a redução da investigação social do intruso familiar por parte do residente desaparece, levando à conclusão de que a memória de reconhecimento social seria um mecanismo para retenção temporária de informações. $\mathrm{O}$ objetivo central do presente trabalho foi contribuir para o entendimento da memória de reconhecimento social em ratos. Foram realizados três experimentos. No primeiro experimento avaliou-se se a expressão de comportamentos sociais e também da memória de reconhecimento social estão sujeitos à modulação temporal. No segundo experimento avaliou-se em que extensão o aumento do tempo de exposição ao intruso durante o primeiro encontro resulta num aumento da duração da memoria de reconhecimento social. No terceiro experimento avaliou-se se um procedimento de rotina na maioria dos laboratorios, o transporte dos animais da sala de experimentos para o biotério, interfere na memória de reconhecimento social, quando realizado 0,5 ou 6 horas após o primeiro encontro. Os resultados mostraram que (1) a expressão de comportamentos sociais e a memória de reconhecimento social estão sujeitos à modulação temporal, sendo mais intensos quando os testes são realizados na fase inativa (Capítulo 2), de modo que este fator deve ser levado em consideração quando do planejamento de experimentos envolvendo sociabilidade, (2) o aumento da duração do primeiro encontro para 2 horas ou mais revelou uma memória de reconhecimento social que dura pelo menos 24 horas (Capítulo 3), permitindo questionar que se trate de um dispositivo de curta duração, e (3) o transporte dos animais para o biotério 0,5 horas, mas não 6 horas, depois do primeiro encontro, prejudica a memória de reconhecimento social (Capítulo 4), indicando que se deve estar atento às rotinas laboratoriais pois as mesmas 
podem interferir no desempenho dos animais em testes de memória. Em associação com essas relevantes observações experimentais, foram propostas estratégias de análise dos dados gerados com esse tipo de experimentação e também discussões conceituais sobre a caracterização da memória de reconhecimento social, que contribuem marcadamente para essa área de estudos.

Palavras-chave: paradigma intruso residente, memória de reconhecimento social, sociabilidade, PCA, análise de comportamento, região anogenital, comportamentos sociais, memória de longa duração, rotinas de laboratório, modulação temporal, Wistar, comportamento social agonístico, comportamento social investigativo, familiar. 
MOURA, P.J. Contributions to the study of social recognition memory in rats. 2008. $176 \mathrm{f}$. Tese (Doutorado em Fisiologia Geral) - Instituto de Biociências, Universidade de São Paulo, São Paulo, 2008.

The intruder-resident paradigm has been extensively employed in studies of social recognition memory in rodents. Typically, adult rats, named residents, are exposed to two 5-min successive encounters with the same juvenile intruder or with two different juveniles; the time interval between the encounters is $30 \mathrm{~min}$. The amount of social behaviors exhibited by the resident rats towards the same intruder juvenile in the second encounter is substantially smaller when compared to both that seen in the first encounter and that seen towards a different juvenile; these results characterize social recognition memory. When the time interval between encounters is increased to $60 \mathrm{~min}$, that reduction of the investigation towards the familiar juvenile intruder vanishes, which is seen as evidence that social recognition memory corresponds to a short-term memory mechanism. The aim of this study was to contribute for our understanding of social recognition memory in rats. Three experiments were run. The first experiment evaluated to which extent both social behaviors and social recognition memory are influenced by temporal phase effects. The second experiment evaluated to which extent the increase in the duration of the first encounter renders social recognition memory longer. The third experiment evaluated to which extent the transportation of the resident rats from the experimental room to the animal facilities either 0.5 or 6 hours after the first encounter, interferes with social recognition memory. The results showed that (1) the expression of social behaviors and of the social recognition memory are modulated temporal phase effects, being stronger when animals are tested in their inactive phase (Chapter 2); thus, this aspect has to be considered in studies on sociability, (2) the increase of the first encounter duration for 2 hours or longer renders social recognition memory to last at least 24 hours (Chapter 3); this allows to question that social recognition memory corresponds to a short-term memory mechanism, and (3) transportation of the resident rats to the animal facilities 0.5 , but not 6 hours, after the end of the first encounter disrupts social recognition memory (Chapter 4), indicating that one has to be cautious about usual laboratory routines, because they may interfere with performance of the memory tasks when executed a short time after training the animals.Associated with these relevant experimental observations, these studies allowed proposing novel strategies for data analysis and discussing conceptual issues 
about the characterization of social recognition memory that give a substantial contribution for this area.

Key words: rat, intruder resident paradigm, social recognition memory, PCA, behavioral analysis, anogenital region, social behaviors, long term memory, laboratory routine, temporal modulation, Wistar, social investigatory behavior, social agonistic behavior, familiar 


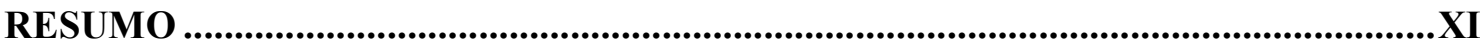

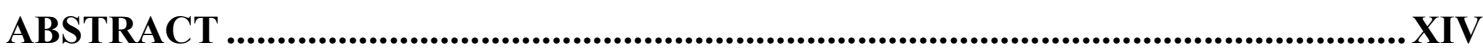

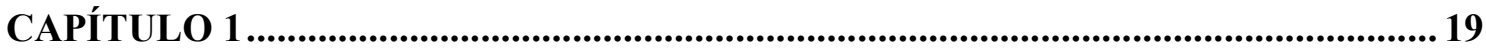

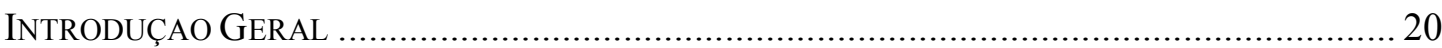

1.1 Os comportamentos sociais e a memória de reconhecimento social.....................20

1.2. Memória de reconhecimento social e fase temporal........................................... 31

1.3. Memória de reconhecimento social e interferência de rotinas laboratoriais ....... 33

1.4. Aspectos críticos da memória de reconhecimento social ..................................... 35

1.4.1. Processamento de informações sociais: ação de feromônios? ………………...... 36

1.4.2. Regiões nervosas relacionadas a memória de reconhecimento social em

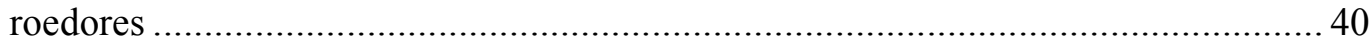

1.4.3. Neurotransmissores que modulam a memória de reconhecimento social ......... 43

1.5. Alternativas adicionais para o estudo da socialidade em roedores ..................... 45

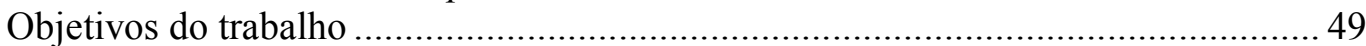

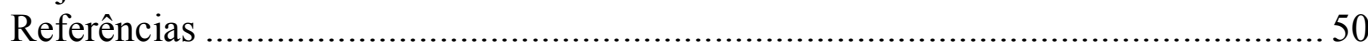

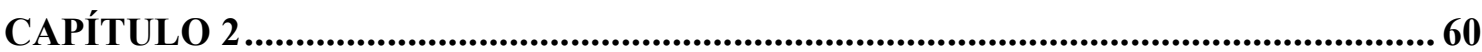

FASE CIRCADIANA E INTERVALO ENTRE ENCONTROS INTERFEREM NA MEMÓRIA DE

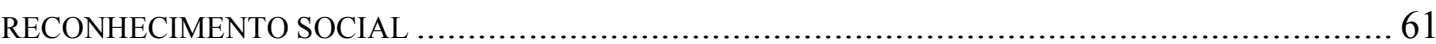

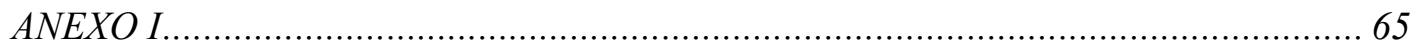

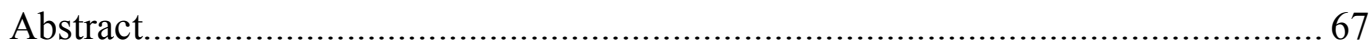

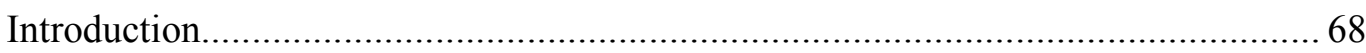

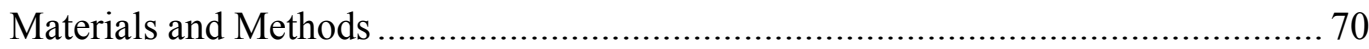

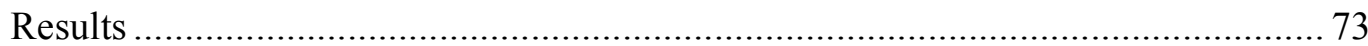

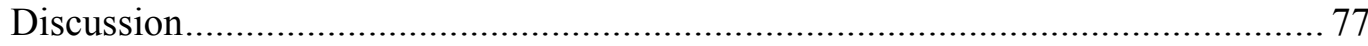

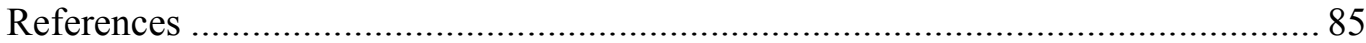

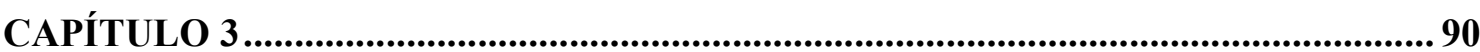

A MEMÓRIA DE RECONHECIMENTO SOCIAL EM RATOS PODE DURAR PELO MENOS 24 HORAS:

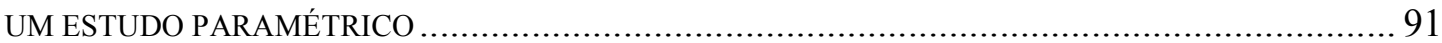

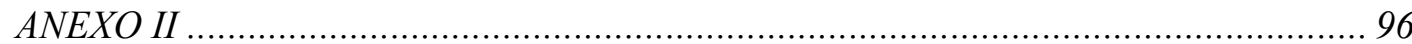

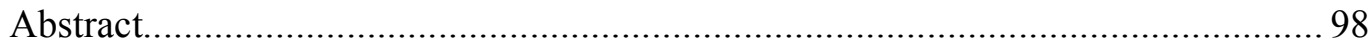

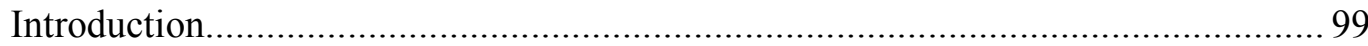

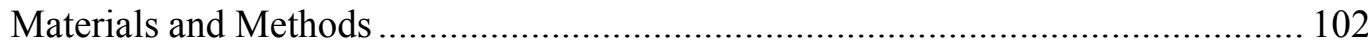

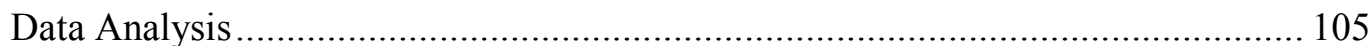

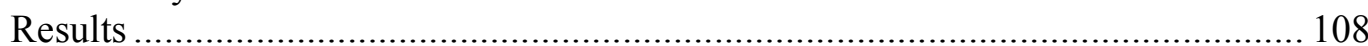

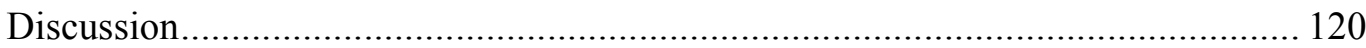

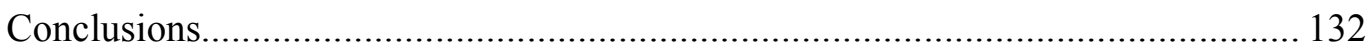

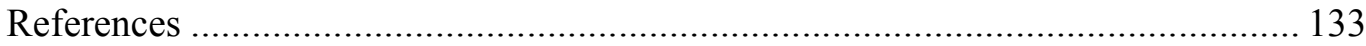

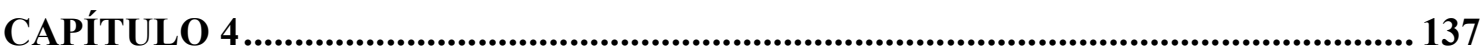

O PARADIGMA INTRUSO-RESIDENTE: ROTINAS LABORATORIAIS IGNORADAS QUE PODEM

INTERFERIR NA MEMÓRIA DE RECONHECIMENTO SOCIAL …………………………......... 138

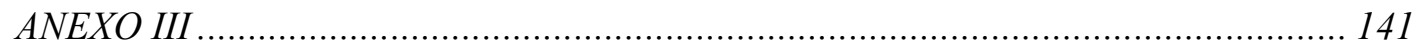




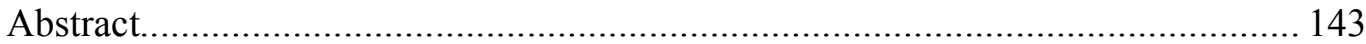

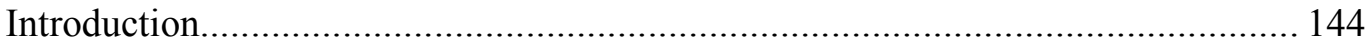

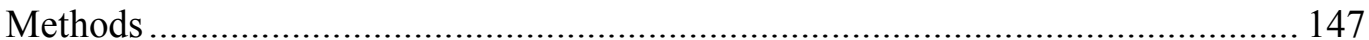

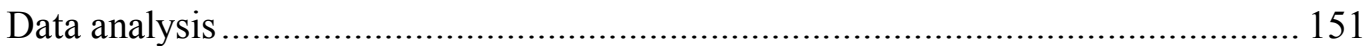

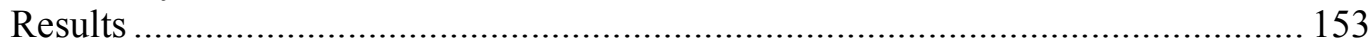

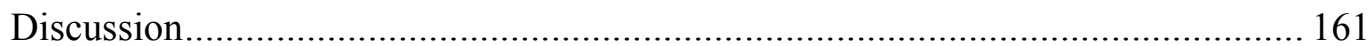

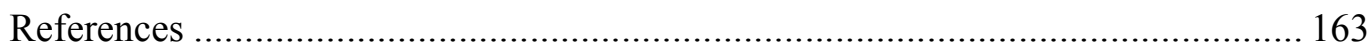

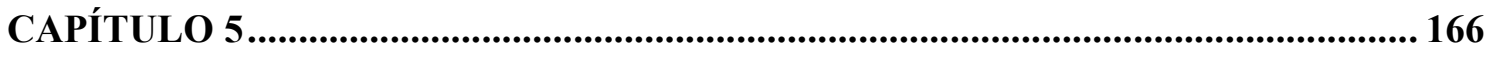

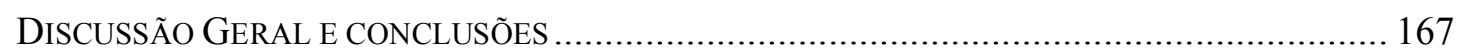

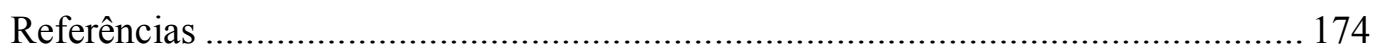


CAPÍTULO 1

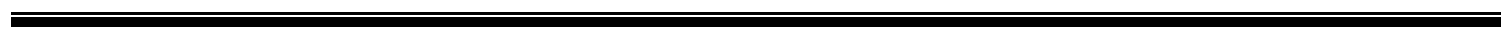




\section{INTRODUÇAO GERAL}

A investigação dos mecanismos fisiológicos, celulares e moleculares vinculados aos comportamentos sociais em modelos animais têm contribuído para o entendimento de comportamentos complexos como a relação de dominância-subordinação, comportamentos sexuais e os de agressão. Todos esses comportamentos têm como pano de fundo lembranças de encontros sociais passados, também conhecidas como memória de reconhecimento social. Parte do desafio em desvelar a neurofisiologia vinculada à sociabilidade se deve à dificuldade de controlar as interações sociais que são, per se, extremamente complexas.

Neste trabalho serão abordados os testes utilizados para inferir sobre a memória de reconhecimento social em roedores, a partir da mensuração de comportamentos sociais emitidos a co-específicos, em função de sua experiência social prévia. Dentre dos fatores que parecem influenciar esse tipo de memória e que serão objeto de análise experimental neste estudo incluimos a influência dos ritmos circadianos, condições de acondicionamento e de realização dos experimentos, duração dos testes, variáveis comportamentais incluídas no estudo e formas de análise dos resultados.

\subsection{Os comportamentos sociais e a memória de reconhecimento social}

Relações sociais são construídas e mantidas a partir das interações entre indivíduos. O reconhecimento de um indivíduo como integrante de um dado grupo social é fundamental para o funcionamento do grupo. Existem vantagens adaptativas na formação de grupos sociais, e. g., (1) animais em grupos são atacados menos freqüentemente do que animais solitários, (2) o desgaste físico para alcançar e abater uma caça é menor, pois vários animais se engajam na busca da presa resultando em maior eficiência, (3) a convivência com animais senis proporciona aos mais jovens a aprendizagem, por imitação, de tarefas essenciais para a 
sobrevivência como a caça ou outras informações importantes como local de açudes que não secam em períodos de estiagem prolongada (Slater, 2000). Com o intuito de estudar como relações sociais são construídas e mantidas, experimentos de laboratório envolvendo animais sociais vêm sendo empregados.

O estudo sistemático do comportamento social de roedores teve início em meados do último século. As primeiras tentativas de identificar comportamentos sociais em roedores levaram à categorização de interações definidas como comportamento de "luta" (fighting behavior) (Davis, 1933; Hall e Klein, 1942). Na década de 1960, estudos baseados também em observações comportamentais de animais definiram a postura "agressiva" (Grant e Mackintosh, 1963). No mesmo ano, Grant (1963) realizou uma análise minuciosa das posturas observadas em encontros sociais de ratos entre 75 e 120 dias de idade, ao longo de sessões de 15 minutos, e relatou 60 tipos diferentes de posturas, incluindo as categorias "agressão" e "luta". Grant (1963) ressaltou a ocorrência de posturas representativas de "mudança de atividade" (displacement activity). Essas posturas aparentemente irrelevantes do ponto de vista da interação social eram assumidas pelos animais quando dois comportamentos estavam fortemente estimulados concomitantemente, quando um deles estivesse extremamente ativado, ou ainda em situações de frustração (Grant, 1963). Comportamentos como beber, comer, escavar, autolimpeza (self-grooming), permanecer na diagonal em relação ao outro animal (sideways posture), entre outros, também seriam, segundo Grant (1963), indicativos de "mudanças de atividade"

Posteriormente, sugeriu-se que os comportamentos sociais poderiam ser classificados em quatro categorias principais, incluindo comportamentos sociais de exploração, contato social direto, comportamentos vinculados à atenção (attentive behaviors) e comportamentos "do tipo" agressivo. Os comportamentos sociais de exploração incluiriam aqueles nos quais um rato investiga o outro cheirando e lambendo, ou mesmo utilizando suas 
vibrissas (Popik e Van Ree, 1998); investigação anogenital parece extremamente importante para a aquisição de informações sobre o co-específico (Popik e Van Ree, 1998). Contatos sociais incluem passar por cima ou por baixo do co-específico, montar e limpeza social (social grooming) (Popik e Van Ree, 1998). Comportamentos de atenção incluem aproximação e perseguição do co-específico. Comportamentos do tipo agressivo incluem mordiscadas, “chutes” e posturas agressivas (Popik e Van Ree, 1998).

Atualmente, na tentativa de simplificar a análise dos comportamentos sociais em laboratório, têm-se observado o tempo que os animais permanecem próximos um do outro (Sekiguchi et al., 1991b; Burman e Mendl, 2000; Ferguson et al., 2000; Ferguson et al., 2001). Por um lado, esse tipo de padronização simplifica a análise comportamental, inclusive pela possibilidade de se utilizar métodos automáticos de registro. Porém, ela limita a análise das informações sobre a natureza dos comportamentos eliciados no encontro social, e seu possível significado, restringindo a compreensão dos fatores que contribuem para a interação social.

Tem sido comum, em estudos sobre memória de reconhecimento social, a inclusão de determinados padrões de comportamento exemplificados na Figura 1. 
A

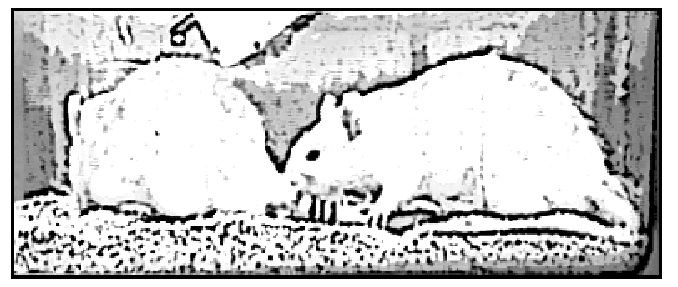

C

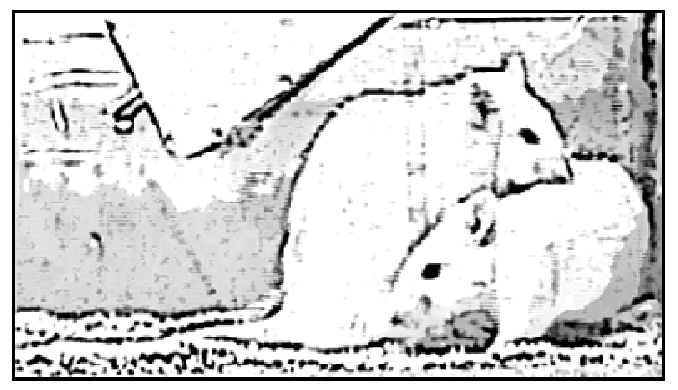

$\mathbf{E}$

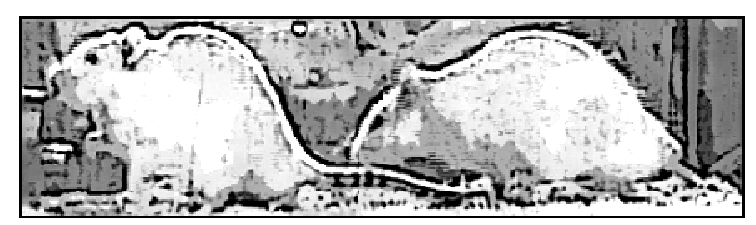

B

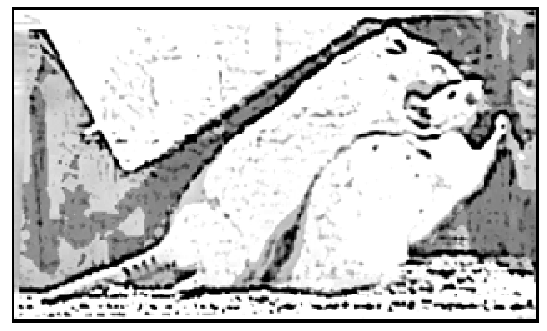

D

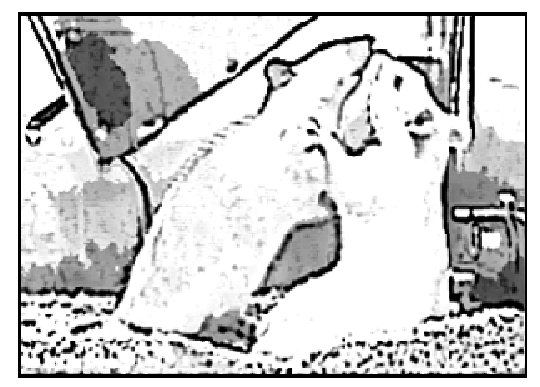

$\mathbf{F}$

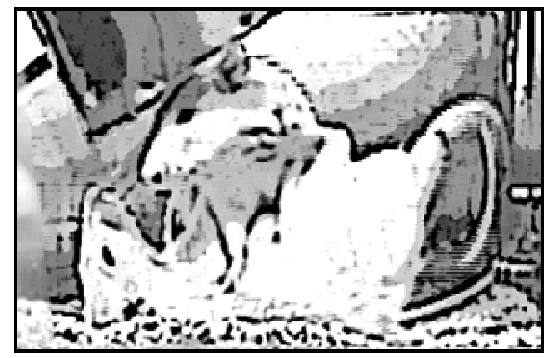

Figura 1. Fotografias exemplificando os principais comportamentos sociais. (A) Investigação anogenital. O rato da direita investiga, cheira e lambe a região anogenital do co-específico, (B) Investigação da cabeça. $O$ rato da esquerda investiga, cheira e lambe a cabeça do animal da direita, (C) Investigação do corpo. O rato da esquerda investiga, cheira e lambe o corpo do animal da direita, (D) Comportamentos agressivos. O rato da esquerda ataca animal da direita, postura conhecida como postura ereta ("upright"), (E) Perseguir. O rato da direita caminha logo atrás do rato da esquerda procurando aproximar-se do mesmo, e (F) Comportamento de dominância. O rato posicionado superiormente apresenta comportamento de dominância segurando o outro rato, em posição de subordinação, com o dorso voltado ao solo.

Fonte: arquivo próprio. 
Uma das hipóteses do presente trabalho é que a análise detalhada do tempo dedicado à execução de cada um desses comportamentos sociais pode contribuir para uma melhor compreensão da estruturação e organização social em roedores (Gheusi et al., 1994b), e também da memória de reconhecimento social.

Outros tipos de comportamentos, caracterizados como não-sociais, também podem contribuir para esse emprendimento (Figura 2).
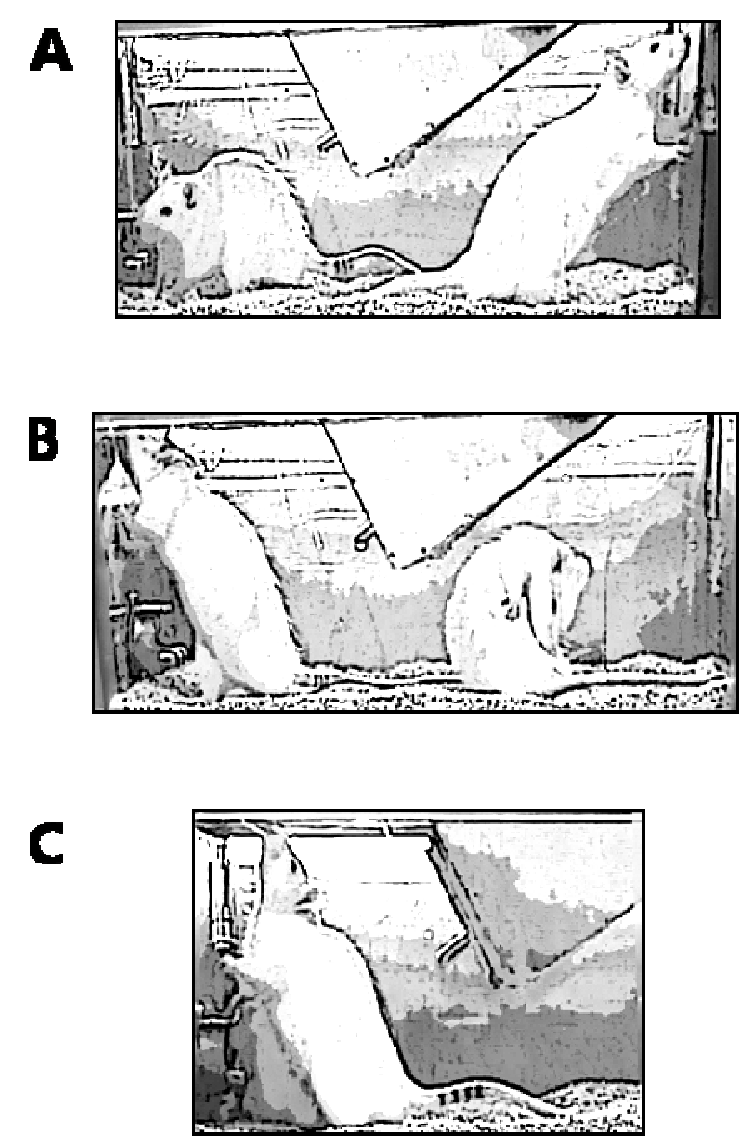

Figura 2. Fotografias exemplificando os principais comportamentos não-sociais. (A) Cheirar o ambiente e levantar-se. $\mathrm{O}$ rato da esquerda cheira as paredes da caixa enquanto o da direita levanta-se nas patas posteriores, apoiando a pata anterior na parede da caixa, (B) Levantar-se e autolimpeza. O rato da esquerda exibe comportamento de levantar-se nas patas posteriores apoiando a pata anterior na parede da caixa e o rato da direita exibe comportamentos de autolimpeza, e (C) Levantar-se. O rato apresenta comportamento de levantar-se nas patas posteriores, sem qualquer apoio das patas dianteiras.

Fonte: arquivo próprio. 
Nos capítulos incluídos no presente trabalho foram analisados os seis comportamentos sociais representados na Figura 1, bem como os três comportamentos nãosociais representados na Figura 2.

Muitos mamíferos exibem a habilidade de discriminar indivíduos da mesma espécie. Contudo, diferentes grupos de animais fazem uso de pistas distintas para esse reconhecimento. Humanos e primatas não-humanos fazem uso preferencial de pistas visuais e auditivas para discriminar e identificar co-específicos; já roedores baseiam-se principalmente em informações de natureza olfatória.

Nos últimos 60 anos foram realizados diversos estudos envolvendo memória de reconhecimento social em roedores de laboratório (Grant, 1963; Thor e Holloway, 1982; Dantzer et al., 1987; Popik et al., 1991; Engelmann et al., 1995). Esses estudos vêm mostrando que roedores são capazes de modular a quantidade de comportamentos sociais de acordo com a familiaridade com o co-específico. Ratos são também capazes de discriminar a maravalha suja, $i$. e., previamente utilizada como forração de gaiola, oriunda de diferentes animais; por exemplo, são capazes de identificar maravalha suja oriunda de fêmeas e machos, e também maravalha suja oriunda de um animal cuja maravalha suja foi investigada anteriormente em relação à oriunda de um animal cuja maravalha suja nunca foi investigada (Sawyer et al., 1984). Esse tipo de resultado levou à sugestão de que roedores exibem “assinaturas olfatórias" (Carr et al., 1976) que seriam cruciais para a formação de grupos sociais, e também na demarcação de territórios.

Há um consenso de que feromônios possuem propriedades importantes para a memória de reconhecimento social. Feromônios são secretados por glândulas localizadas em diferentes locais do corpo; em roedores, principalmente região anogenital. Também tem sido sugerida a presença de feromônios na urina (Karlson e Luscher, 1959). O reconhecimento do indivíduo por meio dessas substâncias parece possibilitar a formação de pares, 
reconhecimento de familiares e o estabelecimento de dominâncias hierárquicas (Maaswinkel et al., 1996; Ferguson et al., 2002; Young, 2002).

Thor e Holloway (1982) mensuraram, em ratos, a quantidade de comportamentos sociais direcionada a um co-específico familiar ou desconhecido, e sugeriram que esse índice pode ser utilizado para investigar, indiretamente, a memória de reconhecimento social. Ratos sexualmente maduros, denominados residentes, foram expostos a dois encontros sucessivos, de 5 minutos cada, a um mesmo rato juvenil, denominado intruso; o intervalo de tempo entre os encontros foi 10, 20, 40 ou 80 minutos. A quantidade de comportamentos sociais do residente em relação ao intruso no segundo encontro foi substancialmente menor em relação ao observado no primeiro encontro, quando o intervalo de tempo entre as sessões foi igual ou menor do que 40 minutos, mas não quando o intervalo de tempo foi 80 minutos. Num segundo experimento, esses autores avaliaram se essa redução da quantidade de comportamentos sociais estaria relacionada à identificação do intruso ou meramente a um fenômeno de habituação ou "fadiga social". Isso envolveu a exposição de ratos residentes a um primeiro encontro com um intruso juvenil, seguido de um segundo encontro com o mesmo intruso juvenil ou com um intruso juvenil novo; o intervalo de tempo entre os encontros foi 10 minutos. O comportamento social dos residentes foi registrado em ambos os encontros. Os residentes exibiram menor quantidade de comportamentos sociais (1) no segundo encontro com o intruso familiar em relação ao primeiro encontro com esse mesmo intruso, replicando os resultados do experimento anterior, e (2) no segundo encontro com um intruso familiar em relação a um segundo encontro com o intruso novo. Diferentemente, a quantidade de comportamentos sociais no segundo encontro com o intruso novo não diferiu daquela exibida no primeiro encontro. Juntos, esses resultados permitiram descartar a hipótese de que houve habituação ou fadiga social, sugerindo que o fenômeno está relacionado com a identificação do intruso previamente encontrado. Thor e Holloway (1982) avaliaram também os 
comportamentos sociais exibidos pelos intrusos juvenis. Embora a quantidade de comportamentos sociais exibida pelos intrusos juvenis tenha sido substancialmente menor do que aquela exibida pelos residentes adultos, os juvenis também revelaram memória de reconhecimento social; porém, sua duração não ultrapassou cerca de 4 minutos. Depois desse estudo seminal, diversos outros autores passaram a utilizar esse paradigma intruso-residente, como ficou conhecido, para investigar a memória de reconhecimento social em roedores.

Outros testes comportamentais têm sido utilizados para testar memória social.

O teste habituação-discriminação baseia-se nas diferentes respostas a um odor familiar em relação a um novo odor (Halpin, 1974). Na primeira fase o animal é exposto a um odor até que ocorra habituação, identificada pela redução da investigação olfatória. Numa segunda fase, o animal é exposto ao odor familiar e a um odor desconhecido; observa-se, usualmente, que os animais investigam mais o odor desconhecido, sendo capaz de discriminálo do novo, após sucessivas apresentações deste último.

No teste de reforço positivo com o uso de estímulo social (Bowers e Alexander, 1967), os animais são recompensados quando respondem ao odor oriundo de um coespecífico e não recompensados quando respondem ao odor de outro co-específico. Se os animais aprendem essa tarefa, depreende-se que são capazes de discriminar que os odores são diferentes. Note que neste caso a exposição a ambos os odores leva à familiaridade; porém, apenas um deles leva à recompensa, sendo conseqüentemente diferente do teste de habituação-discriminação.

No teste de diferentes respostas ao odor de co-específicos, apresentam-se odores provenientes de co-específicos da mesma idade e sexo; quando o roedor responde de forma diferente a esses odores, assume-se que tenha detectado uma diferença entre os mesmos (Carr et al., 1970). Como este teste emprega odores de co-específicos familiares e não-familiares, é 
possível comparar as respostas emitidas a ambos, pois a resposta é dependente da experiência prévia com o odor (Sawyer et al., 1984).

Também o "efeito de Bruce" (Bruce effect) ressalta que roedores são capazes de discriminação social. Esse efeito refere-se ao bloqueio gestacional observado quando uma fêmea prenhe é exposta ao odor de um macho diferente de seu par (Bruce, 1959; Bruce e Parrott, 1960; Parkes e Bruce, 1961).

Uma das principais vantagens no uso deste tipo de testes comportamentais para investigar a memória relaciona-se ao fato de que a resposta dos animais independe de reforçadores ou da punição do comportamento, dependendo apenas da tendência natural de ratos investigarem, de forma olfatória, seus co-específicos (Thor e Holloway, 1982; Gheusi et al., 1994a, b). Comportamentos sociais manifestos ao longo de encontros sucessivos entre residentes e intrusos, separados por determinados intervalos de tempo, constituem a base do paradigma intruso-residente. Geralmente, o rato residente investiga vigorosamente o intruso durante o primeiro encontro e, no caso da formação de uma memória de reconhecimento social, há redução dos comportamentos sociais durante o segundo encontro. Como vimos acima, esse efeito é dependente do intervalo de tempo entre o primeiro e o segundo encontros (Figura 3). 
$1^{\circ}$ encontro

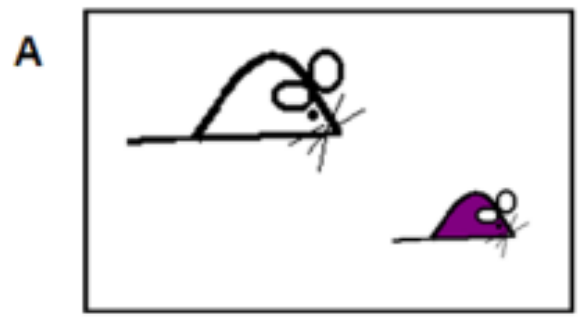

C

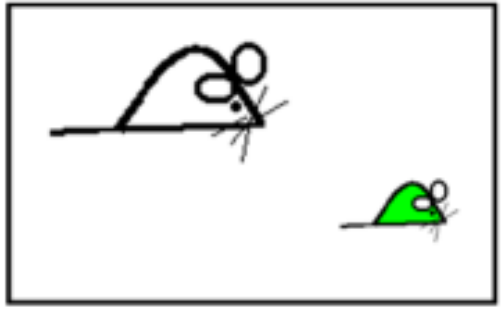

$2^{\circ}$ encontro

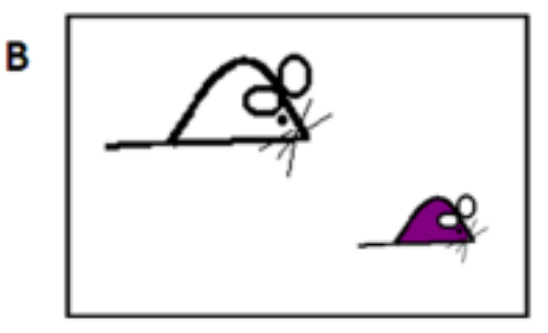

D

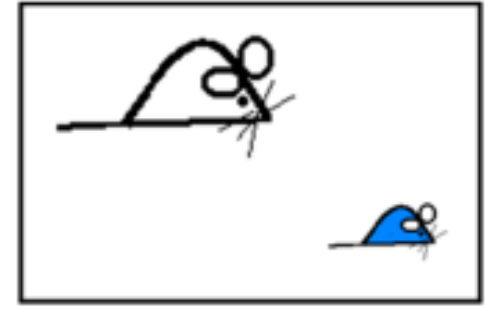

Comportamentos

sociais
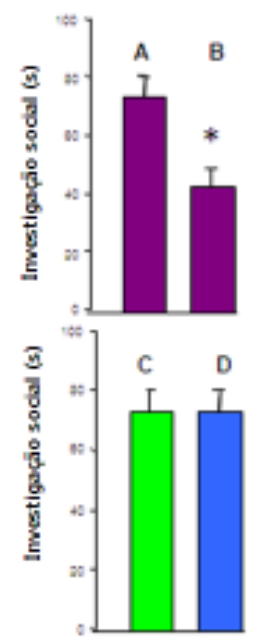

Figura 3. Representação esquemática do paradigma intruso-residente e dos resultados geralmente observados. No primeiro encontro (A e C), introduz-se um intruso (representado pelo roedor colorido pequeno) na caixa do residente (representado pelo rato branco); usualmente, os animais permanecem juntos ao longo de 5 minutos. Então, o intruso é removido da caixa. No segundo encontro, introduz-se na caixa do residente o mesmo intruso (B) ou um intruso novo (D). A quandidade de comportamentos observados nessas condições experimentais são mostrados nos Gráficos à direita. Alega-se que a redução da quantidade de comportamentos sociais do primeiro para o segundo encontro com o mesmo intruso (colunas A e B, respectivamente) sugere a existência de memória social. A ausência de redução na quantidade de comportamentos sociais do primeiro para o segundo encountro com um intruso diferente (colunas $\mathrm{C}$ e $\mathrm{D}$, respectivamente), sugere que o efeito anterior não está associado à habituação decorrente de dois encontros sucessivos.

Fonte: Arquivo próprio.

Há peculiaridades na memória de reconhecimento social que aparentemente a distingue de outros tipos de memória. Por exemplo, sua duração é maior do que a da memória operacional, mas menor do que uma memória do tipo espacial. Isso tem levado alguns autores a caracterizá-la como um tipo específico de memória, distinto de outros descritos na literatura da área (Ferguson et al., 2002).

Assume-se que a memória de reconhecimento social em ratos corresponda a um tipo de memória de curta duração desde a descição inicial do paradigma intruso-residente, em função dos resultados obtidos nesse pagardima comportamental. Isto é, ratos residentes expostos por 5 minutos a um intruso exibem (1) redução dos comportamentos sociais quando 


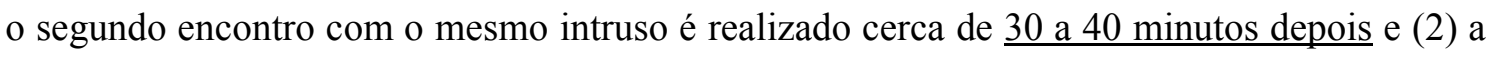
mesma quantidade de comportamentos sociais quando o segundo encontro com o mesmo intruso é realizado 2 horas depois; assim, diversos autores admitem que a memória de reconhecimento social duraria cerca de 60 minutos (Dantzer et al., 1987; Dantzer et al., 1988a; Popik et al., 1991; Sekiguchi et al., 1991a, b; Dantzer et al., 1994; Popik and Van Ree, 1998).

Houve tentativas de aumentar a duração da memória de reconhecimento social em ratos. Inicialmente, aumentou-se a duração do primeiro encontro de 5 minutos com o intruso (Dantzer et al., 1987; Sekiguchi et al., 1991a; Squires et al., 2006) pela inserção de encontros adicionais, cada um deles de 5 minutos cada, realizados a intervalos de tempo variáveis dependendo do estudo. Por exemplo, a exposição do residente a dois encontros sucessivos de 5 minutos cada com o mesmo intruso, levou a um aumento da duração da memória de reconhecimento social para 2 horas. Por outro lado, a exposição do residente a dois encontros sucessivos com intrusos distintos, comprometeu a memória de reconhecimento social em relação ao primeiro intruso, mesmo quando o intervalo de tempo entre o primeiro e o terceiro encontros foi de 30 minutos (Dantzer et al., 1987).

Nesta mesma linha de raciocínio, Sekiguchi et al. (1991b) aumentaram a duração do primeiro encontro para 30 minutos, por meio de um único encontro ou de seis encontros com duração de 5 minutos cada entremeados por intervalos de 10 minutos ou de 24 horas; a memória de reconhecimento social foi avaliada 24 horas depois. Neste caso, não houve qualquer indício de memória de reconhecimento social. Esse mesmo grupo aumentou adicionalmente a exposição do residente ao intruso, por meio de 6 exposições de 5 minutos cada por dia, ao longo de 4 dias, para realizar o teste no quinto dia. Novamente, os animais não revelaram indícios de que se recordam do intruso ao qual foram expostos nesse esquema (Sekiguchi et al., 1991a, b). Portanto, a exposição ao intruso por 30 minutos contínuos ou por 
2 horas divididas em 6 encontros de 5 minutos cada por dia, ao longo de 4 dias, não elevou a duração da memória de reconhecimento social para 24 horas.

Uma das hipóteses avaliadas no presente trabalho é que ratos precisam de uma maior exposição aos intrusos de modo a obter informações sociais suficientes para identificá-los 24 horas depois do último encontro. Resultados que permitiram avaliar essa hipótese estão descritos no capítulo 3, e demonstraram que, de fato, a memória de reconhecimento social pode ser mantida por pelo menos 24 horas quando a duração do primeiro encontro é de 2 horas ou mais.

\subsection{Memória de reconhecimento social e fase temporal}

É notória a existência de processos temporais envolvendo variáveis fisiológicas, neurais e comportamentais entre os seres vivos (Halberg, 1969). Diversos animais modificam seu comportamento ao longo do ciclo de 24 horas, exibindo uma alternância entre atividade e repouso. Diversos processos comportamentais complexos, incluindo aprendizagem e memória sofrem influência desta variação circadiana (Davies et al., 1973; Holloway e Wansley, 1973; Wansley and Holloway, 1976).

A influência de fatores temporais sobre a memória de reconhecimento social também foi objeto de investigações.

Por exemplo, Reijmers et al. (2001) testaram ratos em diferentes momentos do ciclo claro-escuro, utilizando uma versão adaptada do paradigma intruso-residente. No primeiro encontro, os intrusos foram expostos aos residentes por 5 minutos. No segundo encontro, realizado 10 ou 25 minutos depois do primeiro, houve nova exposição de 5 minutos ao mesmo intruso ou a intrusos diferentes. Esses encontros foram conduzidos em quatro momentos diferentes do ciclo claro-escuro (nos "zeitgeber" 3, 9, 15 e 21). Esse arranjo 
experimental levou à conclusão de que não há modulação temporal sobre a memória de reconhecimento social em ratos.

Mesmo tendo havido resultados negativos, uma das possíveis restrições ao estudo de Reijmers et al. (2001) refere-se às diferenças nas condições fóticas em que os animais testados se encontravam (no claro ou no escuro) antes do teste, e essa mesma situação repetia-se durante os testes. $i$. e., animais testados na fase inativa estavam expostos à luz e eram também testados sob luz, enquanto os demais animais da fase ativa estavam no escuro e eram testados também no escuro.Segundo Marques e Waterhouse (1994), a luz pode exercer um efeito inibitório na expressão dos comportamentos em animais com hábitos de vida noturno. Sendo assim, teria sido preferível realizar os testes em fases circadianas distintas, porém, em animais oriundos de condições fóticas similares. Essas condições experimentais são propiciadas por meio da utilização do fotoperíodo esqueleto, ou seja, ao invés de utilizar 12 horas de claro e 12 horas de escuro para sincronizar os animais às 24 horas do dia são usados pulsos de luz nos extremos da fase ativa dos animais para sincronizar os animais às 24 horas (Pittendrigh, 1965). Desta forma os animais de diferentes grupos serão testados sob condições fóticas similares, mas em fases circadianas distintas. Outra possível restrição ao estudo de Reijmers et al. (2001) refere-se ao fato de que esses autores utilizaram apenas os intervalos de tempo de 10 ou de 25 minutos entre o primeiro e o segundo encontros, $i$. e., intervalos de tempo que usualmente resultam no aparecimento da memória de reconhecimento social. Assim, os autores parecem ter partido do pressuposto de que haveria prejuízo da memória de reconhecimento social em determinados momentos do ciclo temporal, mas não consideraram a possibilidade de que pudesse haver aumento dessa duração em determinados momentos do ciclo temporal.

Essas questões foram investigadas no presente trabalho e os resultados são descritos no Capítulo 2; isto é, descreve-se a ocorrência de um aumento da duração da memória de 
reconhecimento para pelo menos 60 minutos, quando os animais são testados em sua fase inativa do ciclo temporal.

\subsection{Memória de reconhecimento social e interferência de rotinas laboratoriais}

Algumas rotinas laboratoriais podem influenciar o comportamento dos animais e também seu desempenho em testes de memória.

Mrosovsky (1988) mostrou que a limpeza das gaiolas é capaz de sincronizar o ritmo circadiano dos hamsters; quando a limpeza ocorre no meio do dia subjetivo há um avanço de fase; já quando os eventos ocorrem no final da noite subjetiva, há um atraso de fase.

O isolamento social de ratos em idade precoce, além de crítico para o desenvolvimento do sistema nervoso, se reflete em diversos comportamentos do animal adulto (Anisman et al., 1998; Caldji et al., 2000). Da mesma forma, o acondicionamento de apenas um animal por gaiola após o desmame, induz significativas alterações no comportamento adulto (Einon e Morgan, 1977; Jones et al., 1989). Alterações na reatividade emocional de roedores causadas pelo isolamento social têm reflexos na atividade locomotora (Gentsch et al., 1988; Wilkinson et al., 1994; Domeney e Feldon, 1998), defecação (Holson et al., 1991), neofobia (Hall et al., 1997a, b), aumento dos comportamentos agressivos em relação a co-específicos (Wongwitdecha e Marsden, 1996), aumento dos comportamentos agressivos ao serem manipulados (Hatch et al., 1963), no condicionamento de preferência a lugares (Coudereau et al., 1997), na inibição pré-pulso ("pre-pulse inhibition”) (Day-Wilson et al., 2006), no condicionamento clássico aversivo ao contexto (Rudy, 1996; Coudereau et al., 1997) e na memória espacial (Pacteau et al., 1989). Não surpreende, portanto, que ratos 
socialmente isolados vêm sendo utilizados como modelo para o estudo da ansiedade (Parker e Morinan, 1986) e da neofobia.

Em estudos envolvendo o paradigma intruso-residente os residentes eventualmente são isolados socialmente por uma semana antes dos testes; alega-se que o objetivo dessa manipulação seja estimular os comportamentos sociais (Thor e Holloway, 1982; Ferguson et al., 2001). Porém, têm havido relatos de que o isolamento social de camundongos pode prejudicar a aprendizagem e memória, inclusive a memória de reconhecimento social, particularmente quando o intervalo de tempo entre encontros é prolongado (Kogan et al., 2000).

Burman e Mendel (2000) mostraram que procedimentos rotineiros de laboratórios podem influenciar o desempenho de ratos no paradigma intruso-residente. Neste experimento os encontros sociais duravam 5 minutos com intervalo de 15 minutos entre os encontros; o mesmo intruso foi apresentado em ambos encontros. As manipulações experimentais aconteciam durante os 5 minutos intermediários do intervalo, i. e., após os 5 minutos iniciais do intervalo, os animais eram submetidos às diferentes condições experimentais por 5 minutos, e nos 5 minutos finais os residentes eram re-colocados em sua caixa. Os animais foram submetidos à cinco condições diferentes (1) residente continuava em sua caixa sem nenhuma manipulação, condição controle, (2) os residentes eram manipulados a cada 15 segundos por 5 segundos durante os 5 minutos, (3) os residentes recebiam um novo intruso por 5 minutos, (4) os residentes eram transportados para uma caixa menor e lá permaneciam por 5 minutos, e (5) os residentes eram transportados para uma caixa do mesmo tamanho da sua caixa também por 5 minutos. Manipulações experimentais como a manipulação, a transferência do residente para uma caixa menor ou a introdução de um intruso diferente durante o intervalo entre os encontros sociais levaram a um prejuízo na memória de reconhecimento social. Em decorrência desses resultados, os autores ressaltaram que nuances 
experimentais como o excesso ou mesmo a ausência de manipulação dos animais, a limpeza das gaiolas antes, durante ou após os experimentos, podem influenciar o desempenho dos animais.

No conjunto, esses resultados ressaltam que as rotinas laboratoriais devem ser consideradas ao se planejar e desenvolver os testes comportamentais para avaliar memória de reconhecimento social, uma vez que os resultados experimentais podem ser influenciados não apenas pelas variáveis que o experimentador julga controlar, mas também pelas variáveis que não foram controladas.

No capítulo 4 do presente trabalho, descrevemos a avaliação da hipótese de que o transporte dos animais da sala de experimentos para o biotério depois do primeiro encontro pode influenciar os resultados no teste de memória de reconhecimento social no paradigma intruso-residente. É comum, em estudos comportamentais que requerem mais do que um dia de testes, que os animais sejam transportados da sala de experimentação para o biotério e vice-versa. Partimos do pressuposto de que o transporte dos animais $0,5 \mathrm{~h}$ depois do primeiro encontro no paradigma intruso-residente geraria efeitos diferentes do transporte $6 \mathrm{~h}$ depois.

\subsection{Aspectos críticos da memória de reconhecimento social}

A investigação dos processos neurais subjacentes aos comportamentos sociais tem se valido de diferentes métodos experimentais. Como discutido anteriormente, os comportamentos sociais são entidades complexas. Nesse sentido, a definição clara e precisa de um teste comportamental para avaliar determinado conjunto de funções é condição fundamental para que se possa realizar progressos no sentido do entendimento dos seus processos neurobiológicos subjacentes. 
Aparentemente, a memória de reconhecimento social pode ser caracterizada como uma entidade única, que se baseia proponderantemente em informações de natureza olfatória.

1.4.1. Processamento de informações sociais: ação de feromônios?

Nos últimos 50 anos diversos trabalhos mostraram uma estreita relação entre pistas olfatórias, comportamentos sociais e memória de reconhecimento social; embora haja relatos de que os sentidos visual e auditivo (especialmente a vocalização ultra-sônica) também contribuem, em menor extensão, para essas funções (Lore e Flannelly, 1977; Sales, 1991), há relativamente poucas informações sobre a natureza dessa contribuição. A maioria das pesquisas na área de memória de reconhecimento social em roedores focaliza o sistema olfatório. Duas grandes classes de informações olfatória são citadas: feromônios e "outros odorantes".

Feromônios são substâncias secretadas por indivíduos de uma espécie que geram reações específicas, quase estereotipadas, em co-específicos (Karlson e Luscher, 1959). Há duas classes de feromônios identificadas pelo seu peso molecular, uma delas volátil, com baixo peso molecular, e a outra não volátil, com alto peso molecular. Respostas neuroendócrinas que resultam em aceleração da puberdade ou mesmo bloqueio gestacional (Bruce e Parrott, 1960) são estimuladas por componentes contidos na urina de co-específicos do sexo oposto. Comportamentos sociais como atração sexual, ou seleção sexual de um indivíduo e agressão estão vinculados às pistas químico-sensoriais de outro co-específico (Johnston, 1998; Keverne, 1999).

Roedores exibem dois sistemas para o processamento de informações olfatórias, o sistema olfatório principal e o sistema olfatório acessório. Até meados da década de 90, postulava-se que o sistema olfatório acessório teria sido selecionado ao longo da adaptação à 
vida terrestre, e seria dedicado exclusivamente à detecção de informações feromonais; diferentemente, o sistema olfatório principal seria responsável pelo processamento de informações sobre demais odorantes (Moncho-Bogani et al., 2002; Dulac e Torello, 2003; Moncho-Bogani et al., 2005). Os receptores do sistema olfatório acessório localiza-se no órgão vomeronasal, enquanto os receptores do sistema olfatório principal no epitélio olfatório .Nos últimos anos esse postulado vem sendo questionado. Por exemplo, Baxi et al. (2006) argumentaram que só é possível admitir que há equivalência entre processamento vomeronasal e processamento feromonal se demonstrar que (1) os sinais químicos feromonais são processados exclusivamente pelo sistema vomeronasal e (2) o sistema vomeronasal não media outra função que não o processamento feromonal. Porém, vem sendo demonstrado que o sistema vomeronasal responde também a estímulos não-feromonais (Buck, 2000; Sam et al., 2001; Trinh and Storm, 2003). Similarmente, informações feromonais também são detectadas pelo epitélio olfatório. Por exemplo, a secreção vaginal de fêmeas de hamster contém feromônios que eliciam comportamentos sexuais no macho, induzem síntese de proteína $c$-fos no núcleo medial da amígdala e área pré-óptica, áreas envolvidas na iniciação da cópula. A destruição do epitélio olfatório, mas não do órgão vomeronasal, elimina esse aumento da expressão de $c$-fos nessas regiões, indicando que o sistema olfatório principal mediaria essas respostas (Swann et al., 2001). Além disso, têm havido descrições de que, em camundongos, ambos os sistemas olfatórios, o principal e o acessório, são estimulados por feromônios e outros odores (Xu et al., 2005).

Baxi et al. (2006) propuseram que moléculas maiores, não-voláteis, seriam detectadas pelo órgão vomeronasal (Lazar et al., 2004); diferentemente, moléculas mais leves, voláteis, seriam processadas pelo epitélio olfatório. Entretanto, há evidências de que moléculas menores também poderiam ser detectadas pelo órgão vomeronasal, quando estivessem ligadas a uma molécula maior. Roedores exibem uma proteína principal urinária (“major urinary 
protein” - MUP) que atuaria como veículo olfatório para pequenas moléculas voláteis. Isto é, estas últimas alcançariam o epitélio olfatório por meio da ligação com essa proteína nãovolátil que, então, ativaria o órgão vomeronasal. Pouco se sabe sobre como esse complexo seria formado; admite-se a existência de duas moléculas feromonais voláteis de camundongos macho, excretadas na urina, a 2,3-dehydro-exo-brevicomin (DHB) e a 2-sec-butyl-4,5dihydrothiazole (SBT), que se ligam à MUP (Bacchini et al., 1992). Haveria uma outra MUP com alta afinidade ao SBT na mucosa nasal, o que sugere que um ou ambos os feromônios são transportados ao órgão vomeronasal quando ligados às proteínas, explicando, assim, o feromônio ser considerado uma molécula não-volátil (Sharrow et al., 2002). Tanto a DHB quanto a SBT estimulam o bulbo olfatório acessório apenas na presença das MUPs (Guo et al., 1997); porém, tem havido relatos de que porções diferentes do bulbo olfatório acessório são estimuladas pelos feromônios voláteis e MUPs (Brennan et al., 1999). A DHB e a SBT parecem capazes de eliciar respostas de neurônios do órgão vomeronasal mantidos in vitro. $\mathrm{E}$ as MUPs também parecem exercer funções vinculadas ao reconhecimento individual (Hurst et al., 2001). Porém, não está claro se a DHB e a SBT são parte do complexo não-volátil com a MUP quando eles entram no órgão vomeronasal, ou se a presença das MUPs é necessária para a estimulação do sistema vomeronasal pela DHB e a SBT.

Luo et al. (2003) investigaram a atividade unitária de neurônios do bulbo olfatório acessório de camundongos machos, durante a investigação social; os disparos neuronais foram modulados pelo contato físico do macho com a fêmea. Isto é, para obter informações feromonais parece necessário que os animais cheirem ativamente o co-específico, estabelecendo contato; ademais, a apresentação de um camundongo artificial, que faculta contato mas não possui cheiro, não foi suficiente para eliciar resposta destes mesmos neurônios. 
Também o padrão de ativação neuronal de camundongos fêmeas expostos ao odor de machos vem sendo investigado, considerando a experiência prévia das mesmas (MonchoBogani et al., 2005). Fêmeas ingênuas nunca expostas ao odor de macho apresentaram expressão de $c$-fos no núcleo basal da amígdala, apenas quando mantêm contato direto com forragem suja da gaiola de machos; diferentemente, quando foram expostas apenas aos odores voláteis advindos da maravalha, sem o contato direto, não houve ativação. Interessantemente, fêmeas com experiência prévia ao odor de machos, por exposição direta ou indireta (contato com a forragem) apresentam ativação não só do núcleo basal da amígdala, mas de outras regiões nervosas sabidamente envolvidas no sistema de recompensa (Moncho-Bogani, Martinez-Garcia et al., 2005). Esses dados sugerem que a associação entre odores voláteis e não-voláteis ocorrida no primeiro encontro contribui para a ativação de estruturas do sistema de recompensa no segundo encontro (Moncho-Bogani, Martinez-Garcia et al., 2005). Supostamente, informações sobre odores voláteis oriundos do sistema olfatório principal alcançariam regiões como o núcleo basal da amígdala, via conexões com o córtex entorrinal e córtex piriforme, e seriam integradas com informações sobre odores feromonais não-voláteis, oriundas do sistema olfatório acessório, que chegariam ao núcleo basal da amígdala por conexões diretas (porção póstero-medial do núcleo cortical) e indiretas (núcleo posterior da amígdala).

Assim, o processamento de informações sociais não parece depender exclusivamente da informação feromonal, como já se pensou, pois se trata de um processamento extremamente complexo, envolvendo várias fontes de informação. Aparentemente, ambos os sistemas olfatórios contribuem para a identificação de um co-específico como familiar ou não. Ademais, roedores não se valem exclusivamente de informações de natureza olfatória para a identificação de co-específicos; outros sentidos e outras regiões encefálicas não diretamente relacionadas à olfação também contribuem para o reconhecimento social. 
1.4.2. Regiões nervosas relacionadas a memória de reconhecimento social em roedores

A maioria dos estudos enfatiza o papel da amígdala no reconhecimento social de roedores.

A amígdala é uma estrutura heterogênea, constituída de vários núcleos que podem ser classificados anatomicamente, estruturalmente e funcionalmente (Swanson e Petrovich, 1998). Funcionalmente a amígdala pode ser dividida em quatro grandes grupos: sistema olfatório acessório, sistema olfatório principal, sistema olfatório autonômico e sistema frontotemporal (Swanson e Petrovich, 1998).

O sistema olfatório acessório é composto pelo órgão vomeronasal, bulbo olfatório acessório e suas projeções diretas para estruturas como o núcleo medial da amígdala e região póstero-medial do núcleo cortical da amígdala, e indiretas para amígdala posterior, hipotálamo medial, subiculum ventral, insula agranular e porção medial do córtex pré-frontal (de Olmos et al., 1978; Swanson e Petrovich, 1998; Moncho-Bogani et al., 2002) (Figura 4). Entre as estruturas do sistema olfatório acessório, apenas o núcleo posterior da amígdala não está envolvido diretamente no processamento de informações provenientes do órgão vomeronasal; diferentemente, o núcleo medial da amígdala parece estar fortemente envolvido no processamento de informações oriundas dessa estrutura (de Olmos et al., 1978; Canteras et al., 1995; Swanson e Petrovich, 1998; Moncho-Bogani et al., 2002; Meredith e Westberry, 2004).

O sistema olfatório principal integra informações advindas do epitélio olfatório, que seguem para o bulbo olfatório principal que, por sua vez, se projeta diretamente para as porções póstero-lateral e anterior do núcleo cortical da amígdala, área de transição póspiriforme e área amígdalo-piriforme, e indiretamente para núcleo posterior da amígdala, 
porção posterior do núcleo basolateral, accumbens, hipocampos dentre outras regiões (Swanson e Petrovich, 1998).

O núcleo medial da amígdala de roedores vem sendo associado ao comportamento maternal (Fleming et al., 1980; Fleming et al., 1994; Sheehan et al., 2001), comportamento sexual (Harris e Sachs, 1975; Lehman et al., 1980; Lehman e Winans, 1982; Rajendren e Moss, 1993; Coolen et al., 1997; Petrulis e Johnston, 1999; Dominguez e Hull, 2004), comportamento de dominância (“agonistic") (Koolhaas et al., 1980; Bolhuis et al., 1984; Luiten et al., 1985; Kollack-Walker e Newman, 1995), comportamento de defesa (Savonenko et al., 1999), comportamento agressivo (Vochteloo e Koolhaas, 1987), comportamento social (Stark et al., 1998) e reconhecimento social (Ferguson et al., 2000; Ferguson et al., 2001).

Estudos envolvendo a indução de danos seletivos e a expressão de genes, em roedores, possibilitaram a inclusão de outras regiões nervosas no esquema dos circuitos neurais possivelmente envolvidos na memória de reconhecimento social; entre elas citamos a região retrohipocampal (Bannerman et al., 2002), hipocampo (Squires et al., 2006), as fibras da via perfurante (Lemaire et al., 1994), septo medial (Fournier et al., 1993; Terranova et al., 1994) e regiões frontais (córtex orbitofrontal e giro cingulado anterior). É interessante notar que essas regiões estão direta ou indiretamente relacionadas com regiões que recebem aferências dos bulbos olfatórios. 
A

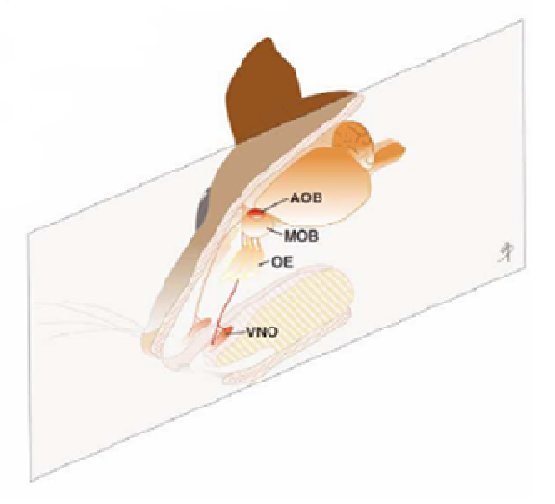

B

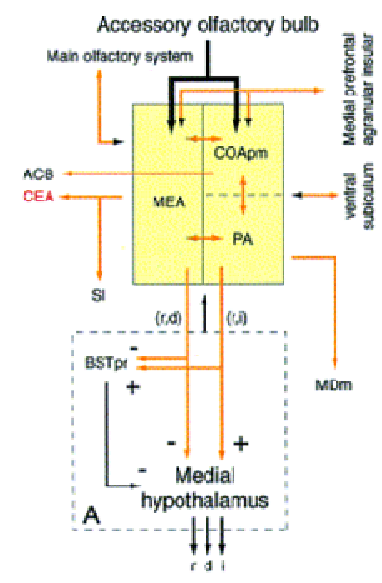

B Accessory ollactory system

$$
\text { II }
$$

C Main olfactory system
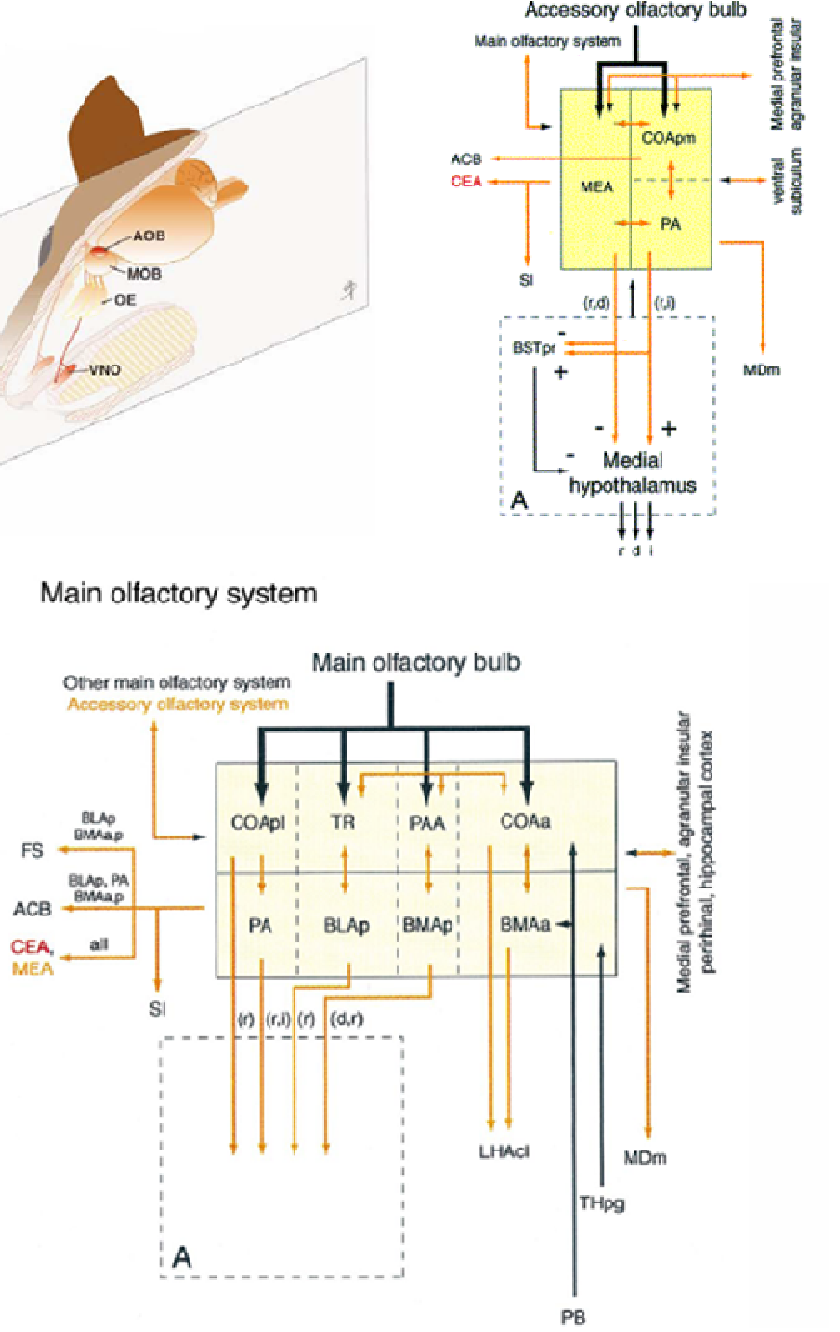

Figura 4. Esquemas representativos das principais conexões do sistema olfatório. (A) localização dos receptores olfatórios, (B) sistema olfatório acessório e (C) sistema olfatório principal. Legenda: ACB: acumbens; AOB: bulbo olfatório acessório; BLAp: parte posterior do núcleo basolateral da amígdala; BMAa,p: núcleo basomedial da amígdala; BMAa: parte anterior do núcleo basomedial da amígdala; BMAp: parte posterior do núcleo basomedial da amígdala; BSTpr: núcleo intersticial da estria terminal; CEA: núcleo central da amígdala; COAa: parte anterior do núcleo cortical da amígdala; COApl: região póstero-lateral do núcleo cortical da amígdala; COApm: região póstero-medial do núcleo cortical da amígdala; d: sistema de comportamento defensivo hipotalâmico lateral; FS: fundo do estriato; i: sistema de comportamento ingestivo hipotalâmico medial; LHAcl: parte caudolateral da área hipotalâmica lateral; MDm: parte medial do núcleo médiodorsal do tálamo; MEA: núcleo medial da amígdala; MOB: bulbo olfatório principal; OE: epitélio olfatório; PA: núcleo posterior da amígdala; PAA: área piriforme-amigdalar; r:sistema de comportamento reprodutivo hipotalâmico medial; SI: substância inominada; THpg: região perigeniculada do tálamo (incluindo o complex geniculado medial, núcleo "limite" posterior e núcleo subparafascicular parvicelular); TR: área transitória pós-piriforme; VNO: órgão voremonasal.

Fonte: Alterado de Swanson e Petrovich (1998) e Baxi et al., (2006). 


\subsubsection{Neurotransmissores que modulam a memória de reconhecimento social}

Diversos estudos associam a oxitocina e vasopressina a processos de memória (De Wied, 1965; De Wied et al., 1974; De Wied, 1976; De Wied et al., 1976; Insel e Shapiro, 1992; Dantzer, 1998; Ferguson et al., 2000; Bielsky e Young, 2004).

A vasopressina e a oxitocina são nonapeptídeos que se distinguem por apenas um aminoácido, sendo encontrados exclusivamente em mamíferos. Ambos são sintetizados no hipotálamo que, por meio projeções axônicas, atingem a neurohipófise. Há relatos de que também regiões extra-hipotalâmicas produzem esses peptídeos (De Vries e Buijs, 1983). A vasopressina e a oxitocina são considerados hormônios endócrinos na periferia (a oxitocina está envolvida na contração uterina durante o trabalho de parto e também na ejeção de leite em fêmeas) e neurotransmissores/neuromoduladores centralmente; e seriam imprescindíveis para a memória de reconhecimento social em roedores (Insel, 1997).

Parcela significativa dos experimentos que associa a ação central da vasopressina à memória de reconhecimento social tem sido conduzida em roedores (Van Wimersma Greidanus et al., 1983; Dantzer et al., 1987; Engelmann e Landgraf, 1994; Everts e Koolhaas, 1997; Popik e Van Ree, 1998; Ferguson et al., 2000; Ferguson et al., 2001; Young, 2002; Young et al., 2002).

A administração sistêmica de vasopressina e oxitocina em ratos promove um aumento da duração da memória de reconhecimento social; Dantzer et al. (1987) mostraram que ratos submetidos à administração de vasopressina logo após o primeiro encontro com um co-específico exibiram redução da quantidade de comportamentos sociais a esse mesmo coespecífico, mas não a um co-específico diferente, num segundo encontro realizado 2 horas depois. Interessantemente, se ao invés de vasopressina administra-se um bloqueador de 
oxitocina, os animais perdem a capacidade de reconhecer o co-específico intruso mesmo quando o segundo encontro é realizado 30 minutos depois do primeiro encontro.

Também administração intra-cerebro-ventricular ou tópica na região septal-lateral, hippocampo ventral e dorsal, bulbo olfatório, desses neurotransmissores altera a memória de reconhecimento social (Le Moal et al., 1987; Engelmann e Landgraf, 1994; van Wimersma Greidanus and Maigret, 1996; Dluzen et al., 1998b; Engelmann et al., 2000). Isto é, a maioria dos estudos mostram que a vasopressina facilita o processamento da memória de reconhecimento social (De Wied et al., 1976; Dantzer et al., 1987; Engelmann e Landgraf, 1994; Van Wimersma Greidanus e Maigret, 1996; Popik e Van Ree, 1998). Diferentemente, enquanto altas doses de oxitocina atenuam a memória de reconhecimento social, doses próximas aos níveis fisiológicos a facilitam (Popik e Vetulani, 1991; Popik et al., 1992a).

Ratos Brattleboro, que não sintetizam vasopressina, testados no paradigma intrusoresidente exibem prejuízo na memória de reconhecimento social; isto é, a quantidade de investigação social do intruso familiar e do intruso novo, num segundo encontro, são iguais, independentemente do intervalo de tempo entre o primeiro e segundo encontros (Engelmann e Landgraf, 1994). Interessantemente, a administração de vasopressina no septo dorsolateral destes animais restabelece o reconhecimento social típico, ou seja, há redução da investigação social quando os animais são re-expostos ao intruso familiar até 60 minutos depois do primeiro encontro. Assim, a deficiência de vasopressina no septo dorsolateral parece crítica para a memória de reconhecimento social em ratos.

Outras estuturas nervosas também parecem envolvidas nessa função. Por exemplo, os níveis de vasopressina no septo lateral influenciam a memória de reconhecimento social (Dantzer et al., 1988b; Bielsky et al., 2005). Além disso, enquanto a micro-injeção de vasopressina no hipocampo dorsal bloqueia o reconhecimento de machos da mesma espécie, 
micro-injeções de vasopressina no bulbo olfatório em ratos machos melhoram o reconhecimento de co-específicos (Dluzen et al., 1998a; Dluzen et al., 1998b).

A administração tópica de oxitocina e de vasopressina no septo dorsolateral e no bulbo olfatório potencializa a memória de reconhecimento social (Popik et al., 1992b). Por outro lado, a administração de baixas doses de oxitocina, mas não de vasopressina, na área pré-óptica medial potencializa a memória de reconhecimento social (Popik et al., 1992a; Ferguson et al., 2002).

Manipulações genéticas permitiram gerar camundongos que não produzem oxitocina, mas que exibem os receptores específicos para este neurotransmissor. Estes animais exibem marcada deficiência da memória de reconhecimento social (Ferguson et al., 2000), não obstante sua audição, olfação e orientação espacial não exibam quaisquer alterações significativas. A administração de oxitocina no núcleo medial da amígdala, mas não no bulbo olfatório, antes, mas não depois, de encontros sociais, levaram à recuperação da memória de reconhecimento social.

Estudos envolvendo genes de expressão imediata em camundongos knockout de oxitocina expostos a encontros sociais com co-específicos revelam a ocorrência de maior expressão de c-fos no núcleo cortical da amígdala, córtex piriforme e septo dorsolateral; diferentemente, em camundongos normais, há maior expressão de c-fos no núcleo medial da amígdala, núcleo intersticial da estria terminal e área pré-óptica medial (Ferguson et al., 2001). O significado destes resultados ainda não está totalmente claro.

\subsection{Alternativas adicionais para o estudo da socialidade em roedores}

Dentre as alternativas interessantes para se investigar a sociabilidade, incluem-se os arganazes (Figura 5, A e B), animais que apresentam sub-grupos com comportamentos sociais 
um tanto distintos. Arganazes do campo (Microtus ochrogaster) são altamente sociáveis, monogâmicos e cuidam da prole. Diferentemente, arganazes da montanha (Microtus montanus) são a-sociais, poligâmicos e não cuidam da prole. Ao comparar essas duas espécies filogeneticamente próximas, (Young, 2002) observou diferenças na distribuição de receptores dos neuropeptídeos oxitocina e vasopressina que, como vimos, estão relacionados a comportamentos sociais, nos encéfalos destes roedores. Arganazes do campo apresentam maior quantidade de receptores de oxitocina no núcleo accumbens e complexo basolateral da amígdala; em contrapartida, arganazes da montanha apresentam mais receptores no septo lateral (Insel e Shapiro, 1992). Receptores de vasopressina, do subtipo V1a, são encontrados em maior quantidade nos arganazes do campo, no pálido ventral e núcleo medial da amígdala; já em arganazes da montanha esses receptores situam-se principalmente no septo lateral (Insel e Shapiro, 1992; Young, 2002; Lim et al., 2004). Aparentemente, essa localização distinta desses receptores no encéfalo pode levar a ativação de circuitos neurais distintos e, conseqüentemente, induzir respostas comportamentais diferentes. Em outras palavras, os arganazes da montanha, por não contarem com a ativação de regiões encefálicas fortemente relacionadas ao sistema de recompensa não exibem motivação para o contato social.

Esse modelo tem contribuído para o entendimento das bases neuroanatomo-funcionais de pessoas com distúrbios sociais como no caso de autistas. Pesquisas mostram que o gene que produz o receptor V1a em arganazes possue semelhanças ao gene AVPRla em humanos, e existem indícios apontando que autistas possuem alterações neste gene. No entanto, o custo dessas pesquisas é alto devido a complexidade das técnicas utilizadas. 

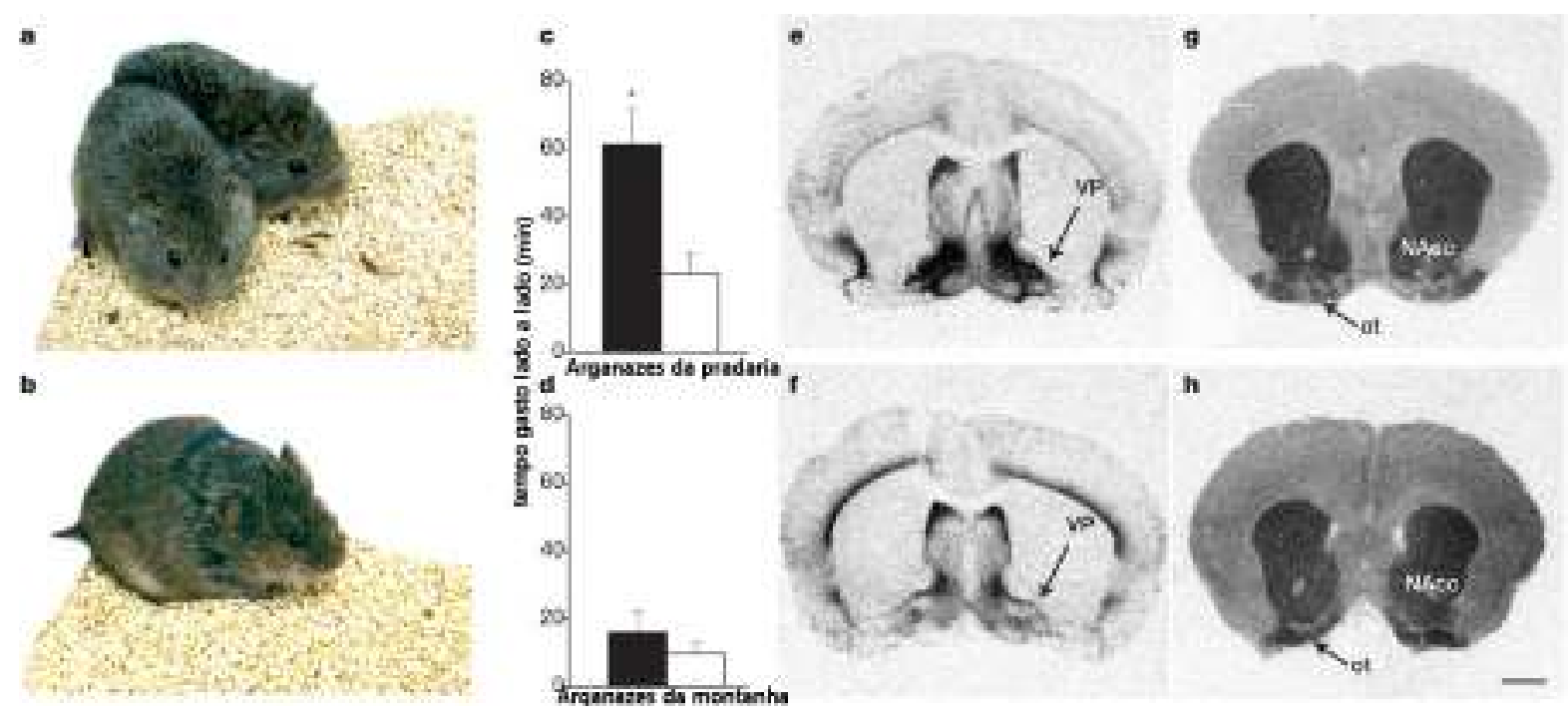

Figura 5. Arganazes da pradaria (A) e da montanha (B). Arganazes da montanha e da pradaria são similares na aparência, porém os da pradaria são altamente afiliativos preferindo investir maior parte do tempo ao lado de um co-específico. (C) Após cruzamento e co-habitação com uma fêmea, o arnagaz macho da pradaria investe maior quantidade de tempo em contato com a parceira (coluna preta) do que com uma fèmea desconhecida (coluna branca) $(\mathrm{p}<0.05)$. (D) Diferentemente, arganazes da montanha não exibem preferência pela parceira, investindo relativamente pouco tempo ao lado de uma fêmea familiar ou uma nova. (E) e (F) Autoradiogramas ilustrando o encéfalo típico de um arganaz da pradaria, e da montanha, respectivamente. São evidentes as diferenças entre arganazes da pradaria e da montanha no padrão de distribuição do receptor de vasopressina. (G) e (H) Interessantemente, a distribuição dos receptores de dopamina são similares nessas duas espécies.

Fonte: Alterado de Lim et al. (2004).

Um modelo comportamental descrito recentemente para o estudo da memória de reconhecimento social envolve expor um hamster macho a outros dois machos, sendo um deles separado por uma grade metálica que evita o contato direto, mas permite o trânsito de informações olfatórias, visuais e auditivas, e o outro diretamente na caixa experimental, o que permite contato direto, inclusive com o aparecimento de disputas territoriais. Vinte e quatro horas depois dessa primeira exposição, os animais "perderam" ou que "ganharam" a disputa são testados no labirinto em "Y"; no final de um braço é colocado o animal vencedor e no final do outro braço, é colocado o animais exposto por meio da grade. Os perdedores preferem o braço com o animal apresentado com a grade ao invés daquele com o qual ele teve contato direto (Lai et al., 2005), revelando a memória de reconhecimento social. 
Também a preferência alimentar transferida socialmente vem sendo empregada em estudos sobre a memória de reconhecimento social. Neste teste dois animais são agrupados pelos dois dias que antecedem os testes com o intuito torná-los familiares. Um dos animais, denominado demonstrador, é privado de ração para estimular seu apetite. No momento dos testes, o demonstrador é transferido para outra sala e recebe, ao longo de 30 minutos, ração com odor de chocolate ou canela. Logo a seguir, o demonstrador é pareado com o observador por 15 minutos. Então, o observador, agora transferido para uma caixa de testes, é exposto às duas rações, a experimentada pelo demonstrador e a outra. O observador apresenta marcada preferência pela ração consumida pelo demonstrador. Testes adicionais revelam que esse efeito não está relacionadao à palatibilidade ou odor dos alimentos, nem à exposição prévia ao seu odor, e sim ao pareamento do alimento ingerido pelo demonstrador e o encontro social com o mesmo (Galef et al., 1983).

Mesmo havendo alternativas, o paradigma intruso-residente tem sido o teste preferido para estudos sobre memória de reconhecimento social, há mais de 25 anos. Esse teste é vantajoso no estudo de memória de reconhecimento social em roedores devido (1) a um único encontro para a aquisição da informação social e um outro encontro para testar a memória de reconhecimento social e (2) também, pelo fato de utilizar-se da tendência natural dos animais de interagir socialmente, sem a necessidade de estímulos aversivos para induzir a aprendizagem. No entanto, existem muitas limitações ligadas ao método em si que necessitam esclarecimentos já que este teste é amplamente utilizado em neurociências. Neste sentido, o presente trabalho almejou aprimorar esse importante instrumento de análise, para usos futuros em estudos sobre a neurobiologia da sociabilidade. 


\section{Objetivos do trabalho}

O objetivo principal do presente trabalho foi contribuir para o entendimento da memória de reconhecimento social. Ademais, considerando que o paradigma intruso-residente vem sendo amplamente empregado em estudos sobre memória de reconhecimento social, almejamos também investigar em que extensão a expressão e duração da memória de reconhecimento social e/ou comportamentos sociais se alteram em função do momento do ritmo temporal circadiano em que os animais são avaliados (Capítulo 2). Avaliou-se ainda se a memória de reconhecimento social trata-se, de fato, de um sistema específico de memória de curta duração ou se essa observação da maioria dos laboratórios que empregam esse instrumento é um artefato das manipulações experimentais empregadas. Isso foi avaliado por meio do aumento do tempo de exposição ao co-específico adulto no primeiro encontro e realização do teste de memória de reconhecimento social 24 horas depois (Capítulo 3); avaliou-se ainda em que extensão os parâmetros usualmente empregados para avaliar a memória de reconhecimento social são adequados ou se seria possível aprimorá-los, por meio de uma análise comportamental mais refinada (Capítulo 3). Finalmente, ainda no contexto da discussão sobre a memória de reconhecimento social como um mecanismo de curta duração, avaliou-se em que extensão rotinas laboratoriais usualmente adotadas na grande maioria dos laboratórios que realizam testes comportamentais com animais, no presente caso, o transporte da sala de experimentação para o biotério após o primeiro encontro, podem interfir nos parâmetros indicativos de memória de reconhecimento social (Capítulo 4). 


\section{Referências}

ANISMAN, H.; ZAHARIA, M.D.; MEANEY, M.J.; MERALI, Z. Do early-life events permanently alter behavioral and hormonal responses to stressors? Int J Dev Neurosci, v. 16, p. 149-64, 1998.

BACCHINI, A.; GAETANI, E.; CAVAGGIONI, A. Pheromone binding proteins of the mouse, Mus musculus. Experientia, v. 48, p. 419-21, 1992.

BANNERMAN，D.M.; LEMAIRE，M.; YEE，B.K.; IVERSEN，S.D.; OSWALD，C.J.; GOOD, M.A.; RAWLINS, J.N. Selective cytotoxic lesions of the retrohippocampal region produce a mild deficit in social recognition memory. Exp Brain Res, v. 142, p. 395-401, 2002.

BAXI, K.N.; DORRIES, K.M.; EISTHEN, H.L. Is the vomeronasal system really specialized for detecting pheromones? Trends Neurosci, v. 29, p. 1-7, 2006.

BIELSKY, I.F.; YOUNG, L.J. Oxytocin, vasopressin, and social recognition in mammals. Peptides, v. 25, p. 1565-74, 2004.

BIELSKY, I.F.; HU, S.B.; REN, X.; TERWILLIGER, E.F.; YOUNG, L.J. The V1a vasopressin receptor is necessary and sufficient for normal social recognition: a gene replacement study. Neuron, v. 47, p. 503-13, 2005.

BOLHUIS, J.J.; FITZGERALD, R.E.; DIJK, D.J.; KOOLHAAS, J.M. The corticomedial amygdala and learning in an agonistic situation in the rat. Physiol Behav, v. 32, p. 575-79, 1984.

BOWERS, J.M.; ALEXANDER, B.K. Mice: individual recognition by olfactory cues. Science, v. 158, p. 1208-10, 1967.

BRENNAN, P.A.; SCHELLINCK, H.M.; KEVERNE, E.B. Patterns of expression of the immediate-early gene egr-1 in the accessory olfactory bulb of female mice exposed to pheromonal constituents of male urine. Neuroscience, v. 90, p. 1463-70, 1999.

BRUCE, H.M. An exteroceptive block to pregnancy in the mouse. Nature, v. 184, p. 105, 1959.

BRUCE, H.M.; Parrott, D.M. Role of olfactory sense in pregnancy block by strange males. Science, v. 131, p. 1526, 1960.

BUCK, L.B. The molecular architecture of odor and pheromone sensing in mammals. Cell, v. 100, p. $611-18,2000$.

BURMAN, O.H.; MENDL, M. Short-term social memory in the laboratory rat: its susceptibility to disturbance. Appl Anim Behav Sci, v. 67, p. 241-54, 2000. 
CALDJI, C.; DIORIO, J.; MEANEY, M.J. Variations in maternal care in infancy regulate the development of stress reactivity. Biol Psychiatry, v. 48, p. 1164-74, 2000.

CANTERAS, N.S.; SIMERLY, R.B.; SWANSON, L.W. Organization of projections from the medial nucleus of the amygdala: a PHAL study in the rat. J Comp Neurol, v. 360, p. 213-45, 1995.

CARR, E.J.; YEE, L.; GABLE, D.; MARASCO, E. Olfactory recognition of conspecifics by domestic Norway rats. J Comp Physiol Psychol, v. 90, p. 821-28, 1976.

CARR, W.J.; KRAMES, L.; COSTANZO, D.J. Previous sexual experience and olfactory preference for novel versus original sex partners in rats. J Comp Physiol Psychol, v. 71, p. 216-22, 1970.

COOLEN, L.M.; PETERS, H.J.; VEENING, J.G. Distribution of Fos immunoreactivity following mating versus anogenital investigation in the male rat brain. Neuroscience, v. 77, $\mathrm{p}$. 1151-61, 1997.

COUDEREAU, J.P.; DEBRAY, M.; MONIER, C.; BOURRE, J.M.; FRANCES, H. Isolation impairs place preference conditioning to morphine but not aversive learning in mice. Psychopharmacology (Berl), v. 130, p. 117-23, 1997.

DANTZER, R. Vasopressin, gonadal steroids and social recognition. Prog Brain Res, v. 119, p. 409-14, 1998.

DANTZER, R.; BLUTHE, R.M.; LEMOAL, M. Experimental assessment of drug-induced changes in cognitive function: vasopressin as a case study. Neurotoxicology, v. 9, p. 471-77, 1988a.

DANTZER, R.; ENGELMANN, M.; LANDGRAF, R. Microdialysis administration of vasopressin into the septum improves social recognition in Brattleboro rats. Physiol Behav, v. 55, p. 145-49, 1994.

DANTZER, R.; BLUTHE, R.M.; KOOB, G.F.; LE MOAL, M. Modulation of social memory in male rats by neurohypophyseal peptides. Psychopharmacology (Berl), v. 91, p. 363-68, 1987.

DANTZER, R.; KOOB, G.F.; BLUTHE, R.M.; LE MOAL, M. Septal vasopressin modulates social memory in male rats. Brain Res, v. 457, p. 143-47, 1988 b.

DAVIES, J.A.; NAVARATNAM, V.; REDFERN, P.H. A 24-hour rhythm in passiveavoidance behaviour in rats. Psychopharmacologia, v. 32, p. 211-14, 1973.

DAVIS, F.C. The measurement of aggressive behavior in laboratory rats. J Genet Psychol, v. 43, p. 213-17, 1933.

DAY-WILSON, K.M.; JONES, D.N.; SOUTHAM, E.; CILIA, J.; TOTTERDELL, S. Medial prefrontal cortex volume loss in rats with isolation rearing-induced deficits in prepulse inhibition of acoustic startle. Neuroscience, v. 141, p. 1113-21, 2006. 
DE OLMOS, J.; HARDY, H.; HEIMER, L. The afferent connections of the main and the accessory olfactory bulb formations in the rat: an experimental HRP-study. J Comp Neurol, v. 181, p. 213-44, 1978.

DE VRIES, G.J.; BUIJS, R.M. The origin of the vasopressinergic and oxytocinergic innervation of the rat brain with special reference to the lateral septum. Brain Research, $\mathrm{V}$. 273, p. 307-17, 1983.

DE WIED, D. The influence of the posterior and intermediate lobe of the pituitary and the pituitary peptides on the maintenance of a conditioned avoidance responses in rats. Int $\mathrm{J}$ Neuropharmacol, v. 4, p. 157-67, 1965.

DE WIED, D. Behavioral effects of intraventricularly administered vasopressin and vasopressin fragments. Life Sci, v. 19, p. 213-20, 1976.

DE WIED, D.; VAN WIMERSMA GREIDANUS, T.B.; BOHUS, B. The rat supraopticneurohypophyseal system and behavior: role of vasopressin in memory processes. Probl Actuels Endocrinol Nutr Serie, v. 18, p. 323-28, 1974.

DE WIED, D.; VAN WIMERSMA GREIDANUS, T.B.; BOHUS, B.; URBAN, I.; GISPEN, W.H. Vasopressin and memory consolidation. Prog Brain Res, v. 45, p. 181-94, 1976.

DLUZEN, D.E.; MURAOKA, S.; LANDGRAF, R. Olfactory bulb norepinephrine depletion abolishes vasopressin and oxytocin preservation of social recognition responses in rats. Neurosci Lett, v. 254, p. 161-164, 1998a.

DLUZEN, D.E.; MURAOKA, S.; ENGELMANN, M.; LANDGRAF, R. The effects of infusion of arginine vasopressin, oxytocin, or their antagonists into the olfactory bulb upon social recognition responses in male rats. Peptides, v. 19, p. 999-1005, 1998 b.

DOMENEY, A.; FELDON, J. The disruption of prepulse inhibition by social isolation in the Wistar rat: how robust is the effect? Pharmacol Biochem Behav, v. 59, p. 883-90, 1998.

DOMINGUEZ, J.M.; HULL, E.M. Medial amygdala regulates mating-induced dopamine release in medial preoptic area. Ann NY Acad Sci, v. 985, p. 515-18, 2004.

DULAC, C.; TORELLO, A.T. Molecular detection of pheromone signals in mammals: from genes to behaviour. Nat Rev Neurosci, v. 4, p. 551-62, 2003.

EINON, D.F.; MORGAN, M.J. A critical period for social isolation in the rat. Dev Psychobiol, v. 10, p. 123-32, 1977.

ENGELMANN, M.; LANDGRAF, R. Microdialysis administration of vasopressin into the septum improves social recognition in Brattleboro rats. Physiol Behav, v. 55, p. 145-49, 1994. 
ENGELMANN, M.; WOTJAK, C.T.; LANDGRAF, R. Social discrimination procedure: an alternative method to investigate juvenile recognition abilities in rats. Physiol Behav, v. 58, p. 315-321, 1995.

ENGELMANN, M.; WOTJAK, C.T.; EBNER, K.; LANDGRAF, R. Behavioural impact of intraseptally released vasopressin and oxytocin in rats. Exp Physiol, v. 85, 125S-130S, 2000.

EVERTS, H.G.; KOOLHAAS, J.M. Lateral septal vasopressin in rats: role in social and object recognition? Brain Res, v. 760, p. 1-7, 1997.

FERGUSON, J.N.; YOUNG, L.J.; INSEL, T.R. The neuroendocrine basis of social recognition. Front Neuroendocrinol, v. 23, p. 200-24, 2002.

FERGUSON, J.N.; ALDAG, J.M; INSEL, T.R.; YOUNG, L.J. Oxytocin in the medial amygdala is essential for social recognition in the mouse. J Neurosci, v. 21, p. 8278-85, 2001.

FERGUSON, J.N.; YOUNG, L.J.; HEARN, E.F.; MATZUK, M.M.; INSEL, T.R.; WINSLOW, J.T. Social amnesia in mice lacking the oxytocin gene. Nat Genet, v. 25, p. $284-$ $88,2000$.

FLEMING, A.S.; VACCARINO, F.; LUEBKE, C. Amygdaloid inhibition of maternal behavior in the nulliparous female rat. Physiol Behav, v. 25, p. 731-43, 1980.

FLEMING, A.S.; SUH, E.J.; KORSMIT, M.; RUSAK, B. Activation of Fos-like immunoreactivity in the medial preoptic area and limbic structures by maternal and social interactions in rats. Behav Neurosci, v. 108, p. 724-34, 1994.

FOURNIER, J.; STEINBERG, R.; GAUTHIER, T.; KEANE, P.E.; GUZZI, U.; COUDE, F.X.; BOUGAULT, I.; MAFFRAND; J.P.; SOUBRIE, P.; LE FUR, G. Protective effects of SR 57746A in central and peripheral models of neurodegenerative disorders in rodents and primates. Neuroscience, v. 55, p. 629-41, 1993.

GALEF JR, B.G.; WIGMORE, S.W.; KENNETT, D.J. A failure to find socially mediated taste aversion learning in Norway rats (R. norvegicus). J Comp Psychol, v. 97, p. 358-63, 1983.

GENTSCH, C.; LICHTSTEINER, M.; FRISCHKNECHT, H.R.; FEER, H.; SIEGFRIED, B. Isolation-induced locomotor hyperactivity and hypoalgesia in rats are prevented by handling and reversed by resocialization. Physiol Behav, v. 43, p. 13-16, 1988.

GHEUSI, G.; BLUTHE, R.M.; GOODALL, G.; DANTZER, R. Ethological study of the effects of tetrahydroaminoacridine (THA) on social recognition in rats. Psychopharmacology (Berl), v. 114, p. 644-50, 1994a.

GHEUSI, G.; BLUTHE, R.M.; GOODALL, G.; DANTZER, R. Social and individual recognition in rodents: methodological aspects and neurobiological bases. Behavioural Process, v. 33, p. 59-88, 1994 b. 
GRANT, E.C. An analysis of the social behaviour of the male laboratory rat Behaviour, v. 21, p. 260-81, 1963.

GRANT, E.C.; MACKINTOSH, J.H. A description on the social postures of some laboratory rodents. Animal Behavior, v. 21, p. 246-59, 1963.

GUO, J.; ZHOU, A.; MOSS, R.L. Urine and urine-derived compounds induce c-fos mRNA expression in accessory olfactory bulb. Neuroreport, v. 8, p. 1679-83, 1997.

HALBERG, F. Chronobiology. Annu Rev Physiol, v. 31, p. 675-725, 1969.

HALL, C.S.; KLEIN, S.J. Individual differences in aggressiveness in rats. J Comp Psychol, v. 33, p. 371-83, 1942.

HALL, F.S.; HUMBY, T.; WILKINSON, L.S.; ROBBINS, T.W. The effects of isolationrearing of rats on behavioural responses to food and environmental novelty. Physiol Behav, v. 62 , p. 281-90, 1997a.

HALL, F.S.; HUMBY, T.; WILKINSON, L.S.; ROBBINS, T.W. The effects of isolationrearing on preference by rats for a novel environment. Physiol Behav, v. 62, p. 299-303, $1997 b$.

HALPIN, Z.T. Individual differences in the biological odors of the Mongolian gerbil (Meriones unguiculatus). Behav Biol, v. 11, p. 253-59, 1974.

HARRIS, V.S.; SACHS, B.D. Copulatory behavior in male rats following amygdaloid lesions. Brain Res, v. 86, p. 514-18, 1975.

HATCH, A.; BALAZS, T.; WIBERG, G.S.; GRICE, H.C. Long-term isolation stress in rats. Science, v. 142, p. 507, 1963.

HOLLOWAY, F.A.; WANSLEY, R.A. Multiple retention deficits at periodic intervals after active and passive avoidance learning. Behav Biol, v. 9, p. 1-14, 1973.

HOLSON, R.R.; SCALLET, A.C.; ALI, S.F.; TURNER, B.B. "Isolation stress" revisited: isolation-rearing effects depend on animal care methods. Physiol Behav, v. 49, p. 1107-18, 1991.

HURST, J.L.; PAYNE, C.E.; NEVISON, C.M.; MARIE, A.D.; HUMPHRIES, R.E.; ROBERTSON, D.H.; CAVAGGIONI, A.; BEYNON, R.J. Individual recognition in mice mediated by major urinary proteins. Nature, v. 414, p. 631-34, 2001.

INSEL, T.R. A neurobiological basis of social attachment. Am J Psychiatry, v. 154, p. 726$35,1997$.

INSEL, T.R.; SHAPIRO, L.E. Oxytocin receptor distribution reflects social organization in monogamous and polygamous voles. Proc Natl Acad Sci USA, v. 89, p. 5981-85, 1992. 
JOHNSTON, R.E. Pheromones, the vomeronasal system, and communication. From hormonal responses to individual recognition. Ann N Y Acad Sci, v. 855, p. 333-48, 1998.

JONES, G.H.; ROBBINS, T.W.; MARSDEN, C.A. Isolation-rearing retards the acquisition of schedule-induced polydipsia in rats. Physiol Behav, v. 45, p. 71-7, 1989.

KARLSON, P.; LUSCHER, M. Pheromones': a new term for a class of biologically active substances. Nature, v. 183, p. 55-6, 1959.

KEVERNE, E.B. The vomeronasal organ. Science, v. 286, p. 716-20, 1999.

KOGAN, J.H.; FRANKLAND, P.W.; SILVA, A.J. Long-term memory underlying hippocampus-dependent social recognition in mice. Hippocampus, v. 10, p. 47-56, 2000.

KOLLACK-WALKER, S.; NEWMAN, S.W. Mating and agonistic behavior produce different patterns of Fos immunolabeling in the male Syrian hamster brain. Neuroscience, v. 66, p. 721-36, 1995.

KOOLHAAS, J.M.; SCHUURMAN, T.; WIEPKEMA, P.R. The organization of intraspecific agonistic behaviour in the rat. Prog Neurobiol, v. 15, p. 247-68, 1980.

LAI WS, RAMIRO LL, YU HA, JOHNSTON RE Recognition of familiar individuals in golden hamsters: a new method and functional neuroanatomy. J Neurosci, v. 25, p. 11239-47, 2005.

LAZAR, J.; RASMUSSEN, L.E.; GREENWOOD, D.R.; BANG, I.S.; PRESTWICH, G.D. Elephant albumin: a multipurpose pheromone shuttle. Chem Biol, v. 11, p. 1093-1100, 2004.

LE MOAL, M.; DANTZER, R.; MICHAUD, B.; KOOB, G.F. Centrally injected arginine vasopressin (AVP) facilitates social memory in rats. Neurosci Lett, v. 77, v. 353-59, 1987.

LEHMAN, M.N.; WINANS, S.S. Vomeronasal and olfactory pathways to the amygdala controlling male hamster sexual behavior: autoradiographic and behavioral analyses. Brain Res, v. 240, p. 27-41, 1982.

LEHMAN, M.N.; WINANS, S.S.; POWERS, J.B. Medial nucleus of the amygdala mediates chemosensory control of male hamster sexual behavior. Science, v. 210, p. 557-60, 1980.

LEMAIRE, M.; BOHME, G.A.; PIOT, O.; ROQUES, B.P.; BLANCHARD, J.C. CCK-A and CCK-B selective receptor agonists and antagonists modulate olfactory recognition in male rats. Psychopharmacology (Berl), v. 115, p. 435-40, 1994.

LIM, M.M.; MURPHY, A.Z.; YOUNG, L.J. Ventral striatopallidal oxytocin and vasopressin V1a receptors in the monogamous prairie vole (Microtus ochrogaster). J Comp Neurol, v. 468 , p. 555-70, 2004.

LORE, R.; FLANNELLY, K. Rat societies. Sci Am, v. 236, p. 106-16, 1977. 
LUITEN, P.G.; KOOLHAAS, J.M.; DE BOER, S.; KOOPMANS, S.J. The cortico-medial amygdala in the central nervous system organization of agonistic behavior. Brain Res, v. 332, p. 283-97, 1985.

LUO, M.; FEE, M.S.; KATZ, L.C. Encoding pheromonal signals in the accessory olfactory bulb of behaving mice. Science, v. 299, p. 1196-201, 2003.

MAASWINKEL, H.; BAARS, A.M.; GISPEN, W.H.; SPRUIJT, B.M. Roles of the basolateral amygdala and hippocampus in social recognition in rats. Physiol Behav, v. 60, p. 55-63, 1996.

MARQUES, M.D.; WATERHOUSE, J.M. Masking and the evolution of circadian rhythmicity. Chronobiol Int, v. 11, p. 146-55, 1994.

MEREDITH, M.; WESTBERRY, J.M. Distinctive responses in the medial amygdala to samespecies and different-species pheromones. J Neurosci, v. 24, p. 5719-25, 2004.

MONCHO-BOGANI, J.; MARTINEZ-GARCIA, F.; NOVEJARQUE, A.; LANUZA, E. Attraction to sexual pheromones and associated odorants in female mice involves activation of the reward system and basolateral amygdala. Eur J Neurosci, v. 21, p. 2186-98, 2005.

MONCHO-BOGANI, J.; LANUZA, E.; HERNANDEZ, A.; NOVEJARQUE, A.; MARTINEZ-GARCIA, F. Attractive properties of sexual pheromones in mice: innate or learned? Physiol Behav, v. 77, p. 167-76, 2002.

MROSOVSKY, N. Phase response curves for social entrainment. J Comp Physiol, v. 162, p. 35-46, 1988.

PACTEAU, C.; EINON, D.; SINDEN, J. Early rearing environment and dorsal hippocampal ibotenic acid lesions: long-term influences on spatial learning and alternation in the rat. Behav Brain Res, v. 34, p. 79-96, 1989.

PARKER, V.; MORINAN, A. The socially-isolated rat as a model for anxiety. Neuropharmacology, v. 25, p. 663-64, 1986.

PARKES, A.S.; BRUCE, H.M. Olfactory stimuli in mammalian reproduction. Science, v. 134, p. 1049-54, 1961.

PETRULIS, A.; JOHNSTON, R.E. Lesions centered on the medial amygdala impair scentmarking and sex-odor recognition but spare discrimination of individual odors in female golden hamsters. Behav Neurosci, v. 113, p. 345-57, 1999.

PITTENDRIGH, C.S. On the mechanism of entrainment of circadian rhythms by light cycles. In: Circadian Clocks (Aschoff J, ed). Amsterdam: North Holland, 1965, p. 277-97.

POPIK, P.; VETULANI, J. Opposite action of oxytocin and its peptide antagonists on social memory in rats. Neuropeptides, v. 18, p. 23-27, 1991. 
POPIK, P.; VAN REE, J.M. Neurohypophyseal peptides and social recognition in rats. Prog Brain Res, v. 119, p. 415-36, 1998.

POPIK, P.; VETULANI, J.; VAN REE, J.M. Low doses of oxytocin facilitate social recognition in rats. Psychopharmacology (Berl), v. 106, p. 71-74, 1992a.

POPIK, P.; VOS, P.E.; VAN REE, J.M. Neurohypophyseal hormone receptors in the septum are implicated in social recognition in the rat. Behav Pharmacol, v. 3, p. 351-58, 1992 b.

POPIK, P.; VETULANI, J.; BISAGA, A.; VAN REE, J.M. Recognition cue in the rat's social memory paradigm. J Basic Clin Physiol Pharmacol, v. 2, p. 315-27, 1991.

RAJENDREN, G.; MOSS, R.L. The role of the medial nucleus of amygdala in the matinginduced enhancement of lordosis in female rats: the interaction with luteinizing hormonereleasing hormone neuronal system. Brain Res, v. 617, p. 81-86, 1993.

REIJMERS, L.G.; LEUS, I.E.; BURBACH, J.P.; SPRUIJT, B.M.; VAN REE, J.M. Social memory in the rat: circadian variation and effect of circadian rhythm disruption. Physiol Behav, v. 72, p. 305-309, 2001.

RUDY, J.W. Postconditioning isolation disrupts contextual conditioning: an experimental analysis. Behav Neurosci, v. 110, p. 238-46, 1996.

SALES, D.G. The effect of $22 \mathrm{kHz}$ calls and artificial $38 \mathrm{kHz}$ signals on activity in rats. Behav Processes, v. 24, p. 83-93, 1991.

SAM, M.; VORA, S.; MALNIC, B.; MA, W.; NOVOTNY, M.V.; BUCK, L.B. Neuropharmacology. Odorants may arouse instinctive behaviours. Nature, v. 412, p. 142, 2001.

SAVONENKO, A.; FILIPKOWSKI, R.K.; WERKA, T.; ZIELINSKI, K.; KACZMAREK, L. Defensive conditioning-related functional heterogeneity among nuclei of the rat amygdala revealed by c-Fos mapping. Neuroscience, v. 94, p. 723-33, 1999.

SAWYER, T.F.; HENGEHOLD, A.K.; PEREZ, A. Chemosensory and hormonal mediation of social memory in male rats. Behavioral Neuroscience, v. 98, p. 908-13, 1984.

SEKIGUCHI, R.; WOLTERINK, G.; VAN REE, J.M. Analysis of the influence of vasopressin neuropeptides on social recognition of rats. Eur Neuropsychopharmacol, v. 1, p. 123-26, 1991a.

SEKIGUCHI, R.; WOLTERINK, G.; VAN REE, J.M. Short duration of retroactive facilitation of social recognition in rats. Physiol Behav, v. 50, p. 1253-56, 1991 b.

SHARROW, S.D.; VAUGHN, J.L.; ZIDEK, L.; NOVOTNY, M.V.; STONE, M.J. Pheromone binding by polymorphic mouse major urinary proteins. Protein Sci, v. 11, p. 2247-56, 2002. 
SHEEHAN, T.; PAUL, M.; AMARAL, E.; NUMAN, M.J.; NUMAN, M. Evidence that the medial amygdala projects to the anterior/ventromedial hypothalamic nuclei to inhibit maternal behavior in rats. Neuroscience, v. 106, p. 341-56, 2001.

SLATER, P.J.B. El comportamiento animal. Madrid: Cambridge, 2000.

SQUIRES, A.S.; PEDDLE, R.; MILWAY, S.J.; HARLEY, C.W. Cytotoxic lesions of the hippocampus do not impair social recognition memory in socially housed rats. Neurobiol Learn Mem, v. 85, p. 95-101, 2006.

STARK, C.P.; ALPERN, H.P.; FUHRER, J.; TROWBRIDGE, M.G.; WIMBISH, H.; SMOCK, T. The medial amygdaloid nucleus modifies social behavior in male rats. Physiol Behav, v. 63, p. 253-59, 1998.

SWANN, J.; RAHAMAN, F.; BIJAK, T.; FIBER, J. The main olfactory system mediates pheromone-induced fos expression in the extended amygdala and preoptic area of the male Syrian hamster. Neuroscience, v. 105, p. 695-706, 2001.

SWANSON, L.W.; PETROVICH, G.D. What is the amygdala? Trends Neurosci, v. 21, p. 323-31, 1998.

TERRANOVA, J.P.; PERIO, A.; WORMS, P.; LE FUR, G.; SOUBRIE, P. Social olfactory recognition in rodents: deterioration with age, cerebral ischaemia and septal lesion. Behav Pharmacol, v. 5, p. 90-98, 1994.

THOR, D.; HOLLOWAY, W.R. Social memory of the male laboratory rat. Journal of Comparative and Physiological Psychology, v. 96, p. 1000-1006, 1982.

TRINH, K.; STORM, D.R. Vomeronasal organ detects odorants in absence of signaling through main olfactory epithelium. Nat Neurosci, v. 6, p. 519-25, 2003.

VAN WIMERSMA GREIDANUS, T.B.; MAIGRET, C. The role of limbic vasopressin and oxytocin in social recognition. Brain res, v. 713, p. 153-59, 1996.

VAN WIMERSMA GREIDANUS, T.B.; VAN REE, J.M.; DE WIED, D. Vasopressin and memory. Pharmacol Ther, v. 20, p. 437-58, 1983.

VOCHTELOO, J.D.; KOOLHAAS, J.M. Medial amygdala lesions in male rats reduce aggressive behavior: interference with experience. Physiol Behav, v. 41, p. 99-102, 1987.

WANSLEY, R.A.; HOLLOWAY, F.A. Oscillations in retention performance after passiveavoidance training. Learning and Motivation, v. 7, p. 296-302, 1976.

WILKINSON, L.S.; KILLCROSS, S.S.; HUMBY, T.; HALL, F.S.; GEYER, M.A.; ROBBINS, T.W. Social isolation in the rat produces developmentally specific deficits in prepulse inhibition of the acoustic startle response without disrupting latent inhibition. Neuropsychopharmacology, v. 10, p. 61-72, 1994. 
WONGWITDECHA, N.; MARSDEN, C.A. Social isolation increases aggressive behaviour and alters the effects of diazepam in the rat social interaction test. Behav Brain Res, v. 75, p. 27-32, 1996.

XU, F.; SCHAEFER, M.; KIDA, I.; SCHAFER, J.; LIU, N.; ROTHMAN, D.L.; HYDER, F.; RESTREPO, D.; SHEPHERD, G.M. Simultaneous activation of mouse main and accessory olfactory bulbs by odors or pheromones. J Comp Neurol, v. 489, p. 491-500, 2005.

YOUNG, L.J. The neurobiology of social recognition, approach, and avoidance. Biol Psychiatry, v. 51, p. 18-26, 2002.

YOUNG, L.J.; PITKOW, L.J.; FERGUSON, J.N. Neuropeptides and social behavior: animal models relevant to autism. Mol Psychiatry 7 Suppl, v. 2, S38-39, 2002. 
CAPÍTULO 2 


\section{FASE CIRCADIANA E INTERVALO ENTRE ENCONTROS INTERFEREM NA MEMÓRIA DE} RECONHECIMENTO SOCIAL

Observação: Uma descrição detalhada do presente experimento é apresentada no anexo I (página 66).

Dentre as variáveis que podem influenciar o desempenho da memória de reconhecimento social em roedores, inclui-se a fase do ciclo temporal em que os testes são realizados. O presente estudo foi delineado para avaliar se o momento de realização dos testes em relação ao ritmo circadiano de ratos influencia a memória de reconhecimento social, em particular na sua duração.

A memória de reconhecimento social em roedores pode ser investigada por meio de uma variante do paradigma intruso-residente também conhecido como paradigma da habituação-desabituação. Usualmente, um rato residente é exposto, em sua gaiola, a duas apresentações de co-específicos, cada qual com 5 minutos de duração, entremeadas por um intervalo de 30 minutos. Durante o primeiro encontro, o rato residente investiga o intruso. A apresentação do mesmo intruso no segundo encontro induz a uma quantidade de investigação social significantemente menor que a observada no primeiro encontro. Em contraste, a apresentação de um intruso diferente induz a uma quantidade igual ou maior de investigação social em relação àquela observada no primeiro encontro (Thor e Holloway, 1982). Na variante do paradigma da habituação-desabituação o residente é exposto repetitivamente a um mesmo intruso, resultando em habituação. Então, a apresentação de um intruso diferente pode resultar em desabituação (e. g., Halpin, 1986; Johnston, 1993; Johnston e Jernigan, 1994).

Para avaliar a memória de reconhecimento social é influenciada pela fase temporal do ritmo circadiano, ratos foram testados na variante do paradigma da habituação-desabituação, em dois momentos diferentes do ciclo. 
Os ratos adultos machos, mantidos individualmente em gaiolas-viveiro com rodas de atividade monitoradas continuadamente por um computador, tiveram seu ritmo de inatividade/atividade mensurado, em relação ao ciclo claro/escuro de 12/12 horas. Depois de uma completa sincronização, a fase escura foi substituida por luz tênue. Tendo ocorrido estabilização do ritmo de inatividade/atividade nessa nova condição, introduziu-se um fotoperíodo esqueleto, no qual dois pulsos de luz são emitidos, cada qual por apenas 30 minutos, no início e no fim da fase ativa do animal; no tempo restante, os ratos foram mantidos em luz tênue. Esse esquema fótico garante a manutenção do ritmo de inatividade/atividade dos animais, mas as fases inativa e ativa ocorrem em condições fóticas idênticas. Assim, é possível avaliar o desempenho dos animais em diferentes momentos do ciclo circadiano, porém, nas mesmas condições de iluminação prévia e presente, o que garante a comparabilidade dos resultados.

Grupos independentes de ratos mantidos nessas condições experimentais foram submetidos a cinco encontros com intrusos juvenis por dia, cada encontro com duração de 5 minutos, ao longo de 4 dias, sendo que o primeiro encontro de cada dia ocorreu duas horas depois do início da fase inativa ou da fase ativa do ciclo, dependendo do grupo; o intervalo de tempo entre os encontros de cada dia foi 30 ou 60 minutos, dependendo do grupo. No primeiro e segundo dias, o intruso juvenil apresentado foi o mesmo em cada encontro; diferentemente, no terceiro e quarto dias o intruso juvenil apresentado foi diferente em cada encontro. Os encontros foram gravados para análise posterior. Um pesquisador treinado registrou os comportamentos sociais exibido pelos residentes, incluindo (1) investigação da região anogenital, (2) investigação da cabeça, (3) investigação do corpo, (4) perseguição ao intruso, (5) comportamentos de dominância e (6) comportamentos agressivos que não comprometessem a integridade física do intruso (a sessão foi monitorada pelo 
experimentador; qualquer comportamento agressivo que pudesse causar danos físicos ao filhote levou à interrupção imedicata da sessão e à exclusão desse residente do estudo.

Analisou-se os escores individuais e também o tempo total investido pelos residentes exibindo comportamentos sociais em cada encontro. Esses resultados foram submetidos a uma análise de variância para medidas repetidas (ANOVA), tendo a fase temporal [zeitberger 14 (ativa) ou zeitberger 02 (inativa)] e intervalo entre sessões (30 ou 60 minutos) como fatores entre sujeitos, e intruso (o mesmo durante o primeiro e segundo dias, e diferentes no terceiro e quarto dias), dia [primeiro e segundo dias com o mesmo intruso (dias 1 e 2), e primeiro e segundo dias com o intruso diferente (dias 3 e 4)] e sessão (5 por dia) como fatores intra-sujeitos.

A exposição repetida ao mesmo intruso levou à redução do tempo que os residentes dedicaram-se à investigação social ao longo das sessões de cada dia, revelando a memória de reconhecimeto social; essa habituação foi mais intensa no primeiro dia de testes nos ratos testados durante a fase inativa, particularmente quando o intervalo entre as tentativas foi 60 minutos. Na primeira sessão do segundo dia de testes, residentes testados em ambas fases exibiram intensa investigação social dos intrusos, sugerindo que a memória de reconhecimento social não estava presente 24 horas depois, independentemente da fase. Além disso, ratos testados na fase inativa, com intervalos de 60 minutos, mas não com intervalos de 30 minutos, e animais testados da fase ativa, com ambos intervalos, mostraram maior quantidade de comportamentos sociais direcionados ao intruso. Por fim, os residentes mostraram aumento da quantidade de comportamentos sociais quando expostos ao intruso novo, independente da fase temporal.

A análise isolada de cada comportamento social registrado praticamente repete essas observações. Constatou-se que mais de 50\% do tempo dedicado à exibição de comportamentos sociais refere-se à investigação da região anogenital. Outro aspecto curioso 
foi que os animais testados na fase inativa e com intervalos de 60 minutos revelaram, no quarto dia de testes, maior habituação à apresentação de intrusos diferentes; esse efeito pode estar relacionado ao fato de que esses animais foram testados durante a fase inativa do ritmo temporal, em que estariam dormindo, e com o fato de que um intervalo de 60 minutos entre as tentativas faz com que a duração do teste no dia se estenda a aproximadamente $4 \mathrm{~h} 25$ minutos. No conjunto, esses resultados mostram que a expressão de comportamentos sociais está sujeita à modulação temporal. Essa modulação parece depender do intervalo de tempo entre os encontros, uma vez que os animais testados com intervalos de tempo de 60 minutos, na fase inativa, exibiram maior quantidade de comportamentos sociais em relação aos demais grupos. Assim, a modulação temporal deve ser levada em consideração no planejamento de experimentos para avaliar não apenas a memória de reconhecimento social, mas também a sociabilidade em ratos. 
ANEXO I

ב




\title{
Circadian phase and intertrial interval interfere with social recognition memory
}

\author{
Paula J. Moura ${ }^{\mathrm{a}}$, João A. Gimenes-Júnior ${ }^{\mathrm{a}}$, Verónica S. Valentinuzzi ${ }^{\mathrm{b}}$, \\ Gilberto F. Xavier ${ }^{\mathrm{a}}$ \\ a Department of Physiology, Biosciences Institute, University of São Paulo, São Paulo, São \\ Paulo, 05508-900, Brazil. \\ ${ }^{\mathrm{b}}$ Presently at Centro de Investigación Científica y de Transferencia Tecnológica- CRILAR, \\ Anillaco, La Rioja, 5301, Argentina. \\ Running title: Circadian phase and social memory
}

Mailing address: Rua do Matão, Travessa 14, n.101, sala 200B, Bairro do Butantã, São Paulo, São Paulo, 05508-900, Brazil.

E-mail: gfxavier@usp.br/pjmoura@usp.br

Phone: (55) 113091 7504, Fax: (55) 1130917568.

Pages: 24

Figures: 2

Table: 0

Grant sponsor: Coordenação de Aperfeiçoamento de Pessoal de Nível Superior (CAPES), Fundação de Amparo à Pesquisa do Estado de São Paulo (FAPESP) and Conselho Nacional de Desenvolvimento Científico and Tecnológico (CNPq).

Key words: circadian phase, social memory, social behaviors, social interaction, recognition memory, intertrial interval, active phase, inactive phase, resident, intruder, habituation/dishabituation paradigm, rat

Artigo submetido: Physiology and Behavior (PHB-D-08-00043R1) 


\begin{abstract}
A modified version of the social habituation/dis-habituation paradigm was employed to examine social recognition memory in Wistar rats during two opposing (active and inactive) circadian phases, using different intertrial intervals (30 and 60 minutes). Wheelrunning activity was monitored continuously to identify circadian phase. To avoid possible masking effects of the light-dark cycle, the rats were synchronized to a skeleton photoperiod, which allowed testing during different circadian phases under identical lighting conditions. In each trial, an infantile intruder was introduced into an adult's home-cage for a 5-minute interaction session, and social behaviors were registered. Rats were exposed to 5 trials per day for 4 consecutive days: on days 1 and 2, each resident was exposed to the same intruder; on days 3 and 4, each resident was exposed to a different intruder in each trial. The resident's social behavior was more intense when different intruders were presented compared to repeated presentation of the same intruder, suggesting social recognition memory. This effect was stronger when the rats were tested during the inactive phase and when the intertrial interval was 60 minutes. These findings suggest that social recognition memory, as evaluated in this modified habituation/dis-habituation paradigm, is influenced by the circadian rhythm phase during which testing is performed, and by intertrial interval.
\end{abstract}




\section{Introduction}

Rhythmicity is a general feature of behavioral and physiological variables. Even complex processes such as learning and memory express different kinds of temporal modulation. Simple learning processes such as habituation to sound in pigeons [1] or to an open field in mice [2] are affected by the phase of the light-dark cycle during which testing is performed. More complex learning processes are also modulated by time. For instance, the performance of rats in passive and active avoidance tasks can vary according to the time of testing $[3,4]$, and similarly, performance in the water maze task may differ between the active and inactive phases [5]. In mice, maze performance [6] and context fear conditioning [2,7] show a clear time-of-day effect. A common timing phenomenon in cognitive processes is time-stamping in which performance is better when testing is performed at the same time of day as training. This phenomenon has been observed in different learning tasks, including active avoidance [8], passive avoidance [8,9,10], appetitive learning [11], conditioned place preference $[12,13]$ and place aversion [14].

It is thus of interest to establish the temporal dynamics of learning tasks commonly used in cognitive sciences. Social recognition memory in rats has been proposed to represent an interesting model for studies of autism spectrum disorders (e. g., [15]). This type of memory has been investigated using an intruder-resident paradigm in which the social behavior of a resident animal directed towards an intruder is evaluated. The typical paradigm consists of two 5- minute exposure periods to either the same or to different intruders [16,17]; social memory is demonstrated when the resident animal spends more time investigating novel conspecifics than familiar intruders. In the original description of the test, Thor and Holloway [16] varied the interval between the two sessions. This and subsequent experiments 
revealed that the animals could recognize the intruder in the second session only when the inter-exposure interval was less than 30-40 minutes [18,19,20,21,22,23,24].

Another technique used to evaluate social learning is the habituation/dis-habituation task [e. g., 25,26,27] in which an animal is repeatedly exposed to the odor of a particular individual, which should result in habituation, before being exposed to the odor of a novel individual; this latter exposure may lead to dis-habituation. Burman and Mendl [28] used a modification of this task, considering the decrease in investigation of a juvenile by an adult as an index of habituation. Sekiguchi et al. [22] described the occurrence of habituation after six bouts of 5-minute exposures, separated by 10 -min intervals, also demonstrating that the habituation effect disappeared after a 24-hour interval.

An alternative to the above paradigms is the social discrimination test in which two intruders rather than one are presented to the resident in the second session: the familiar intruder presented in the first session, together with a new intruder [17]. Reijmers et al. [29] used this paradigm to analyze social recognition memory taking into account the temporal phase in which the animals were evaluated. Rats were tested at four different time points of the light-dark cycle (at zeitgeber times 3, 9, 15 and 21; respectively, ZT03, ZT09, ZT15 and ZT21) with an intertrial interval (ITI) of either 10 or 25 minutes. The authors found no temporal modulation of social recognition memory.

The present study further analyzes this issue by evaluating rats in two opposing phases of the circadian locomotor activity rhythm, at zeitgeber times 2 (ZT02) and 14 (ZT14) in a modified version of the habituation/dis-habituation paradigm. We also aim to extend previous work by focusing on the social behavior of the laboratory rat, particularly the habituation of investigative behavior after repeated presentations of the same and different conspecifics, testing the subjects at intertrial intervals of 30 or 60 minutes. 


\section{Materials and Methods}

Animals. Thirty-three, 8 week-old, male Wistar rats, weighing about $250 \mathrm{~g}$, were purchased from the School of Medicine of the University of São Paulo. On arrival in the laboratory the animals were housed together (4-5 per cage) in the animal facility under a $12 \mathrm{~h}$ light: $12 \mathrm{~h}$ dark (LD) cycle (lights on at 0600 hours). Temperature was held at $21 \pm 2{ }^{\circ} \mathrm{C}$. Food (Nuvilab) and water were provided ad libitum. The rats were divided into two groups: one tested during the active phase (ZT14), the other during the inactive phase (ZT02). Each group was subdivided according to testing session ITI (30 or $60 \mathrm{~min}$ ). A further 120 young rats (about 25 days old), weighing from 50 to $100 \mathrm{~g}$, housed in groups ( 8 per cage) held under the same conditions as the adults, were used as intruders to elicit social behaviors in the adult animals. Young animals were used rather than adults to avoid sexual or aggressive behaviors [16].

All procedures and animal care at the Laboratory for Neuroscience and Behavior of the Biosciences Institute of the University of São Paulo, complied with the Institute's guidelines, which conform to national and international standards and policies.

Light cycles and wheel-running activity recording. After 2 weeks of adjustment to laboratory conditions, the adult animals were placed in individual home-cages (46 x $25 \times 38$ $\mathrm{cm})$ with computer-monitored running wheels $(30 \mathrm{~cm}$ diameter, $10 \mathrm{~cm}$ width, $0.5 \mathrm{~cm}$ between bars). Cages were held in ventilated wooden cabinets $(180 \times 55 \times 50 \mathrm{~cm})$ and maintained on a $12 \mathrm{~h}$ : $12 \mathrm{~h}$ LD cycle. Two weeks later, the $12 \mathrm{~h}$ dark phase was replaced by $12 \mathrm{~h}$ of dim light (Light: Dim cycle). The dim light (15-25 lux) was provided by three $100 \mathrm{~W}$ incandescent lamps connected to a dimmer (Exatron Exata $500 \mathrm{~W}$ ); intense light (400-500 lux) was provided by two $30 \mathrm{~W}$ fluorescent lamps. When the activity rhythms were stable and precisely synchronized to the Light: Dim cycle, a skeleton photoperiod was established [30] consisting of two 30-minute bright light pulses separated by $11 \mathrm{~h}$ or $12 \mathrm{~h}$ of dim light (i.e., $30 \mathrm{~min}$ bright 
light: $11 \mathrm{~h}$ dim light, or 30 min bright light: $12 \mathrm{~h}$ dim light). This condition was continued for the duration of the experiment. The reason for using this type of synchronizing agent was to allow testing at different circadian time points, under identical illumination conditions. After 7 days in the skeleton photoperiod, behavioral testing started.

Wheel-running activity was continuously recorded using an in-house computer program. Each turn of the wheel activated a micro-switch that was registered as one pulse of activity. The resulting data were analyzed and visualized using ClockLab software (Actimetrics, Inc., Evanston, IL). The activity data were plotted as actograms and were used to monitor entrainment to the Light: Dim and skeleton photoperiod cycles, and to confirm that testing took place during the desired circadian phases.

Behavioral testing was performed within the resident animals' home-cages. During each test, a camera (Sony CCD) was adapted on top of the cage (40 $\mathrm{cm}$ above the cage floor) where it remained throughout the entire session. The camera was connected to a 29 " TV apparatus (Philips) to monitor the session, and to a video system (Philips VR456/78) for behavioral recording.

Behavioral task. A modified version of the habituation/dis-habituation paradigm was used in association with Thor and Holloway's social recognition test $[16,22,28]$. Each trial began when a young intruder was introduced into the resident's home-cage for a 5-minute interaction session. At the end of the trial, the intruder was removed and returned to an individual holding cage. Each day, every resident was subjected to 5 trials; ITI was 30 or 60 min, depending on the group. On the first and second days the residents were exposed to the same intruder. On the third and fourth days a different intruder was presented to the residents in every individual trial. 
This treatment allowed us to evaluate (1) whether long-term decrease in social investigation takes place from one day to the next (long-term habituation), both when the same intruder is presented (from the first to the second days) and when different intruders are presented (from the third to the fourth days); (2) whether short-term decrease in social investigation occurs from one trial to the next on any particular day (short-term habituation); (3) whether repeated exposure to either the 'same intruder' or to 'different intruders' results in habituation; and (4) if these effects are affected by intertrial interval and by phase of the circadian rhythm.

The residents' behaviors measured were those oriented towards the intruder and included (1) sniffing the anogenital region, (2) sniffing the head, (3) sniffing the body, (4) following the intruder, (5) dominance (the resident handling the intruder whose back is on the floor) and (6) aggression (only behaviors that did not injure the intruder, e. g., kicks) $[18,19]$.

The trials were videotaped and the behaviors exhibited by the resident rats were subsequently scored. A computer-assisted data acquisition system allowed an experimenter unaware of the treatments to quantify the time spent by each resident in performing each behavior, which was then summed to provide the total duration of social behaviors. Resident rats that exhibited behaviors such as biting or any other behavior that might injure the intruder were excluded from the experiment. During the behavioral tasks, mainly the residents ran on the wheels.

Data Analysis. The sum of the social behaviors was analyzed using a five-way ANOVA with three repeated measures. 'Circadian Phase' (ZT14 and ZT02) and 'ITI' (30 or 60 min) were the between-subjects factors. The within-subjects factors were 'Intruder' (Same Intruder on the first and second days, and Different Intruders on the third and fourth days), 'Day' (either first and second days with the same intruder, or first and second days with a different intruder; 
note that the latter correspond to the third and fourth days of testing), and 'Trial' ( 1 to 5 per day) (SAS Institute, Inc. Cary, NC). Additionally, separate ANOVAs were performed for each social behavior scored. Post hoc comparisons, when required, were performed using Duncan's Test. Differences were considered significant at $P \leq 0.05$.

\section{Results}

Figure 1 provides representative actograms of a rat tested during its active phase (ZT14, top panel) and of another rat tested during its inactive phase (ZT02, lower panel). An activity rhythm synchronized to the external LD cycle (days 1 through 12) and to the subsequent Light: Dim cycle (days 13 through 25) is present. Wheel-running activity was concentrated mainly during the dark and dim phases. When the Light: Dim cycle was replaced by the skeleton photoperiod (day 26), entrainment continued. Once behavioral testing began with exposure of the resident animal to an intruder, a masking component appeared, $i$. e., immediately after the intruder session, the resident rats ran intensively on their wheels (Figure 1) (masking is considered to occur when an external agent - exposure to the social experience in the present case - produces a direct effect on wheel-running activity, without exerting its effect through the biological clock). This occurred in rats tested in both phases. In animals tested during their active phase, wheel-running activity was more intense compared to that seen during the corresponding phase of undisturbed days. In contrast, rats tested during their inactive phase exhibited an intense bout of post-test activity. Despite this masking effect, synchronization with the skeleton photoperiod appeared to continue and, consequently, we considered that testing was performed at the circadian time points planned. 

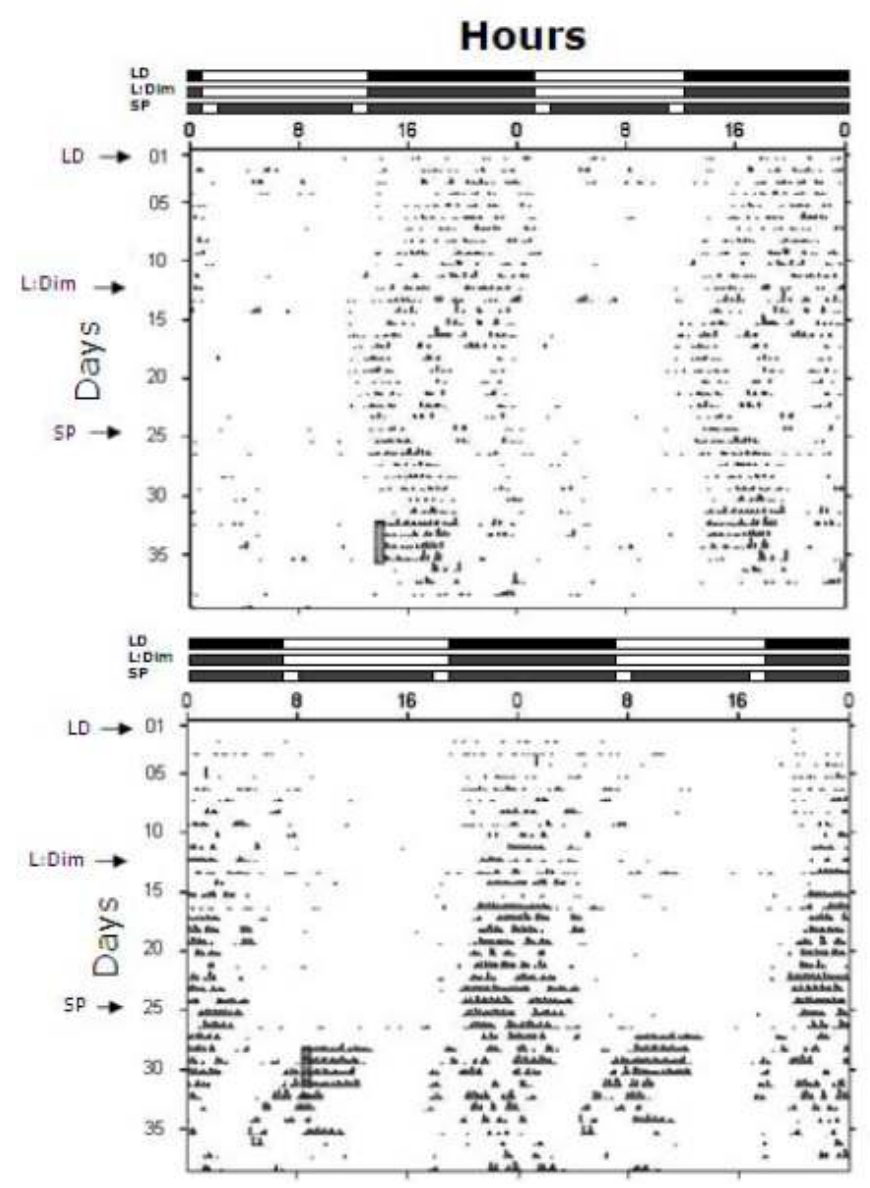

Figure 1. Representative actograms of an animal tested during its active phase (top panel) and another tested during its inactive phase (lower panel). Time is plotted across the horizontal axis (48 hours per line), and successive days are plotted beneath one another. The uppermost bar indicates the light-dark (LD) cycle to which the animals where initially submitted during days 1 through 12 . The middle bar indicates the light-dim cycle from days 13 to 25 , while the lower bar indicates the skeleton photoperiod to which the animals were subsequently submitted. The horizontal arrows to the left indicate when each cycle was begun. The vertical bars within the actograms indicate when behavioral testing was performed.

Figure 2 shows time spent in social behaviors by the resident rats when tested during the inactive (ZT02; left graph) and active (ZT14; right graph) phases of their circadian rhythm, over four testing days using five trials per day and 30 or 60 min ITIs. On the first and second days, the resident rats were exposed to the same intruder (left side of each graph) and on the third and fourth days they were exposed to different intruders in each trial (right side of each graph). Note that for statistical purposes, the third and fourth days were treated like the first and second days with different intruders. 

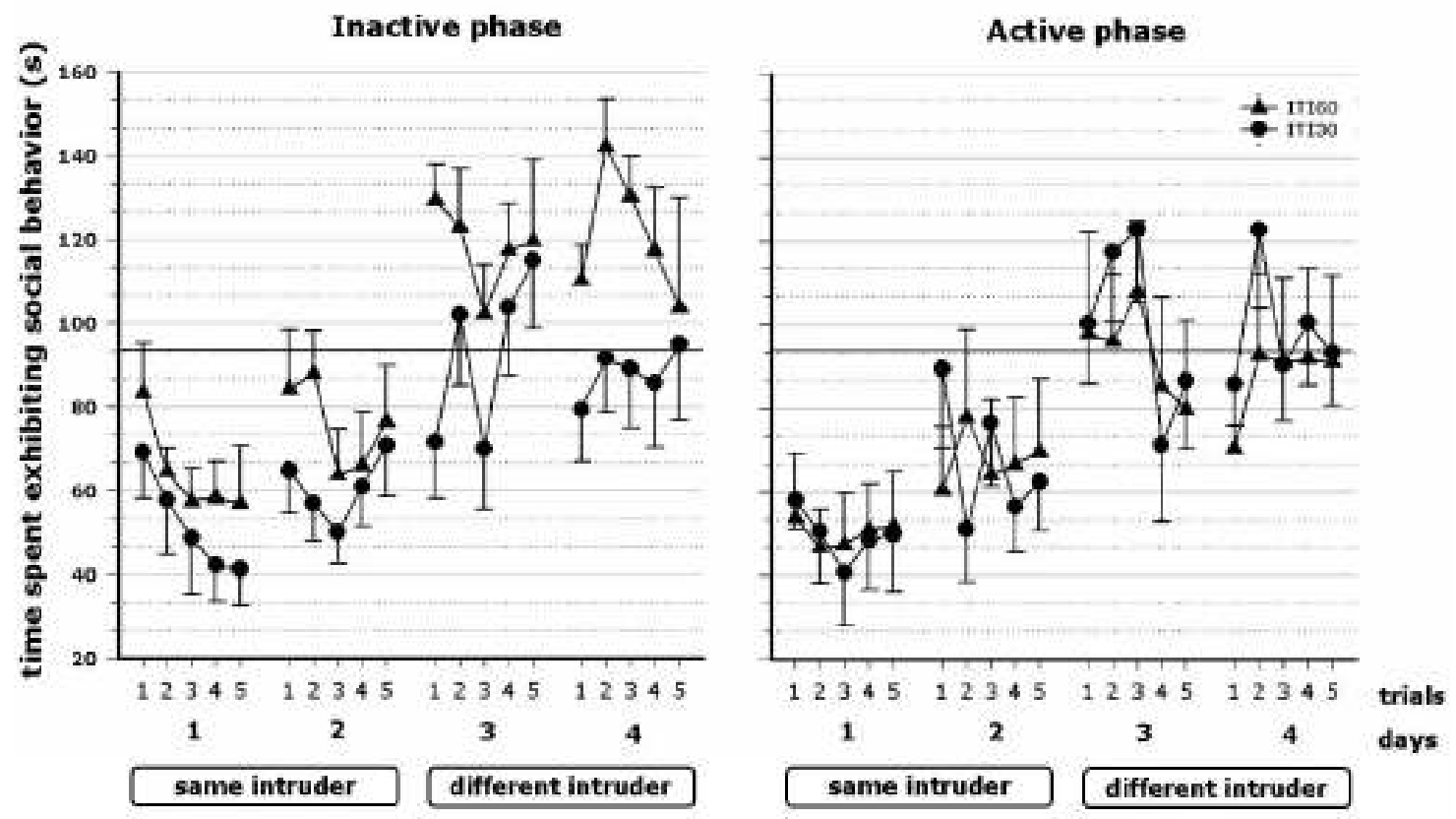

Figure 2. Mean ( \pm SEM) duration in seconds of social behaviors exhibited by resident rats in each of five trials per day, during four consecutive days. During the first and second days, the resident rats were exposed to the same intruder; during the third and fourth days they were exposed to a different intruder in each trial. Two groups of animals were tested during their inactive phase (left panel) and another two groups during their active phase. In each case, one group of animals was tested with a 60 -minute ITI $(\boldsymbol{\Delta})$ and one group with a 30 minute ITI $(\bullet)$.

Long-term habituation was not seen, either to the same intruder (first and second days) or to different intruders (third and fourth days). That is, during the early trials of the second testing day with the same intruder, the resident rats exhibited greater social investigation compared to the late trials of the previous day; this effect was independent of testing phase. When comparing the third and fourth days with different intruders in each single trial, no general decrease in social investigation was seen in either phase. The ANOVA revealed a significant Intruder x Day x Trial x Phase interaction effect $(F(4,116)=8.06 ; \mathrm{p}<0.0001)$.

Short-term habituation of social investigation was mainly seen when the resident rats were exposed to the same intruders; this effect was affected by phase. The ANOVA revealed a significant Trial effect $(F(4,116)=3.14 ; p<0.018)$ and a significant Intruder $\mathrm{x}$ Trial interaction effect $(F(4,116)=6.7 ; p<0.0001)$ (see additional ANOVA results below). Figure 
2 shows that when exposed to the same intruder over repeated trials within a single day, the resident rats exhibited a decrease in social behaviors expressing habituation to the same intruder. Conversely, when exposed to different intruders, the resident rats showed no such decrease in social investigation. Note that this habituation effect to repeated exposure to the same intruder during the first testing day was stronger for animals tested during their inactive phase (compare left and right panels for day 1).

These results also reveal a clear intertrial interval effect that was affected by phase of circadian rhythm. That is, resident rats tested in their inactive phase exhibit greater social investigation towards the intruders when ITI was $60 \mathrm{~min}$, compared to an ITI of $30 \mathrm{~min}$ (the ANOVA revealed a significant Trial $\mathrm{x}$ Phase $\mathrm{x}$ ITI interaction effect $-F(4,116)=2.91 ; p<$ 0.02) (Figure 2, left panel). This effect did not occur in resident rats tested during their active phase; $i$. e., social investigation by these rats when tested using either 30 or $60 \mathrm{~min}$ ITIs did not differ (Figure 2, right panel). Despite an apparent ITI effect during the first trial of day one in subjects tested during their inactive phase, a careful contrast analysis revealed a lack of statistical significance; thus, these animals showed no pre-existing differences in social investigation.

Exposure to different intruders induced significantly greater social investigation compared to exposure to the same intruder (Intruder effect, $F(1,29)=114.62 ; p<0.0001$ ). This effect was seen both in rats tested during their inactive phase (Figure 2, left panel) and those tested during their active phase (Figure 2, right panel).

In addition to analyzing the sum of all social behaviors, each previously defined social behavior was analyzed separately (data not shown). Many of these behaviors showed significant phase effects including anogenital investigation (Trial x Phase interaction effect: $F(4,116)=4.21 ; p<0.01 ;$ Intruder $\mathrm{x}$ Day $\mathrm{x}$ Trial $\mathrm{x}$ Phase interaction effect: $F(4,116)=2.34$ $p<0.05$; Trial $\mathrm{x}$ Phase $\mathrm{x}$ ITI interaction effect: $F(4,116)=3.51 ; p<0.01$; Intruder $\mathrm{x}$ Day $\mathrm{x}$ 
Trial x Phase interaction effect: $F(4,116)=6,35 ; p<0.0001)$, sniffing the intruder's body (Intruder $\mathrm{x}$ Trial $\mathrm{x}$ Phase $\mathrm{x}$ ITI interaction effect: $F(4,116)=2.90 ; p<0.05$; Intruder $\mathrm{x}$ Day $\mathrm{x}$ Trial $\mathrm{x}$ Phase interaction effect: $F(4,116)=2.62 ; p<0.05)$, following the intruder (Intruder $\mathrm{x}$ Phase interaction effect: $F(1,129)=4.99 ; p<0.05$; Intruder $\mathrm{x}$ Trial $\mathrm{x}$ Phase $\mathrm{x}$ ITI interaction effect: $F(4,116)=3.44 ; p<0.01)$ and dominance behavior (Intruder $\mathrm{x}$ Phase effect: $F(1,29)=$ 4.26; $p<0.04$; Intruder $\mathrm{x}$ Phase $\mathrm{x}$ ITI interaction effect: $F(1,29)=4.59 ; p<0.05$; Intruder $\mathrm{x}$ Day x Trial x Phase x ITI interaction effect: $F(4,116)=2.34 ; p<0.05)$. In general, the time spent by the resident rats exhibiting these behaviors was greater when tested during their inactive phase and when the ITI was $60 \mathrm{~min}$. More than $50 \%$ of the time spent exhibiting social behaviors corresponded to anogenital investigation. Thus, the effects represented in Figure 2 correspond largely to anogenital investigation. When this behavior is analyzed separately, the data are very similar to those for total social behavior.

\section{Discussion}

This study employed a modified version of the habituation/dis-habituation paradigm to investigate the effects of circadian phase and intertrial interval on social recognition memory. The parameters evaluated were long-term habituation and short-term habituation to known and unknown intruders. The main findings suggest that short-term habituation to the same intruder, defined as a decrease in social investigation from one trial to another within a single testing day, is more evident in animals tested during their inactive phase, using a 60 -minute intertrial interval.

As expected, the resident rats did not exhibit long-term habituation, either when exposed to the same intruder or when exposed to different intruders, independently of testing 
phase. That is, habituation to an intruder after five, 5-minute exposure sessions on the first day is not transferred to the second day of testing with the same intruder. This occurred even considering the fairly long exposure to the same intruder (25 minutes divided into 5 trials of 5-min each). This finding replicates earlier data showing that social recognition resembles short-term memory rather than long-term memory [18,19,20,21,22,23,24], and that even prolonged exposure during the first session does not improve memory retention [22].

Short-term habituation of social investigation was seen after repeated exposure to the same intruder; this process was affected by phase. That is, when exposed to the same intruder over repeated trials within a single day, the resident rats exhibited a decrease in social behaviors expressing habituation to the same intruder; this finding suggests social memory. Conversely, when exposed to different intruders, the resident rats showed no such decrease in social investigation. Together the decreased social investigation towards the same intruder and the maintenance of social investigation towards different intruders, suggest that the resident rats not only identified a particular juvenile, but also kept this information in their social memory during the intertrial interval. Thus, the habituation process and consequent social recognition seem to be focused on the characteristics of a particular intruder. Note that this habituation effect to repeated exposure to the same intruder during the first testing day was stronger in animals tested during their inactive phase (Figure 2, compare left and right panels on day 1), revealing that habituation to the same intruder may also be affected by testing phase.

The phase of circadian rhythm also influenced the intertrial interval effects on social investigation. That is, resident rats tested in their inactive phase showed greater social investigation towards intruders when ITI was $60 \mathrm{~min}$ compared to an ITI of $30 \mathrm{~min}$; this effect was not seen in resident rats tested during their active phase (Figure 2). In their initial description of the intruder-resident paradigm, Thor and Holloway [16] varied the time interval 
between two 5-minute trials, revealing that the resident rats could recognize the intruder in the second trial only when the intertrial interval was not longer than 30-40 min; this effect has been confirmed by several laboratories $[18,19,20,21,22,23,24]$. Since a 60 -minute intertrial interval would require holding information about the intruder in memory for a longer period, the effect seen here may reflect a social recognition memory failure, particularly when the rats were tested during their inactive phase, a natural sleeping period, with lower attention levels. However, rats tested during both phases displayed lower levels of social investigation towards the same intruder on the second trial of the first day of testing (see Figure 2) independently of ITI. Thus, social recognition memory function does not appear to have failed. Rather, the data suggest that the greater social investigation seen in rats tested during their inactive phase when ITI was 60 minutes reflects the cumulative effect of repeated exposures initially to the same intruder (on the first and second days of testing) and then to different intruders (on the third and fourth days of testing) (see below).

It is likely that social interactions occur during the rats' active phase [32]. Thus, the appearance of an intruder during the residents' inactive phase, a period during which encounters are unexpected, may intensify the reaction to this social stimulus and hence lead to greater social investigation, at least in the earlier trials of exposure to the intruder. While this interpretation explains the increased social investigation when resident rats are tested in their inactive phase, it does not explain why this effect is restricted to rats tested with a 60 -minute ITI. However, it is well known that repeated exposure to the same stimulus leads to habituation, an effect that increases as ITI decreases $[33,34,35]$. Thus, these animals show less habituation to the social stimulus when ITI is longer (see Figure 2, left panel, day 1), an effect carried over to testing with different intruders (Figure 2, left panel) (see below). Note, however, that this latter interpretation does not apply to the results for rats tested in their active phase (Figure 2, right panel), since the amount of social investigation seen here is 
independent of ITI. Thus, there may be an association between both intensification of the reaction to social stimulus when the test is performed in the inactive phase and slower habituation associated with a longer ITI.

Circadian phase did not affect the difference between social investigation directed towards the same or different intruders. That is, exposure to different intruders induced significantly greater social investigation compared to exposure to the same intruder, suggesting once again that the resident rats recognized individual intruders. This effect was seen both in rats tested during their inactive phase (Figure 2, left panel) and those tested during their active phase (Figure 2, right panel). The data reveal that resident rats tested either during their inactive or active phases exhibit social recognition memory. These results confirm previous observations that a resident rat spends more time investigating a different and novel conspecific than a familiar one (e.g., $[16,17])$, and extends these findings, showing that this effect occurs in rats tested during both their active and inactive phases of circadian rhythm.

Habituation is affected by circadian phase $[1,36]$. In the present study, animals tested during their inactive phase and repeatedly exposed to the same intruders on the first and second day exhibit a stronger decrease in their social investigation response, revealing that they learned to recognize the intruder as familiar. Apparently, social memory was being acquired and expressed in their decreased reaction to the repetitive stimulus. Congruently, habituation can be seen during the first-day trials; note, however, that habituation was slower in rats exposed using a 60-minute ITI, as predicted by Staddon et al. [34] model of habituation, memory decay, and interval timing. On the second day, the level of social investigation increased indicating that the interposition of a 24-hour interval leads to "dishabituation" and, further, to intensified social investigation. This latter effect may be related 
to non-photic synchronization, i. e., a time-related increase in the animals' general activity in anticipation of a relevant event [37] which, in the present case, corresponds to the social encounters. In fact, the actograms of animals tested during their inactive phase reveal an increase in activity level just before, and just after testing; this effect was already visible on the day following the first social encounter, becoming stronger as testing proceeded over time (see a representative example in Figure 1, lower panel). Similar circadian effects have been described in rats trained in the Morris water maze task [38], indicating that social encounter is also a significant arousing experience. Synchronization to social stimuli is well known (see [37]). Such intensification of activity level may have contributed to the increase in social investigation particularly when the animals were tested during their inactive phase.

In addition to increased social investigation, running activity also was induced immediately after social interaction. All the actograms of animals tested during the inactive phase showed a post-test bout of activity on the running wheels. These data clearly show that responsiveness to social interaction depends on circadian phase. The production and release of pheromones may be circadian, and such substances may interfere with the resident rats' circadian rhythm (see [39]). Since social behavior in rodents is mainly based on olfactory cues $[19,24]$, a circadian rhythm of pheromone production may explain the effect of time on social behavior in these animals. This issue remains to be evaluated.

The present findings do not conflict with those of Reijmers et al. [29] who reported that social discrimination is not influenced by circadian phase when the second trial is performed either 10 or 25 minutes after the first session. Our study shows that there were no phase effects on social investigation when ITI was 30 minutes; however, our data did reveal phase effects when ITI is increased to 60 minutes. Reijmers' experiments used many methodological differences compared to the present study; e. g., their rats were entrained to a 
standard light-dark cycle, and thus, groups tested in different phases were tested under different lighting conditions. Light exerts an inhibitory effect on the expression of behaviors by nocturnal animals [40]. Our use of a skeleton photoperiod allowed testing during different circadian phases but under exactly the same lighting conditions, thus avoiding both the aversive effects of light and the facilitatory effects of darkness. This protocol also unmasked the influence of circadian phase on social behavior.

The 30- and 60-minute ITI protocols used here entail considerable differences in duration of the daily experimental procedures. For a 30 minute ITI, the experiment lasted 2 hours 25 minutes per day; for 60 minutes, the daily experiments required 4 hours 25 minutes. This difference implies a longer interference interval, the consequences of which may be dissimilar when performed during a phase in which sleeping is preferred. The actograms of animals tested using a 60-minute ITI during their inactive phase display an activity pattern less organized than those of rats tested using a 30-minute ITI. To what extent this difference may have affected performance is not clear.

Our findings appear to conflict with the literature suggesting that social memory corresponds to a short-term memory type $[18,19,20,21,22,23,24]$. According to this notion, memory of a single 5-minute social encounter lasts less than 40 minutes; thus, 60 minutes after a social encounter, resident rats should investigate a previously exposed intruder and a novel intruder equally. No signs of habituation to a previously presented intruder should be apparent. However, our data show similar habituation effects when 30- and 60-minute ITIs were used, at least during the initial testing trials. Thus, the experimental design used here seems to have improved social memory retention. One explanation for this finding is that testing during the inactive phase improves social memory. Congruent with this interpretation, most studies on social memory have typically tested animals during their active phase 
$[18,19,20,21,22,23,24]$; the present results also show no evidence of social memory when rats were tested using a 60-minute ITI during their active phase. However, the typical intruderresident paradigm employs only two social exposures using a 30 -minute intertrial interval. In the second trial, half the subjects receive the same conspecific while the other half receives a novel intruder. In the adapted paradigm used here, rats were subjected to many social encounters. This repeated social stimulation during the inactive phase with a 60 min ITI may have lead to memory consolidation of the social information and consequently to identification of the same intruder rat.

The resident animals in the present study were housed individually in cages provided with running wheels for one month before social behavioral testing began. Exercise is known to improve performance in certain learning tasks (e. g., [41]). Such animals may be able to consolidate their memories better, and evaluation of this hypothesis requires further investigation. However, these rats were also isolated for at least one month before beginning testing. In the typical intruder-resident paradigm, rats are isolated for only 7 days before testing, supposedly to improve social interaction. Social isolation in rats can lead to several behavioral changes such as increased aggression and avoidance, as well as anxiety behaviors and working memory impairments among other factors like neuroendocrine alterations $[42,43,44]$. Our animals may be exhibiting alterations in social behavior, improving their ability to distinguish between a familiar and a novel conspecific, even when the intertrial interval is as long as 60 minutes $i$. e., even though social isolation may negatively affect memory in some tasks, those that evaluate sociability may be affected differently by social isolation. Since our animals had been isolated for a lengthy period, their altered reaction to conspecifics may have led to a differential capability to remember such interactions. Similarly, alterations due to social isolation may underlie the finding that animals tested 
during their inactive phase and submitted to a 60-minute intertrial interval exhibit more intense social investigation.

In summary, the performance data generated by this adapted habituation/dishabituation paradigm under the experimental conditions used here, suggest that the temporal modulation of social behaviors takes place mainly when the animals are tested using a 60minute intertrial interval. These temporal differences in social performance should be carefully considered when analyzing data from animals tested at different points of the circadian cycle. 


\section{References}

[1] Valentinuzzi VS, Ferrari EA. Habituation to sound during morning and night sessions in pigeons (Columba livia). Physiol Behav 1997;62:1203-9.

[2] Valentinuzzi VS, Kolker DE, Hotz Vitaterna M, Ferrari EAM, Takahashi JS, Turek FW. Effect of circadian phase on context and cued fear conditioning in C57BL/6J mice. Animal Learning and Behavior 2001;29:133-142.

[3] Davies JA, Navaratra V, Redfern PH. A 24-hour rhythm in passive-avoidance behavior in rats. Psychophysiology (Berl) 1973;32:211-214.

[4] Catalá MD, Pallardo F, Roman A, Villanueva P, Viña Giner JM. Effect of pinealectomy and circadian rhythm on avoidance behavior in the male rat. Physiology and Behavior $1985 ; 34: 327-333$.

[5] Valentinuzzi VS, Menna-Barreto M, Xavier GF. Effect of circadian phase on performance of rats in the Morris water maze task. J Biol Rhythms 2004;19:312-24.

[6] Hoffmann HJ, Balschun D. Circadian differences in maze performance of C57BL/6 mice. Behavioral Process 1992;27:77-84.

[7] Chaudhury D, Colwell CS. Circadian modulation of learning and memory in fearconditioned mice. Behav Brain Res 2002;133:95-108.

[8] Holloway FA, Wansley R. Multiple retention deficits at periodic intervals after active and passive avoidance. Behav Biol 1973;9:1-14

[9] Holloway FA, Wansley R. Multiphasic retention deficits at periodic intervals after passive-avoidance learning. Science 1973;180:208-210.

[10] Wansley RA, Holloway FA. Oscillations in retention performance after passiveavoidance training. Learn Motiv 1976;7:296-302. 
[11] Wansley RA, Holloway FA. Multiple retention deficits following one-trial appetitive training. Behavioral Biology 1975;14:135-149.

[12] Cain SW, Ko CH, Chalmers JA, Ralph MR. Time of day modulation of conditioned place preference in rats depends on the strain of rat used. Neurobiol Learn Memory $2004 ; 81: 217-220$.

[13] Valentinuzzi VS, Neto SPD, Carneiro BS, Santana KS, Araújo JF, Ralph MR (In Press) Memory for time of training modulates performance on a place conditioning task in marmosets. Neurobiology of Learning and Memory.

[14] Cain SW, Tina Chou, Ralph MR. Circadian modulation of performance on an aversionbased place learning task in hamsters. Behavioral Brain Research 2004;150:201-205.

[15] Marin JC, Moura PJ, $\underline{\text { Cysneiros RM, Colugnati DB }}$, Cavalheiro EA, Scorza FA, Xavier GF, Zilbovicius M, Mercadante MT. (In Press) Temporal lobe epilepsy and social behavior: An animal model for autism? Epilepsy and Behavior.

[16] Thor DH, Holloway WR. Social memory of the male laboratory rat. J Comp Physiol Psychol 1982;96:1000-1006.

[17] Engelmann M, Wotjak CT, Landgraf R. Social discrimination procedure: an alternative method to investigate juvenile recognition abilities in rats. Physiol Behav 1995;58:31521.

[18] Dantzer R, Koob GF, Bluthe RM, Le Moal M. Septal vasopressin modulates social memory in male rats. Brain Res 1988;457:143-7.

[19] Dantzer R, Bluthe RM, Koob GF, Le Moal M. Modulation of social memory in male rats by neurohypophyseal peptides. Psychopharmacology (Berl) 1987;91:363-8.

[20] Popik P, Wolterink G, De Brabander H, van Ree JM. Neuropeptides related to [Arg8] vasopressin facilitates social recognition in rats. Physiol Behav 1991;49:1031-5. 
[21] Sekiguchi R, Wolterink G, van Ree JM. Analysis of the influence of vasopressin neuropeptides on social recognition of rats. Eur Neuropsychopharmacol 1991;1:123-6.

[22] Sekiguchi R, Wolterink G, van Ree JM. Short duration of retroactive facilitation of social recognition in rats. Physiol Behav 1991;50:1253-6.

[23] Engelmann M, Landgraf R. Microdialysis administration of vasopressin into the septum improves social recognition in Brattleboro rats. Physiol Behav 1994;55:145-9.

[24] Popik P, van Ree JM. Neurohypophyseal peptides and social recognition in rats. Prog Brain Res 1998;119:415-36.

[25] Halpin ZT. Individual odors among mammals: origins and functions. Advances in the Study of Behavior 1986;16:40-70.

[26] Jonhston RE. Memory for individual scent in hamsters (Mesocricetus auratus) as assessed by habituation methods. J Comp Psychol 1993;107:201-207.

[27] Johnston RE, Jernigan P. Golden hamsters recognize individuals, not just individual scents. Anim Behav 1994;47:129-136.

[28] Burman O, Mendl M. The effects of environmental context on laboratory rat social recognition. Anim Behav 1999;58:629-634.

[29] Reijmers LG, Leus IE, Burdach JP, Spruijt BM, Van Ree JM. Social memory in the rat: circadian variation and effect of circadian rhythm disruption. Physiol Behav $2001 ; 72: 305-9$

[30] Pittendrigh CS. On the mechanism of entrainment of circadian rhythms by light cycles. In: Circadian Clocks, Amsterdam: North Holland, 1965. pp 277-297.

[31] Garau A, Marti MA, Sala J, Balada F. Age effects on the social interaction test in early adulthood male rats. Depress Anxiety 2000;12:226-31. 
[32] Sams-Dodd F. Effects of continuous D-amphetamine and phencyclidine administration on social behavior, stereotyped behavior, and locomotor activity in rats. Neuropsychopharmacology 1998;19:18-25.

[33] Thompson RF, Spencer WA. Habituation: a model phenomena for the study of neuronal substrates of behavior. Pshycol Rev 1966;73:16-43.

[34] Staddon JER, Chelaru IM, Higa JJ. Habituation, memory and the brain: The dynamics of interval timing. Behavioural Processes 2002;57:71-88;

[35] Buhusi CV, Meck WH. What makes us tick? Functional and neural mechanisms of interval timing. Nature Reviews Neuroscience 2005;6:755-765.

[36] Valentinuzzi VS, Buxton OM, Chang AM, Scarbrough K, Ferrari EA, Takahashi JS, Turek FW. Locomotor response to an open field during C57BL/6J active and inactive phases: differences dependent on conditions of illumination. Physiol Behav. 2000;69:269-75.

[37] Mrosovsky N. Locomotor activity and non-photic influences on circadian clocks. Biol Rev 1996;71:342-372.

[38] Valentinuzzi VS, Diniz GP, Menna-Barreto L, Xavier GF. The experience in the water maze task can affect the circadian rhythm of locomotor activity. Biological Rhythm Research 2007;38:399-414.

[39] Jechura TJ, Stimpson CD, Lee TM. Odor-facilitated reentrainment in male and female juvenile Octodon degus. Physiol Behav 2006;89:617-22.

[40] Marques MD, Waterhouse JM. Masking and the evolution of circadian rhythmicity. Chronobiol Int 1994;11:146-55.

[41] van Praag H, Christie BR, Senowski TJ, Gage FH. Running enhances neurogenesis, learning, and long-term potentiation in mice. Proc Natl Acad Sci USA 1999;96:1342731. 
[42] Wongwitdecha N, Marsden CA. Effects of social isolation rearing on learning in the Morris water maze. Brain Res 1996;715:119-24.

[43] Weiss IC, Pryce CR, Jongen-Relo AL, Nanz-bahr NI, Feldon J. Effect of social isolation on stress-related behavioural and neuroendocrine state in the rat. Behav Brain Res 2004;52:279-95.

[44] Sandstrom NJ. Sex differences in the long-term effect of preweanling isolation stress on memory retention. Horm Behav 2005;47:556-62. 
CAPÍTULO 3 


\section{A MEMÓRIA DE RECONHECIMENTO SOCIAL EM RATOS PODE DURAR PELO MENOS 24 HORAS: UM ESTUDO PARAMÉTRICO}

Observação: Uma descrição detalhada do presente experimento é apresentada no anexo II (página 97).

A memória de reconhecimento social em ratos tem sido tratada na literatura da área como um mecanismo transitório para o arquivamento de informação. No entanto, ratos são animais sociais; depreende-se assim que dependem de uma memória de reconhecimento social mais prolongada, para o estabelecimento de relações sociais.

O paradigma intruso-residente vem sendo utilizado para testar a memória de reconhecimento social em roedores; tipicamente, ratos são expostos a dois encontros com coespecíficos, de 5 minutos cada, intercalados por um intervalo de 30 minutos. No segundo encontro, o rato residente é exposto ao mesmo intruso ou a um intruso diferente. A redução dos comportamentos sociais direcionados ao mesmo intruso no segundo encontro é tomado como um indicador da memória de reconhecimento social.

No presente estudo, partiu-se da hipótese de que o tempo de exposição ao coespecífico no primeiro encontro, 5 minutos, seria insuficiente para a formação de uma memória de reconhecimento social duradoura. Para avaliar essa hipótese, realizou-se um experimento paramétrico empregando o paradigma intruso-residente em que grupos independentes de animais foram apresentados a um co-específico adulto por 0,083 (5 minutos), 0,5 (30 minutos), 2, 24 e 168 horas, e, 24 horas depois foram apresentados ao mesmo intruso ou a um intruso diferente, numa sessão de 10 minutos; como os residentes e os intrusos eram animais adultos, foram denominados "residentes" animais introduzidos na caixa experimental 20 minutos antes do início do primeiro encontro e mantidos na mesma caixa durante o intervalo de tempo entre o primeiro e segundo encontro; neste intervalo, os intrusos foram transferidos para uma gaiola limpa. 
Os experimentos foram conduzidos durante a fase inativa do ciclo circadiano, pois estudo prévio de nosso laboratório mostrou que a memória de reconhecimento social exibe maior duração nesta fase [Moura et al. (A), submitted; Capítulo 2]. Os animais foram conduzidos à sala experimental uma hora antes do início dos testes. O segundo encontro social foi filmado; posteriormente, os comportamentos dos residentes e dos intrusos foram registrados por um pesquisador treinado. O tempo investido por cada animal exibindo comportamentos sociais como (1) investigação da região anogenital (ANO) (2) investigação da cabeça (HEA), (3) investigação do corpo (BOD), (4) perseguição do co-específico (FOL), (5) comportamentos de dominância (DOM), e (6) comportamentos agressivos (AGR) (neste último caso, que não comprometam a integridade física dos animais), e também comportamentos não-sociais incluindo (7) cheirar o ambiente (ENV), (8) levantar-se nas patas trasseiras (REA) e (9) auto-limpeza (GRO), foi mensurado em janelas de tempo de 150 segundos cada, num total de 4 janelas de tempo

Os resultados foram analisados por meio de uma análise de variância para medidas repetidas (ANOVA) tradicional, e também uma análise exploratória inicial conhecida como análise de componentes principais (PCA, da sigla inglesa Principal Component Analysis), complementada por uma ANOVA envolvendo os escores da PCA.

A PCA revelou que mais de 50\% da variância dos resultados pode ser explicada pelos primeiros dois componentes principais. O primeiro componente, representado pelos comportamentos de coleta de informações, teve ANO, BOD, HEA e FOL no lado positivo, opondo-se a REA e ENV no lado negativo; assim, enquanto o primeiro conjunto de comportamentos foi tomado como expressão dos comportamentos investigativos sociais, o segundo conjunto de comportamentos foi tomado como expressão da busca por informações ambientais. O segundo componente da PCA é determinado, no lado positivo, por GRO, que reflete comportamento relacionado a conflito individual, em oposição, no lado negativo, por 
AGR e DOM, relacionados a comportamentos sociais que contribuem para o estabelecimento de relações hierárquicas. Note que na maioria dos estudos envolvendo o paradigma intrusoresidente, os comportamentos de AGR e DOM são incluídos na lista de comportamentos sociais investigativos; porém, a presente análise demonstrou que sua natureza difere. Neste contexto, pareceu plausível incluir uma outra sub-categoria de comportamentos sociais, denominada comportamentos sociais agonísticos, incluindo apenas AGR e DOM.

Os resultados do presente estudo mostraram, pela primeira vez que tenhamos conhecimento, que ratos exibem memória de reconhecimento social que se mantém por pelo menos 24 horas após o primeiro encontro, quando este último dura pelo menos 2 horas; esse efeito foi revelado não apenas pelo aumento significativo da investigação social exibida pelo residente em direção ao intruso diferente, mas também pela redução dessa investigação em relação ao intruso familiar. Além disso, ao serem expostos ao intruso, no primeiro encontro, por 0.083 ou 0.5 horas, os residentes não relevaram sinais de memória de reconhecimento social. Todos esses resultados foram confirmados pela PCA complementados pela ANOVA e também pela ANOVA tradicional.

A distinção dos comportamentos sociais em duas sub-categorias, de comportamentos sociais investigativos e de comportamentos sociais agonísticos, possibilitou revelar de forma inequívoca efeitos que de outra forma seriam mascarados pela soma de todos os comportamentos sociais. Isso é, a quantidade de comportamentos sociais investigativos direcionados pelo residente ao intruso familiar no segundo encontro claramente se reduz em função do aumento da duração do primeiro encontro. Diferentemente, a quantidade de comportamentos sociais (total) direcionados ao intruso no segundo encontro não se reduziu da mesma forma, particularmente quando a duração do primeiro encontro foi igual ou maior do que 2 horas, em decorrência do aumento da quantidade de comportamentos sociais agonísticos nestes grupos. Uma das conseqüências desses efeitos, que exemplifica claramente 
a importância da opção pelo uso dos comportamentos sociais investigativos, em contraposição aos comportamentos sociais (total), está no fato de que no grupo de residentes expostos ao intruso por 168 horas, a quantidade de comportamentos sociais investigativos direcionados ao intruso familiar no segundo encontro foi significantemente menor do que em relação ao intruso diferente, ao passo que a quantidade de comportamentos sociais (total) não exibiu qualquer diferença significante nessa mesma comparação. Esses resultados mostram que os comportamentos sociais investigativos se constituem numa ferramenta mais acurada para avaliar a memória de reconhecimento social em comparação aos comportamentos sociais (total) que também incluem comportamentos sociais agonísticos.

O comportamento social e não-social dos intrusos também foi avaliado no presente estudo. Estes animais apresentaram maior quantidade de comportamentos não-sociais do que os residentes, especialmente quando expostos a um residente diferente. Como $76 \%$ dos comportamentos não-sociais correspondem ao comportamento de investigar o ambiente (ENV - que inclui principalmente o comportamento de cheirar as paredes da caixa e a maravalha) esses resultados sugerem que os intrusos são capazes de identificar os residentes, resultado que se expressa por meio da investigação do ambiente habitado, e provavelmente demarcado quimicamente, pelo mesmo. Porém, não houve diferenças significantes na expressão desses comportamentos em função da duração do primeiro encontro. Mais estudos seriam necessários para se aquilatar o significado desses resultados.

No conjunto, os resultados deste experimento demonstraram inequivocamente, e contrariamente ao preconizado na literatura dessa área, que ratos exibem memória de reconhecimento social que dura pelo menos 24 horas, quando duração do primeiro encontro é igual ou maior do que 2 horas contínuas. Os resultados mostraram ainda que há vantagens na sub-divisão dos comportamentos sociais em duas sub-categorias, ao de comportamentos sociais investigativos e de comportamentos sociais agonísticos, sendo a primeira mais 
apropriada para se avaliar memória de reconhecimento social em ratos em comparação com a soma das duas. O presente estudo ressalta também a importância de se definir memória de reconhecimento social não apenas em função da redução da investigação social em direção ao intruso familiar, critério comumente adotado na literatura da área, mas também em função do aumento da investigação social em direção ao intruso diferente; ou seja, é da comparação da quantidade de comportamentos sociais investigativos direcionada aos intrusos familiar e diferente que se extrai informações seguras sobre a manifestação da memória de reconhecimento social. Finalmente, este estudo revelou que a PCA se constitui numa ferramenta com grande potencial para revelar relações significativas entre as variáveis mensuradas neste tipo de estudo, que usualmente não são reveladas pela estatística tradicional. 
ANEXO II  


\title{
Social recognition memory in rats may last at least 24 hours: a parametric study
}

\author{
Paula J. Moura ${ }^{1}$, Sérgio Tadeu Meirelles ${ }^{2}$, Gilberto F. Xavier ${ }^{1}$
}

Article type: Research Paper

${ }^{1}$ Department of Physiology, Biosciences Institute, University of São Paulo, SP, Brazil

${ }^{2}$ Department of Ecology, Biosciences Institute, University of São Paulo, SP, Brazil

Running title: Long-term social recognition memory in rats

Corresponding author: Gilberto F. Xavier, Ph D, Department of Physiology, Biosciences Institute, University of São Paulo, Rua do Matão, Travessa 14, 101, São Paulo, SP, Brazil, 05508-900.

E-mail: gfxavier@usp.br / pjmoura@usp.br

Phone: (55) 113091 7504, Fax: (55) 1130917568.

Pages: 39

Figures: 5

Table: 5

Grant sponsor: Coordenação de Aperfeiçoamento de Pessoal de Nível Superior (CAPES), Fundação de Amparo à Pesquisa do Estado de São Paulo (FAPESP) and Conselho Nacional de Desenvolvimento Científico and Tecnológico (CNPq).

Key-words: long-term social memory, grooming, social category, social behaviors, anogenital investigation, intruder-resident paradigm, memory, behavior, social investigatory, social agonistic, long-term memory, social interaction, rat 


\section{Abstract}

A modified version of the intruder-resident paradigm was used in this study to investigate the effects of increasing the time exposure to the intruder conspecific on the social recognition memory evaluated 24 hours after the end of the first encounter. Independent groups of rats were exposed to an intruder conspecific for either 0.083 (5 min.), 0.5 (30 min.), 2, 24 or 168 hours and tested 24 hours after the end of the first encounter with either the familiar or a different intruder conspecific. Social and non-social behaviors of both the resident and the intruder rats were separately scored. Furthermore, a factor analysis was employed aiming at identifying possible associations between each of the scored behaviors and their relationships with the treatments, in addition to the traditional analysis of variance for total time exhibiting social and non-social behaviors. This approach revealed that resident rats exhibit a 24-hours social recognition memory, when the duration of the first encounter with the intruder conspecific was 2 hours or longer. In addition, the results showed that the scores of distinct behavioral categories of social and non-social behaviors in the second encounter depend on how long was the first encounter, expressing familiarity with a conspecific; for instance, while dominance and mild aggression scores were greater for resident rats exposed to longer first encounters, self-grooming scores were greater for resident rats exposed to shorter first encounters. Furthermore, while behaviors including sniffing the anogenital area, sniffing the body, sniffing the head and following the conspecific, exhibited mostly by the resident rats, characterized social investigation, allowing to unravel long-term social recognition memory, behaviors including sniffing the environment and rearing, exhibited mostly by the intruder rats, characterized non-social behaviors. Together, these results suggest that social recognition memory in rats may last at least 24 hours and that a 
detailed behavioral analysis of these scores may contribute to a better understanding of the social relationships established during performance of the intruder-resident paradigm.

\section{Introduction}

Identification of a conspecific is advantageous because members of the group can dedicate energy on activities related to the group management and protection instead of on vigorous investigation of a previously met unhazardous individual. Social memory refers to the ability of animals to change their social behavior towards a conspecific as a consequence of a previous social encounter with it. Social memory in rodents seems to be based mainly on olfactory cues (Carr et al., 1976; Popik et al., 1991b; Gheusi et al., 1994a; Ferguson et al., 2002; Young, 2002).

A classic behavioral model to access rodents' social memory in the laboratory is the intruder-resident paradigm (Thor and Holloway, 1982; Dantzer et al., 1987; Le Moal et al., 1987; Dantzer et al., 1988; Bluthe et al., 1990; Bluthe et al., 1991; Popik et al., 1991b; Sekiguchi et al., 1991b, a; Bluthe and Dantzer, 1992; Popik and Van Ree, 1992; Popik et al., 1992; Bluthe and Dantzer, 1993; Popik and van Ree, 1998; Ferguson et al., 2000; Ferguson et al., 2001; Prediger et al., 2004). In short, when an intruder conspecific is introduced within a resident male rat's homecage for a 5-min session, the resident rat exhibits intense social investigation activity towards the intruder. The introduction of the familiar intruder within the resident's home cage for another 5-min session elicits far less investigation as compared to both that seen during the prior encounter with the familiar intruder and that seen towards a novel intruder; however, this effect is only seen when the intertrial interval is about 30-60 min, but not when it is about 2 hours (Dantzer et al., 1987; Dantzer et al., 1988; Burman and Mendl, 2000; Garau et al., 2000; Ferguson et al., 2001; Young, 2002; Prediger and Takahashi, 2003; Castner et al., 2004; Prediger et al., 2004; Prediger and Takahashi, 2005); in other 
words, at longer intertrial intervals (ITI) the effect vanishes. This decrease in social investigation during the second encounter with the familiar intruder, associated with a lack of decrease in social investigation towards a different intruder, is taken as an evidence of social recognition memory.

Because of these characteristics the intruder-resident paradigm has been used as a research tool to investigate short-term memory in rats (Dantzer et al., 1987; Dantzer et al., 1988; Burman and Mendl, 2000; Garau et al., 2000; Young, 2002; Prediger and Takahashi, 2003; Castner et al., 2004; Prediger et al., 2004; Prediger and Takahashi, 2005; Marin et al., 2008).

There have been attempts to increase the duration of the social recognition memory in the intruder-resident paradigm in order to use it as a research tool for investigating social interaction dysfunctions (Dantzer et al., 1987; Sekiguchi et al., 1991b; Squires et al., 2006). For instance, by using two 5-min successive exposures to the intruder, Dantzer et al. (1987) revealed consistent social recognition memory when testing was performed 2 hours after the last exposure. Similarly, Sekiguchi et al. (1991b) tested the effects of either one 30-min exposure or six 5-min exposures to the familiar intruder, with ITIs of 10 minutes, and tested the animals 24 hours later; results showed that social recognition memory had vanished for both groups.

The time spent by the resident animal performing the so called social behaviors is usually scored taking into account its distance relative to the intruder smaller than one centimeter, and includes the following behavioral categories: (1) sniffing the anogenital area, (2) sniffing the body, (3) sniffing the head, (4) dominance (one rat holds its conspecific against the floor), (5) maternal behavior (involving pup-caring activities), (6) following (the rat walks behind the conspecific approaching it), (7) aggression (the rat hits the conspecific with its anterior paws or exhibits aggressive postures), (8) cross over (the rat completes a 
locomotor cross over the dorsal surface of the other rat), (9) cross under (the rat completes a locomotor cross under the dorsal surface of the other rat) and (10) social grooming (the rat grooms the other rat) (Thor and Holloway, 1982; Dantzer et al., 1987; Popik et al., 1991b; Popik et al., 1991a; Sekiguchi et al., 1991a; Gheusi et al., 1994a; Engelmann et al., 1995). However, since these scores are usually pooled together, the contribution of each of these behaviors for evaluating social recognition memory is poorly understood.

This study used a modified version of the intruder-resident paradigm to investigate the effects of increasing the time exposure to the intruder conspecific on the social recognition memory evaluated 24 hours after the end of the first encounter. Independent groups of rats were exposed to an intruder conspecific for either 0.083 (5 min.), 0.5 (30 $\mathrm{min}.), 2,24$ or 168 hours and tested 24 hours after the end of the first encounter with either the familiar or a different intruder conspecific. Social and non-social behaviors of both the resident and the intruder rats were separately scored. Furthermore, a factor analysis was employed aiming at identifying possible associations between each of the scored behaviors and their relationships with the treatments, in addition to the traditional analysis of variance for total time exhibiting social and non-social behaviors. This approach revealed that resident rats exhibit a 24-hours social recognition memory, when the duration of the first encounter with the intruder conspecific was 2 hours or longer. In addition, the results showed that the scores of distinct behavioral categories of social and non-social behaviors in the second encounter depend on how long was the first encounter, expressing familiarity with a conspecific; for instance, while dominance and mild aggression scores were greater for resident rats exposed to longer first encounters, self-grooming scores were greater for resident rats exposed to shorter first encounters. Furthermore, while behaviors including sniffing the anogenital area, sniffing the body, sniffing the head and following the conspecific, exhibited mostly by the resident rats, characterized social investigation, allowing to unravel long-term social recognition memory, 
behaviors including sniffing the environment and rearing, exhibited mostly by the intruder rats, characterized non-social behaviors. Together, these results suggest that social recognition memory in rats may last at least 24 hours and that a detailed behavioral analysis of these scores may contribute to a better understanding of the social relationships established during performance of the intruder-resident paradigm.

\section{Materials and Methods}

Subjects. One hundred and fourty six naïve, male Wistar rats (Rattus norvegicus) from the Biosciences Institute colony, 12 weeks old at the beginning of the experiments, were used. Groups of 4-5 rats were maintained in the same cage $(40 \times 32 \times 16.5 \mathrm{~cm})$. Light was provided from 06:00-18:00 $\mathrm{h}$, and room temperature was maintained at $21 \pm 3^{\circ} \mathrm{C}$. Food and water were available ad libitum. The animals were individually handled for 10 minutes per day along 2 days before the beginning of the experiments in order to reduce manipulation-induced stress. Since rats exhibit more social behaviors during their inactive phase (Moura et al. (A), submitted), all experiments were run from 8:00 - 11:00 h. Half of these rats was used as intruders and the other half as residents (see below); these social roles were defined by random. The procedures involving the animals and their care at the Laboratory for Neuroscience and Behavior of the Biosciences Institute of the University of São Paulo, respected the Institute guide lines, which comply with national and international rules and policies.

Testing Chamber. The behavioral tests were run in a 39 × 32 x $18 \mathrm{~cm}$ Plexiglas cage having one of the longer walls transparent. A video camera (Sony CCD) positioned $30 \mathrm{~cm}$ beside the transparent wall cage allowed tape recording both the intruder and the resident social interaction. 
Behavioral procedure. A modified version of the intruder-resident paradigm (see Thor and Holloway, 1982) was used. Animals were transported from the animal facility to the testing room one hour before testing started. The so called resident rats were then placed into the testing chamber 20 minutes before the introduction of an intruder conspecific within the same chamber; this first encounter lasted either 0.083 (5 min.) $(n=14), 0.5(30 \mathrm{~min}).(n=14), 2(n$ $=16), 24(n=15)$ or 168 hours $(n=14)$, depending on the group. Note that the resident and the intruder rats had never been with each other before, and also both animals had similar body weight; the intruder was at least 10 grams lighter than the resident. At the end of the specified duration of this encounter, the intruder rat was removed from the testing chamber and individually housed in another cage; differently, the resident rat was individually maintained within the same testing chamber during 24 hours. During this time period, residents and intruders were maintained in opposite sides of the animal facility. One hour before the second encounter (testing session), intruders and residents were transported to the experimental room and maintained in their individual cages located in the opposite sides of the room. Then, while still in the testing chamber, the resident rats were exposed to a second social encounter that consisted of the introduction of either the familiar (same) or a different (unfamiliar) intruder which was maintained in the testing chamber for 10 minutes; half of the animals exposed to each treatment condition in the first encounter was exposed to the familiar intruder and the other half to the different intruder. Note that the intruder rats, naïve to the experimental procedure before the first encounter, also conveyed their first-encounterexperience to the second encounter. Note, in addition, that similarly to the resident rats, the intruder rats were also exposed either to a familiar or to an unfamiliar (resident) conspecific during the second encounter; furthermore, the intruders exposure to an different conspecific involved a resident rat belonging to the same time-duration group as that of the first encounter 
(for instance, intruders which first encounter lasted 2 hours were exposed to unfamiliar residents having the same time duration experience with an intruder).

The testing session was tape recorded allowing to score the time spent by both the resident and the intruder rats performing either social or non-social behaviors, defined according to previous studies (see Dantzer et al., 1987; Gheusi et al., 1994; Garau et al., 2000; Ferguson et al., 2001) and also based on the most frequent behaviors observed during social encounters in rats (Moura, personal observation), which description is presented on Table 1. Social behaviors included (1) sniffing the anogenital region (ANO), (2) sniffing the head, (3) sniffing the body (BOD), (4) following the conspecific (FOL), (5) dominance behavior (DOM) (corresponding to handling the conspecific which back is either on the floor or on the wall), and (6) mild aggression (AGR) (to beat using the legs). Non-social behaviors included (7) sniffing the environment (ENV), (8) self-grooming (GRO) and (9) rearing (REA) (Dantzer et al., 1987; Sekiguchi et al., 1991b; Gheusi et al., 1994a; Garau et al., 2000; Ferguson et al., 2001).

Table 1. Description of the behaviors scored

\begin{tabular}{|c|c|c|}
\hline Social Behaviors & Code & Description \\
\hline $\begin{array}{l}\text { sniffing the anogenital } \\
\text { region }\end{array}$ & ANO & $\begin{array}{l}\text { Rat's nose is } 1 \mathrm{~cm} \text { or less from the anogenital area of the con-specific. The animal may } \\
\text { hold the con-specific during sniffing. }\end{array}$ \\
\hline sniffing the head & HEA & $\begin{array}{l}\text { Rat's nose is } 1 \mathrm{~cm} \text { or less from the head of the conspecific. The animal may hold the con- } \\
\text { specific during sniffing. }\end{array}$ \\
\hline sniffing the body & BOD & $\begin{array}{l}\text { Rat's nose is } 1 \mathrm{~cm} \text { or less from the body of the conspecific with exception of the anogenital } \\
\text { and the head areas. The animal may hold the con-specific during sniffing. }\end{array}$ \\
\hline following the conspecific & FOL & The animal walks behind the con-specific approaching it. \\
\hline dominance behavior & DOM & The animal holds the conspecific against the floor with its back or ventral part on the floor. \\
\hline aggression & AGR & The animal hits the con-specific with the posterior paws or exhibits an aggressive posture. \\
\hline Non-social Behaviors & Code & Description \\
\hline sniffing the environment & ENV & $\begin{array}{l}\text { The animal sniffs the cage walls standing either on two or four paws (touching the cage } \\
\text { walls with its anterior paws) or sniffs the bedding. }\end{array}$ \\
\hline self-grooming & GRO & $\begin{array}{l}\text { The animal performs movements including wiping, licking, and scratching the fur, towards } \\
\text { its own head and body. }\end{array}$ \\
\hline rearing & REA & $\begin{array}{l}\text { The animal stands in its posterior limbs without touch the cage and performs up and down } \\
\text { movement, usually sniffing. }\end{array}$ \\
\hline
\end{tabular}


Our planning involved the exclusion of rats exhibiting biting attacks or any other aggressive behavior that could injure the conspecific (Dantzer et al., 1987; Gheusi et al., 1994a; Burman and Mendl, 1999; Ferguson et al., 2000). However, this was not required since such behaviors were never observed by the experimenter that monitored every session. A computer-assisted data acquisition system allowed an experimenter blind to the treatments to score each of these individual behaviors along four time bins of 150 seconds each; the successive time bins corresponded to the time intervals from 0 to 150,150 to 300,300 to 450 , and 450 to $600 \mathrm{~s}$.

\section{Data Analysis}

The total time spent by each rat exhibiting social and non-social behaviors was calculated both for each time bin and also for the complete testing session. Furthermore, the relative percentage of time spent performing each scored behavior relative to the total time of its corresponding (social or non-social) category was also calculated for each individual rat; for representational purposes, a general mean, including both resident and intruder rats exposed to all experimental conditions, was calculated in order to express the relative contribution of each scored behavior to its corresponding category. Finally, taking into account the results of the Principal Component Analysis (PCA) (see below), it seemed relevant to subdivide social behaviors in two categories; thus, we calculated the total time each rat spent performing either (1) social investigatory behaviors, which corresponded to the sum of times spent performing ANO, HEA, BOD and FOL, or (2) social agonistic behaviors, which corresponded to the sum of times spent performing DOM and AGR. Even though the social behaviors and its subcategories, social investigatory and social agonistic behaviors, 
partially overlap, it seemed relevant, for comparisons purposes, to analyze and show different aspects of all these results (see below).

$P C A$

The time spent by both the resident and the intruder rats performing each scored behavior during the testing session was subjected to a PCA, taking into account the groups treatments (time duration of the first encounter), the social role (resident or intruder) played by each animal, and (preliminarily) the four time bins (after this preliminary analysis, only scores relative to the first time bin were included in the PCA - see below); these correlations were represented by the factor loading. This procedure was run after applying a square root transformation to homogenize and reduce the dispersion of the original matrix containing nine variables (ANO, HEA, BOD, FOL, DOM, AGR, REA, GRO and ENV) and 146 units representing data of each individual rat; no further rotation procedures were applied. The resulting loading vectors and individuals' scores generated by the PCA transformation were represented on a Euclidian biplot. The data was represented by the average of each group scores on an Euclidian biplot to facilitate understanding the effects since the representation of the individuals values on groups were very similar to the representation of the individuals autovalues itself. Subsequently, the PCA scores of interest were further subjected to a univariate analysis of variance (ANOVA).

A preliminary PCA including the four time bins revealed a high colinearity among the responses, possibly due the fact that they were taken sequentially; thus, in order to minimize the impact of this factor in the general analysis, only the first time bin scores (measured from zero to $150 \mathrm{~s}$ of the testing session) were thereafter included in the PCA.

Correlations between the loading factors generated by processing individuals scores was revealed by the PCA and they were interpreted following the guidelines proposed by 
Cohen (1988); i.e., (1) positive 1.00 to 0.50 and negative -1.00 to -0.50 values were considered large correlations, (2) positive 0.49 to 0.30 and negative -0.49 to -0.30 values were considered medium correlations and (3) positive 0.29 to 0.10 or negative -.029 to -0.10 values were considered small correlations.

Since two out of 9 principal components explain about $53.8 \%$ of the data variance, they were further analyzed using a General Linear Model (GLM) to test the hypothesis for segregation of all variables applied.

The analyses designed included "familiarity", "social role" and "first encounter duration" as the between-subjects factors and each component axis as the within-subjects factors. Post hoc Tukey HSD tests were used when applicable. All statistical procedures were run using Statistical Package for the Social Sciences (SPSS) and A MultiVariate Statistical Package (MVSP) (Kovach, 1997); graphs were prepared using Sigma Plot Package.

Analysis of Variance (ANOVA)

The times spent by the rats performing each individually scored behavior, and the total time spent performing social, non-social, and the subcategories, social investigatory and social agonistic behaviors, were compared using traditional repeated measures ANOVAs, having (1) "familiarity" to the conspecific (familiar versus unfamiliar), (2) "social role" (intruder versus resident) and (3) "first encounter duration" [0.083 (5 min), 0.5 (30 $\mathrm{min}), 2,24$ and 168 hours (7 days)] as the between-subjects factors, and (4) "time bins" as the withinsubject factor; separated ANOVAs were run for each individual score and also for the total times exhibiting social, non-social, social investigatory and social agonistic behaviors. Post hoc comparisons involved the Tukey's test. Differences were considered significant when the $p$-value was smaller than 0.05 . All statistical procedures were run using STATISTICA (StatSoft) and graphs were prepared using Sigma Plot Package. 


\section{Results}

The Figure 1 shows the total times spent by both the resident and the intruder rats performing social (Figures 1A and 1D), social investigatory (Figures $1 \mathrm{~B}$ and $1 \mathrm{E}$ ) and non-social behaviors (Figures 1C and 1F) in the second encounter, as a function of the first encounter duration and of the presentation of either the familiar or a different conspecific. Table 2 shows the time percentual of each behavior scored relative to the total time of its corresponding (social and non-social) category. Figures 2, 3 and 4 show the times spent by resident and intruder rats exhibiting, respectively, social investigatory behaviors, social agonistic behaviors and non-social behaviors, along the four time bins of the second encounter with either the familiar or with a different intruder, separated according to the first encounter duration (see ANOVAs for these results below).

\section{Social Behaviors}
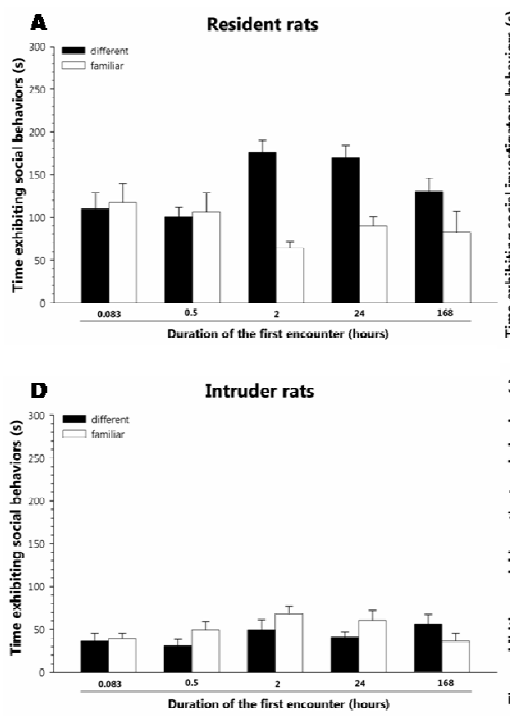
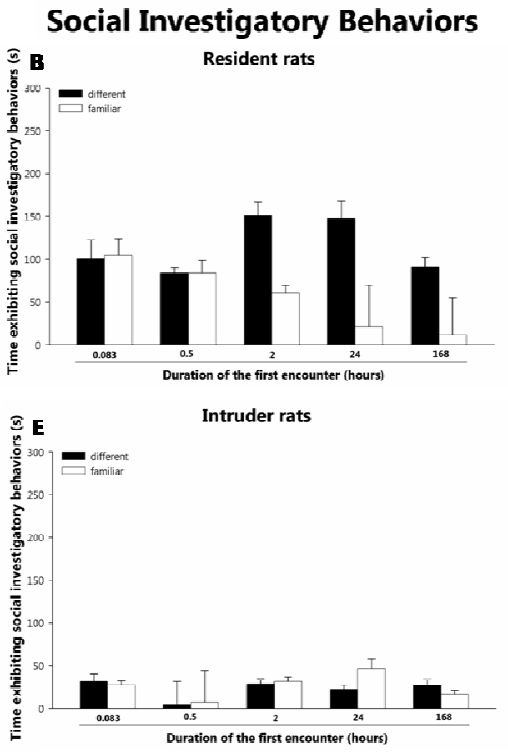

Non-social Behaviors
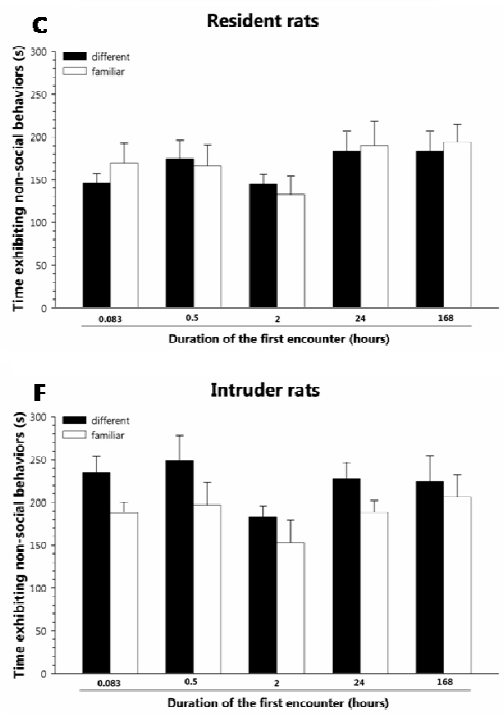

Figure 1. Time spent during the four time bins on social, social investigatory and non-social behaviors during the five different first encounter duration. (A) Represents the time of residents exhibiting social behaviors. An increase of their social behaviors toward a different intruder (black bars) was seeing after being exposed for 2 and 24 hours when compare to the amount of behaviors towards the same intruder (white bar). (B) Time spent by residents on social investigatory behaviors showing a dramatic decrease when the residents were exposed to 2, 24 and 168 hours to an intruder and then re-exposed to it in comparison to those exposed to a different resident on the second encounter. (C) Time spent by the residents in non-social behaviors. No differences were found. (D) Represents the time spent by the intruders exhibiting social behaviors. No differences were found. (E) Time spent by the intruders on social investigatory behaviors showing no difference among groups. (F) The amount of time exhibiting non-social behaviors by intruders. Intruders exposed to a different resident showed more non-social behaviors (black bars). ( $\mathrm{n}=7$ or 8 , mean \pm S.E., $\mathrm{p}<0.05$ ). 

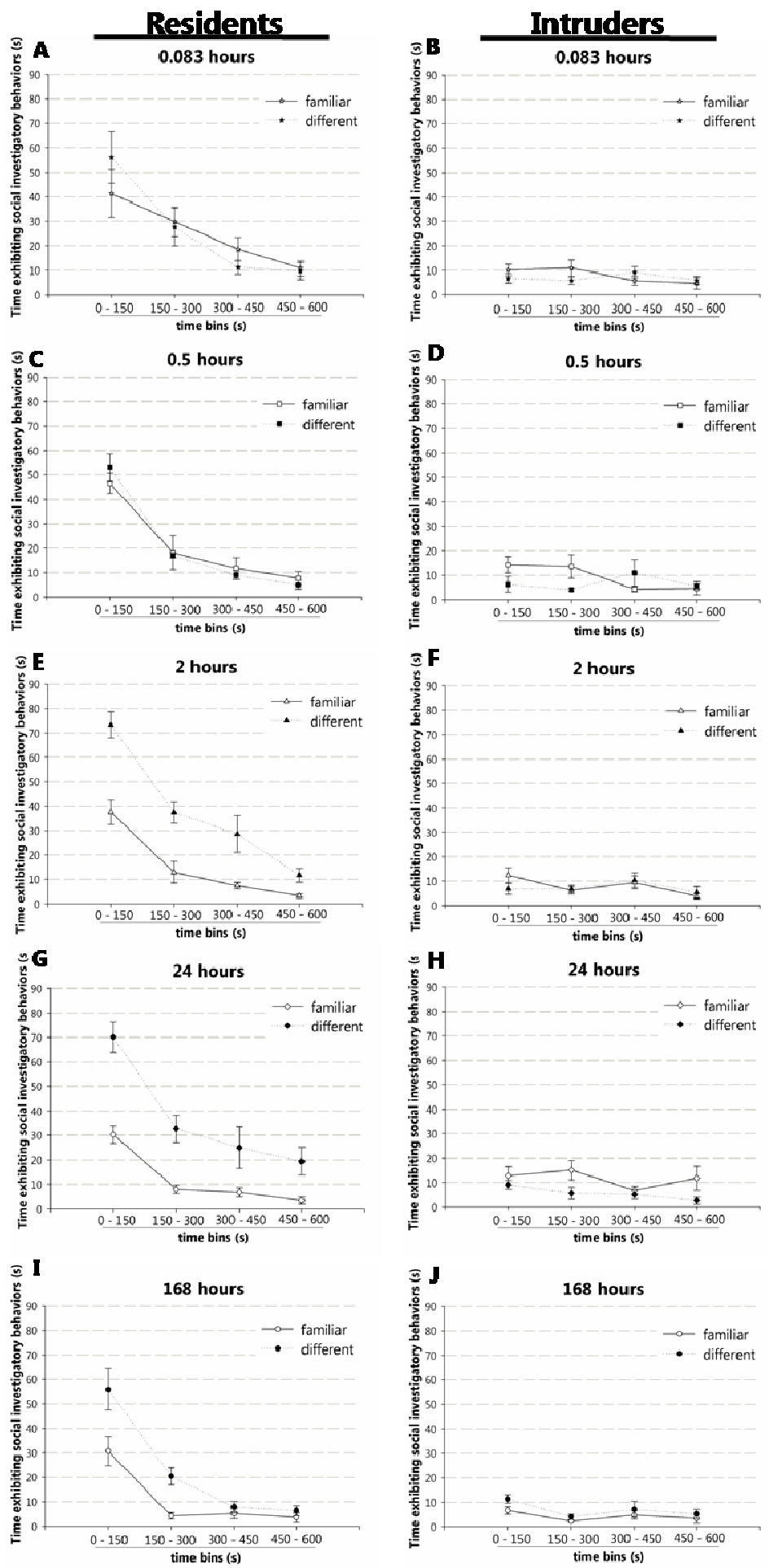

Figure 2. Social investigatory behaviors on the five different first encounters during each time bin. Similar to Figure 3, residents (A) (C) (E) (G) (H) exhibited a decrease of their social behaviors across the bins. Short social encounters such as $0.083 \mathrm{~h}$ (A) or $0.5 \mathrm{~h} \mathrm{(C)} \mathrm{did} \mathrm{not} \mathrm{enable} \mathrm{behavioral} \mathrm{differences} \mathrm{when} \mathrm{the} \mathrm{resident} \mathrm{met} \mathrm{a} \mathrm{familiar}$ (open symbols) or a different (closed symbols). However, longer social encounters with 2 or more hours (E) (G) (H) leaded to differences on the amount of behaviors toward the familiar or a different animal suggesting social recognition memory. Intruders (B) (D) (F) (H) (J) showed similar amount of social investigatory behaviors across the four bins. Intruders showed less social investigatory behaviors on all groups in comparison to residents (compare the side by side figures). (Mean \pm S.E.). 

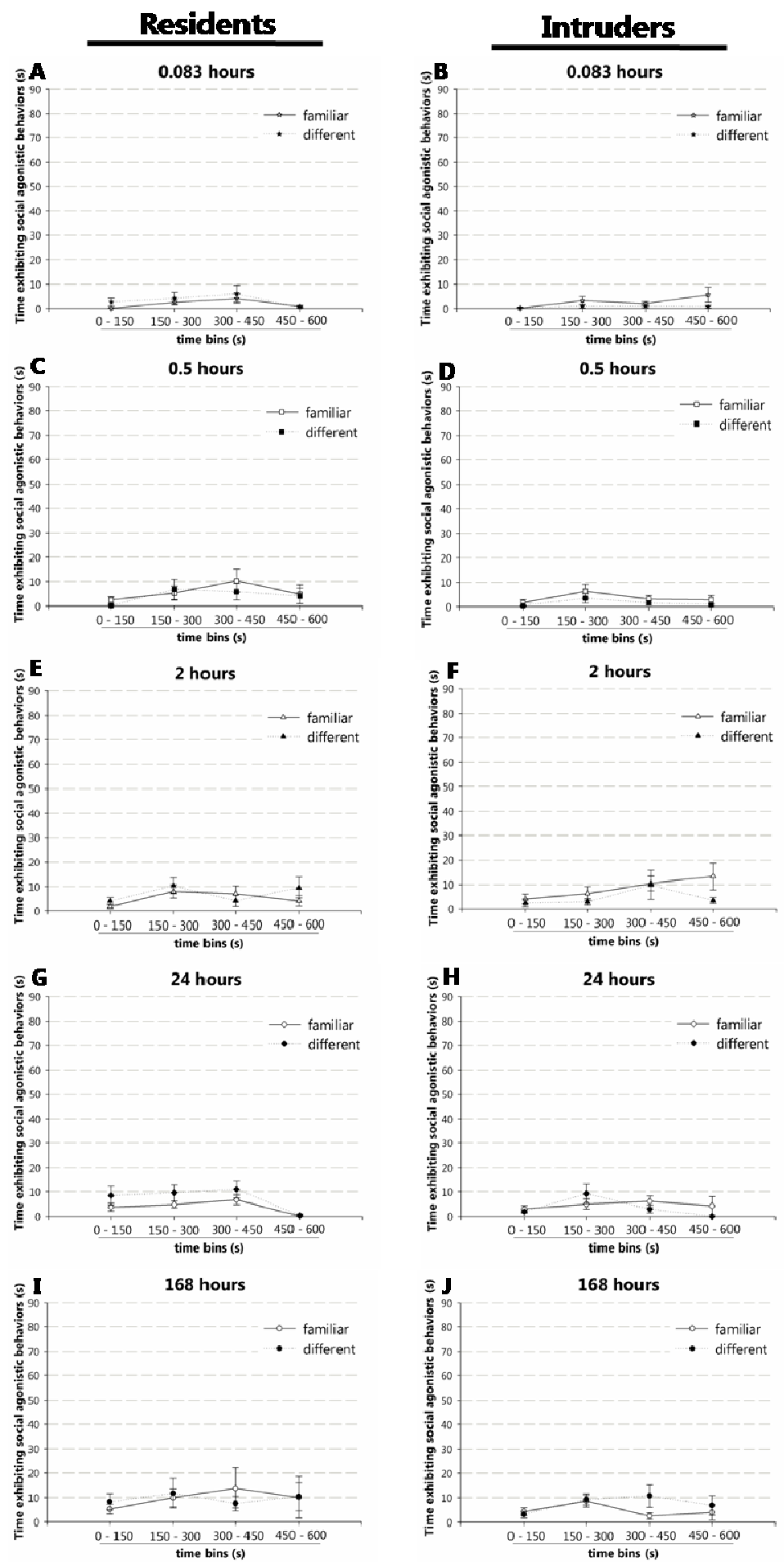

Figure 3. Social agonistic behaviors on the five different first encounters during each time bin. Residents (A) (C) (E) (G) (H) and also intruders (B) (D) (F) (H) (J) showed similar amount of social agonistic behaviors across the four bins. Intruders and residents showed slightly more social agonistic behaviors proportionally with the duration of their first encounter. That is, the amount of agonistic behaviors increases after 2 or more hours of first encounter for both resident and intruder (compare (A) (B) (C) (D) with (E) (F) (G) (H) (I) (J)). (mean \pm S.E.). 

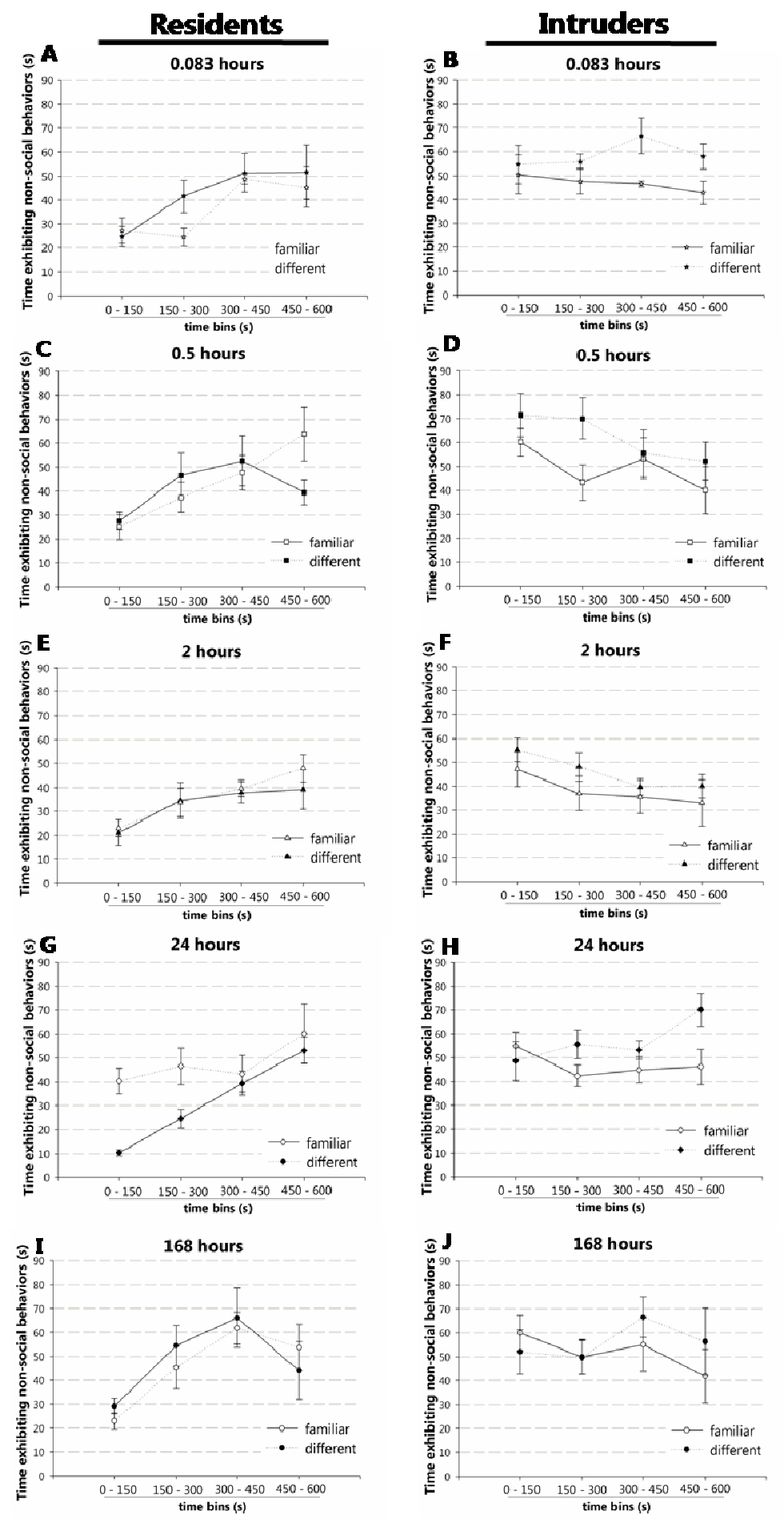

Figure 4. Non-social behaviors on the 5 different first encounters during each time bin. Residents (A) (C) (E) (G) (H) exhibited in general a gradual increase on non-social behaviors. Intruders (B) (D) (F) (H) (J) showed similar amount of non-social behaviors across the four bins. (mean \pm S.E.). 
Table 2. Time percentual of each scored behavior relative to the total time of its corresponding (social and non-social) category

\begin{tabular}{lc}
\hline Social Behaviors & \% of the total \\
\hline ANO & $49.9 \%$ \\
HEA & $3.0 \%$ \\
BOD & $17.9 \%$ \\
FOL & $3.1 \%$ \\
DOM & $23.8 \%$ \\
AGR & $2.3 \%$ \\
TOTAL & $\mathbf{1 0 0} \%$ \\
\hline Non-social Behaviors & \% of the total \\
\hline ENV & $76.8 \%$ \\
GRO & $8.9 \%$ \\
REA & $14.3 \%$ \\
TOTAL & $\mathbf{1 0 0} \%$ \\
\hline
\end{tabular}

PCA

The PCA revealed that while the first component explained $37.6 \%$ of the matrix varianc and the second component explained $16.1 \%$ of this variance; together, these components explained more than $53 \%$ of the variance, indicating that they correspond to the three main components of the rats' behavior tested in the intruder-resident paradigm as employed in this study. The Table 3 shows the loading factors for each individual behavior in each of the considered principal components. Table 4 shows the correlation matrix for pairs of behaviors; note (1) the large positive correlations involving ANO and BOD, ANO and FOL, BOD and HEA, and BOD and FOL, (2) the negative large correlations between ENV and ANO, ENV and BOD, and ENV and FOL, (3) the medium positive correlations between ANO and HEA, HEA and FOL, and ENV and REA, and (4) the medium negative correlations between REA and ANO, REA and BOD, and REA and FOL. 
Table 3. Principal component analysis: correlation matrix of the loading factors. In bold scores exhibiting large correlations

\begin{tabular}{lccc}
\hline & Social Behaviors & \multicolumn{3}{c}{ Components } \\
& $\mathbf{1}$ & $\mathbf{2}$ & $\mathbf{3}$ \\
\hline ANO & $\mathbf{. 8 4 1}$ & .181 & -.241 \\
HEA & $\mathbf{5 9 1}$ & .123 &. $\mathbf{5 6 9}$ \\
BOD & $\mathbf{. 8 1 9}$ & -.082 & .248 \\
FOL & $\mathbf{7 9 8}$ & .283 & -.249 \\
DOM & .256 & $\mathbf{- . 7 0 4}$ & .187 \\
AGR & -.029 & $\mathbf{- . 6 7 0}$ & .272 \\
ENV & $\mathbf{- . 7 8 9}$ & .042 & .204 \\
GRO & -.023 & $\mathbf{. 5 3 0}$ & .696 \\
REA & $\mathbf{. 5 7 9}$ & .307 & .001 \\
\hline
\end{tabular}

Table 4. Principal component analysis: correlation matrix between loading factors

\begin{tabular}{|c|c|c|c|c|c|c|c|c|c|}
\hline Behavioral codes & ANO* & HEA* & $\mathrm{BOD}^{*}$ & $\mathrm{FOL}^{*}$ & DOM $^{*}$ & $\mathrm{AGR}^{*}$ & ENV $^{\#}$ & GRO $^{\#}$ & REA $^{\#}$ \\
\hline ANO* & & .352 & .541 & .735 & .030 & -.095 & -.679 & -.038 & -.388 \\
\hline HEA $^{*}$ & & & .562 & .324 & .132 & -.024 & -.283 & .210 & -.247 \\
\hline BOD* & & & & .545 & .280 & .054 & -.547 & .038 & -.400 \\
\hline $\mathrm{FOL}^{\star}$ & & & & & .003 & -.196 & -.575 & -.010 & -.324 \\
\hline DOM $^{*}$ & & & & & & .207 & -.174 & -.188 & -.243 \\
\hline $\mathbf{A G R}^{*}$ & & & & & & & -.036 & -.092 & -.094 \\
\hline ENV $^{*}$ & & & & & & & & .087 & .333 \\
\hline GRO & & & & & & & & & .098 \\
\hline REA $\#$ & & & & & & & & & \\
\hline
\end{tabular}

" Socialbehaviors; "Non-social behaviors;

Figure 5 shows that while ANO, HEA, BOD and FOL were the variables mainly responsible for the first principal component exhibiting positive correlations among each other, ENV and REA exhibited negative correlations to those, contributing for the same principal component in the opposite side of the axis; thus, these behaviors may collectively characterize information gathering. In the positive side of the axis ANO, HEA, BOD and FOL correspond to direct investigation of the conspecific, relating to social information gathering; thus, these individual scores were added together and the resulting score was named social investigatory behaviors. Note that these scores were mainly correlated with the resident rats' behavior (Figure 5, circles, and Figures 1A and 1B), particularly those exposed to different conspecifics in the second encounter (Figure 5, black circles, and Figures 1A and 1B, black 
bars), after being exposed to a conspecific for two hours or longer in the first encounter

(Figure 5, greater black circles, and Figures 1A and 1B).

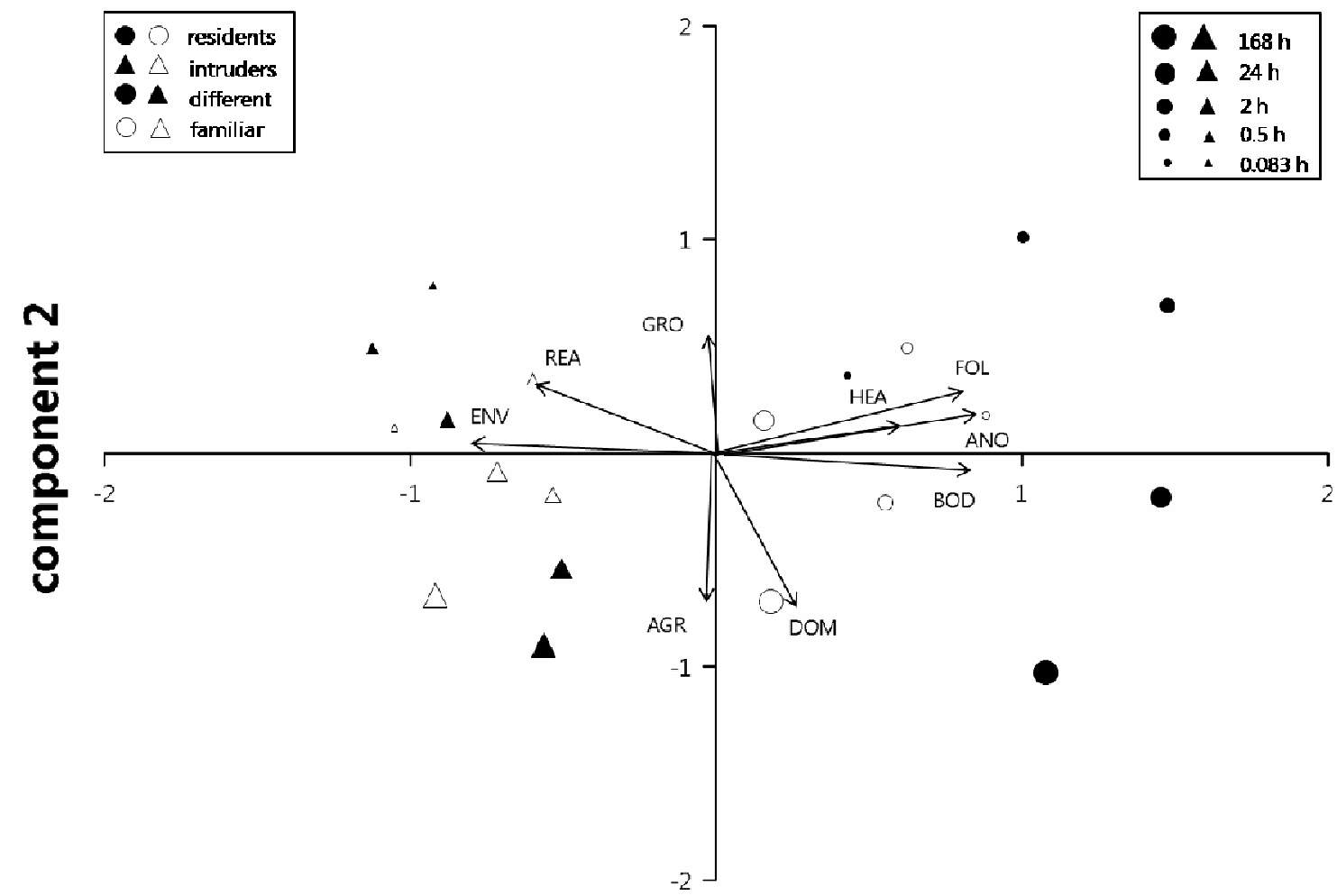

component 1

Figure 5. Principal component analysis of the second encounter: loading variables and mean of the groups. The component 1 formed by social investigatory behaviors such as ANO, BOD, HEA and FOL on the positive side and behaviors related to gathering non-social (or environmental) information such as ENV and REA on the negative side. The scores of the social investigatory behaviors were generated mainly by residents (circles) while intruders (triangles) contribute on the negative side. Residents exposed to a different intruder (black circles) showed more social investigatory behaviors, and also residents that were exposed 2 hours or longer showed less social investigatory behaviors when exposed to an familiar intruder (white circles, the three largest diameter), in comparison to those residents that stayed only 0.5 hours or less that exhibited less amount of those behaviors (white circles, 2 smallest diameter). The data suggested the presence of social recognition memory on those animals that spent 2 or more hours during the first encounter. The component 2 is related to social agonistic behaviors that were generated by the difference on time spent by the rats on their first encounter. That is, longer they spent together (bigger circles or triangles) more AGR and DOM they showed, those that spent less time together (smaller circles or triangles) exhibited more GRO.

As a matter of fact, resident rats exposed to longer first encounters $(2,24$ and $168 \mathrm{~h})$ exhibited more social investigation towards different intruders as compared to that seen towards the familiar intruder (Figure 5, longer distance between white and black circles of 
corresponding sizes for greater, but not smaller, circles, and Figures 1A and 1B). Conversely, resident rats exposed to shorter first encounters ( 0.083 and 0.5 hour) did not exhibit such difference of social investigation towards the familiar or different intruders (Figure 5, shorter distance between white and black circles of corresponding smaller sizes, and Figures 1A and 1B). In the negative side of the first principal component axis, ENV and REA characterized non-social (or environmental) information gathering, being mainly correlated with the intruder rats' behavior (Figure 5, triangles, and Figure 1F).

Figure 5 also shows that the second principal component was mainly determined by GRO, usually considered to reflect an individual conflict-related behavior, in the positive side of the axis, opposing to AGR and DOM, in the negative side of the same axis, related to social interactions that contribute for the establishment of hierarchical relationships in social groups. Thus, the second component of the PCA seems to be characterized by agonisticinduced self-conflict. Since AGR and DOM are usually included among social behaviors but the present analysis revealed that its nature differs from that of social investigatory behaviors, it seemed plausible to include them in a different subcategory, named social agonistic behavior (compare Figures 2 and 3). In general, independently on the social role, there seems to be a segregation such that while GRO behavior was mainly observed in subjects exposed to shorter first encounters (Figure 5, smaller circles and triangles in the positive side of the second component), reflecting greater conflict, opposing to social agonistic behaviors that were mainly seen in subjects exposed to longer first encounters (Figure 5, greater circles and triangles in the negative side of the second component). These figures suggest that while shorter first encounters lead to greater expression of individual conflict-related behaviors during the second encounter, longer first encounters lead to greater agonistic-induced behaviors during the second encounter (Table 2). 
A GLM for critical PCA scores of the first principal component revealed significant effects for the main factors (1) "social role" $[F(1,145)=10.051, p<0.0001]$ and (2) "familiarity" $[F(1,145)=3.019, p<0.005]$; in addition, it revealed significant interaction effects for (3) "familiarity" and "social role" $[F(1,145)=12.652, p<0.001]$, (4) "familiarity" and "first encounter duration" $[F(4,145)=4.012, p<0.005]$, and (5) "familiarity", "social role" and "first encounter duration" $[F(4,145)=3.263, p<0.05]$.

Taken together, these results indicate that there was a clear polarization along the first principal component; while resident rats spent more time exhibiting social gathering information, intruder rats spent more time exhibiting environmental gathering information ("social role" exhibited the highest sum of squares in the GLM) (Figure 5, circles representing resident rats segregated in the right axis, and triangles representing intruders segregated in the left side of the first component axis). In addition, this analysis indicated that while resident rats exposed to different intruders exhibited longer social investigation as compared that seen towards the familiar intruder (Figure 5, black circles segregated in the far most right side of the first component axis as compared to white circles), a similar effect was not seen for the intruder rats (Figure 5, triangles); note, however, that this familiarity-induced effect seen in resident rats depends on the first encounter duration, being greater for longer first encounters (Figure 5, note that the distance between black and white circles of similar sizes are longer for greater circles). Therefore, the increase in the first encounter duration rendered resident rats capable of distinguishing the familiar and the different intruders, in spite of the use of a 24hour time interval between the first and second encounters.

A similar GLM analysis for critical PCA scores of the second principal component revealed significant effects for the "first encounter duration" $[F(4,145)=10.544, p<0.0001]$. As a matter of fact, while shorter first encounters rendered both resident and intruder rats to exhibit more GRO behavior, longer first encounters rendered them to exhibit more AGR and 
DOM behaviors (Figure 5, smaller circles and triangles in the positive side of the second component, and greater circles and triangles in the negative side of it).

ANOVA

Table 5 showed the ANOVA results involving each social and non-social behaviors, as well as total social behaviors (Figures 1A and 1D), the subcategory of social investigatory (Figures 1B, 1E and 2) and social agonistic behaviors (Figure 3), and all non-social behaviors (Figure 1C, 1F and 4).

As expected, these results essentially confirm the major observations of the PCA. Together, they indicate that the resident rats exhibited more social behaviors, particularly social investigatory behaviors, relative to the intruder rats (compare Figures $1 \mathrm{~A}$ and 1D, $1 \mathrm{~B}$ and $1 \mathrm{E}$, and the left and right panels of Figure 2). This increased social investigation by the resident rats was stronger when the second encounter involved a different intruder relative to that seen in the first encounter and when the first encounter lasted 2 hours or longer (Figures 1A, 1B, 2E, 2G and 2I). Note, in addition, that social investigatory behaviors by the resident rats were greater at the beginning of the second encounter (Figure 2, left panels), particularly when different intruders were presented and the first encounter lasted 2 hours or longer (Figures 2E, 2G and 2I), decreasing along time bins; and, furthermore, that very long first encounters $(168 \mathrm{~h})$ render this decrement of social investigation towards a different intruder quicker (compare Figures 2E, 2G and 2I, third and fourth time bins). Therefore, the increase in the first encounter duration for 2 hours or longer rendered resident rats capable of distinguishing familiar and different intruders, in spite of the increase, for $24 \mathrm{~h}$, in the time interval between the first and second encounters. 


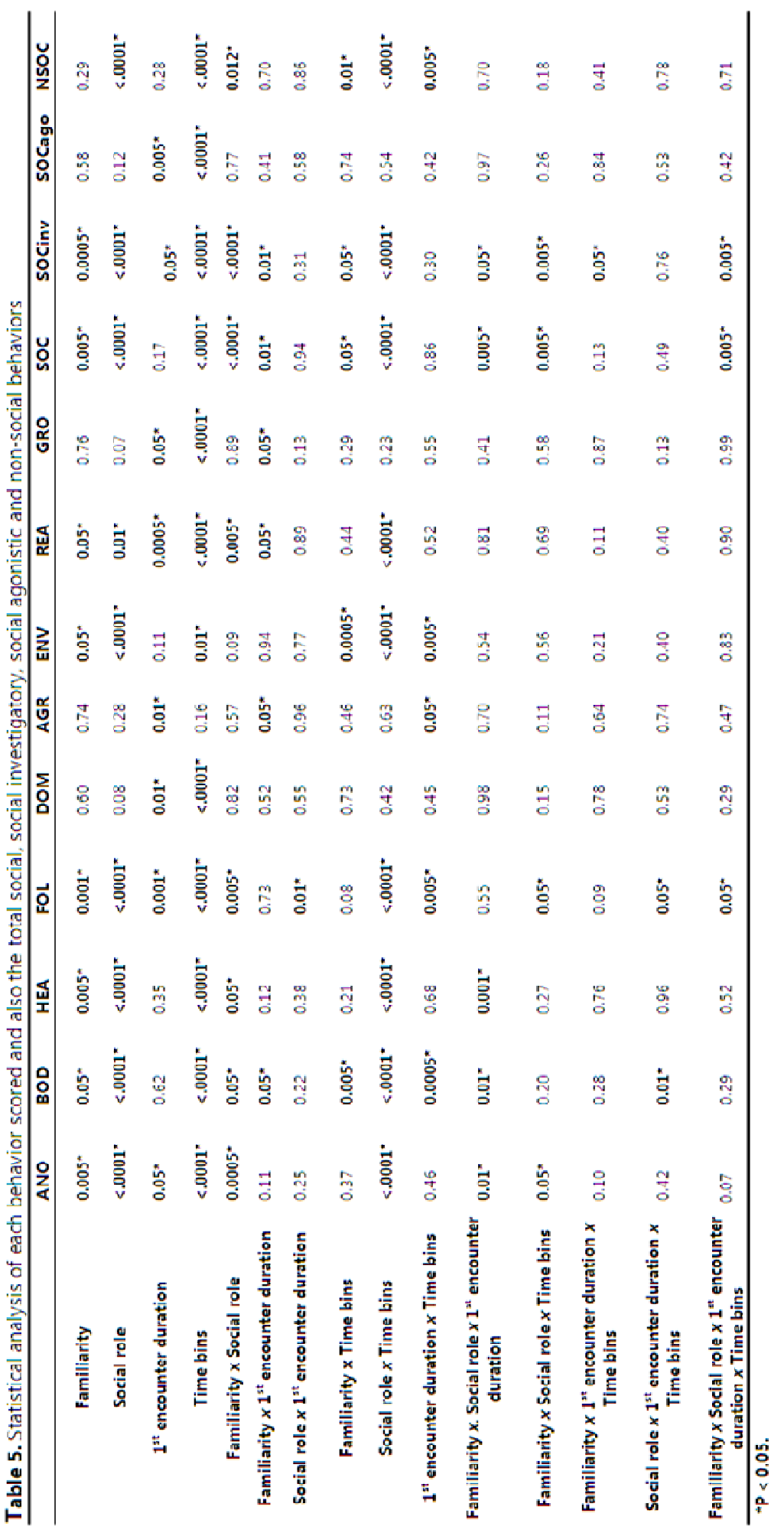


Even though, as expected, the behavioral outcomes reflected by social behavior (Figure 1A) and the subcategory social investigatory behaviors (Figure 1B) were similar, slight differences deserves additional comments. While the time spent by the resident rats exhibiting the subcategory social investigatory behaviors towards the familiar intruder rat consistently decreased as a function of the increase in the first encounter duration (Figure 1B, white bars), this effect was not seen for the total social behaviors (Figure 1A, white bars). The reason for this apparent discrepancy is related to the significant increase of the subcategory social agonistic behavior for both resident and intruder rats as the first encounter duration increased (Figure 3). That is, because total social behaviors include both subcategories, the decrease of social investigatory behaviors as a function of a longer first exposure is compensated by an increase of social agonistic behaviors. As a consequence, while resident rats exposed to an intruder for 168 hours did exhibit a significant difference in the time spent exhibiting social investigatory behaviors towards a different intruder as compared to the familiar intruder $(\mathrm{p}<0.05$, Tukey's post hoc test), this difference was not seen for the time spent exhibiting social behaviors ( $\mathrm{p}>0.05$, Tukey's post hoc test).

As a matter of fact, the intruder adult rats exhibited greater non-social behavioral scores as compared to the resident rats (Figures $1 \mathrm{C}$ and $1 \mathrm{~F}$ ); interestingly, this effect was stronger when the intruder rats were exposed to a different resident rat as compared to exposure to the familiar resident rat (Figure 1F and Figure 4 left panels). Since $76.8 \%$ of the non-social behaviors correspond to sniffing the environment (Table 2), these results seem to indicate that the intruder rats are also capable of identifying the conspecific they were previously exposed to by sniffing the cage walls and bedding where the resident rat was maintained. A gradual increase of non-social behaviors along time bins was seen in resident rats, in general reaching the highest level on the last time bin (Figure 4, left panels); since $76.8 \%$ of non-social behaviors correspond to investigation of the environment (Table 2), this 
result might reflect the time course of priorities of the resident rat when exposed to an intruder rat; that is, it starts investigating the intruder at the begining of the encounter and then investigates the environment. This interpretation also applies to the occurrence of increased expression of non-social behaviors by resident rats at the beginning of the exposure to a familiar conspecific (e. g., Figure 4G). Similar effects were not seen in the intruder rats (Figure 4), that spent longer times exhibiting non-social behaviors along the complete second encounter (Figure 4, right panels).

\section{Discussion}

The results of the present study clearly show, for the first time to our knowledge, that rats do exhibit social recognition memory that lasts at least 24 hours, when the duration of the first encounter with an adult intruder conspecific was 2, 24 or $168 \mathrm{~h}$; this effect was revealed by a significantly longer social investigation by the resident rats exposed to a different intruder conspecific as compared to exposure to the familiar intruder conspecific (Figures 1A and 1B).

In addition, the results of the present study also showed that no social recognition memory was seen in the second encounter occurring 24 hours after the first encounter which duration was 5 or 30 minutes (Figures $1 \mathrm{~A}$ and 1B). This particular observation is congruent with a plethora of reports that a resident rat's social recognition memory to an intruder conspecific does not last more than 60 minutes, when the time duration of the first encounter is 30 minutes or less (Thor and Holloway, 1982; Dantzer et al., 1987; Dantzer et al., 1988; Popik et al., 1991a; Sekiguchi et al., 1991b, a; Engelmann and Landgraf, 1994; Gheusi et al., 1994b; Engelmann et al., 1998; Popik and van Ree, 1998; Burman and Mendl, 2000; Prediger and Takahashi, 2003, 2005; Squires et al., 2006). 


\section{Social Recognition Memory Duration}

Prior attempts to enhance retention of the social recognition memory involved manipulation of different aspects of the intruder-resident paradigm (Thor and Holloway, 1982; Dantzer et al., 1987; Sekiguchi et al., 1991b).

Dantzer et al. (1987) gathered evidence showing that adult rats recognized a juvenile after a single 5-minutes exposure to it, when testing occurred in 30 minutes, but not 2 hours, after the first encounter; the authors interpreted these results as evidence that rats form a transient memory for a particular juvenile. These authors also showed that memory was enhanced when the initial exposure to the juvenile was followed by another 5-min exposure to the familiar juvenile; conversely, memory was impaired when exposure to the original juvenile was followed by a 5-minutes exposure to another juvenile. Note, however, that the first experimental design involved a longer exposure to a specific intruder as compared to that of the second experimental condition. Therefore, one could suggest that an increase of the exposure time to the original juvenile, by way of two 5-min successive encounters with the familiar juvenile, rendered the resident rats' memory to last for at least $2 \mathrm{~h}$. This result suggested that an increase in the time duration of the first encounter could render social memory longer, as in fact we did show in this study.

Sekiguchi et al. (1991b) found no evidence that resident rats could remember a previously met juvenile when a 24-hours interval between encounter sessions was used; this lack of recognition memory 24 hours after the last encounter was consistently observed independently on the prior encounters schedule, that included (1) a single 5-minutes encounter session, (2) a single 30-minutes encounter session, (3) six 5-minutes encounter sessions with an intertrial interval of 10 minutes in the previous day, (4) four 5-minutes sessions with an intertrial intervals of 24 hours, and (5) six 5-minutes encounter sessions per 
day, with an intertrial interval of 10 minutes, along four consecutive days (before the fifth day of testing). These results lead the authors to suggest that social recognition would be a form of short-term memory. It seems interesting to note that in this latter encounters schedule the resident rats were exposed to the familiar intruder for 30 minutes (divided in six 5-minutes sessions) per day, along four days, before testing 24 hours later; therefore the total exposure time to the familiar infantile before testing (on the fifth day of the experiment) was 2 hours. Even though, no significant decrease of social investigation towards the familiar infantile intruder on the first testing session of the following day was observed. These results seem to conflict with the results of the present study which did find social recognition memory 24 hours after a single 2-hour encounter.

Several hypotheses may be raised to explain this difference mentioned before. For instance, while Sekiguchi et al. (1991b) exposed the familiar intruder conspecific six times per day, along four days, to complete 2 hours of exposure, in the present study a single 2-hour session was used; this continuous exposure to the intruder conspecific may have helped the resident rat to gather more consistent information for later memory recognition. In addition, while Sekiguchi et al. (1991b) used an infantile intruder, in the present study an adult intruder was used; since an adult conspecific may represent a potential competitor for the territory of the resident animal, remembering a previous encounter with it may represent a more meaningful experience as compared to that with the infantile intruder, thus rendering better memory. Furthermore, the resident rats in Sekiguchi et al.'s (1991b) experiment were one and a half years old; differently, the subjects employed in the present study were three months old at the beginning of the experiments. It is well known that memory of young adult ats is better when compared to memory of old adult rats (Roman et al., 1996; Erickson and Barnes, 2003). 


\section{Importance of the Categories of Social Behaviors}

In agreement with the literature in the area (Thor and Holloway, 1982; Dantzer et al., 1987; Popik et al., 1991b; Popik et al., 1991a; Sekiguchi et al., 1991a; Gheusi et al., 1994a; Engelmann et al., 1995; Burman and Mendl, 1999) we included ANO, HEA, BOD, FOL, DOM and AGR scores in the category of social behaviors. However, the PCA analysis revealed that these scores may be segregated in two independent principal components (Figure 5); thus, two relevant subcategories of social behaviors, one of them related to actual social investigation, which was then named social investigatory behaviors (which included ANO, HEA, BOD and FOL), and the other related to interactions that lead to the establishment of hierarchical relationships, which was then named social agonistic behaviors (which included DOM and AGR scores) were defined. Thus, in addition to the traditional analysis including social behaviors, social investigatory and social agonistic behaviors were also analysed, with relevant results.

The experimental design employed in the present study allowed to reveal both (1) a substantial decrease in the time spent by the resident rats performing the subcategory of social investigatory behaviors towards the familiar intruder as the first encounter duration increased (Figure 1B, white bars) and (2) an increase of social investigatory behaviors towards a different intruder when the first encounter duration lasted 2, 24, and, to a smaller extent, 168 hours (Figure 1B, black bars). Together, these effects lead to significant differences in the social investigatory behaviors towards the different intruder as compared to that seen towards the familiar intruder, when the first encounter durations were 2, 24 and 168 hours, demonstrating that rats do exhibit a 24-hour long social recognition memory. Even though similar differences were observed for the category of social behaviors (Figure 1A), no substantial decrease in the time spent by the resident rats performing social behaviors 
associated with the increase in the first encounter duration was seen when the residents were exposed for 168 hours during the first encounter (Figure 1A, the last white bar); as mentioned before, this lack of decrease in social behaviors towards the familiar intruder occurred because the time spend by the resident rats exhibiting social agonistic behaviors significantly increased as the first encounter duration increased (Figure 3), compensating that decrease seen in the time spent exhibiting social investigatory behaviors.

The importance of this effect should not be underestimated; the use of either the category of social behaviors or the subcategory of social investigatory behavior could lead to different conclusions. For instance, while resident rats with first encounters lasting 168 hours did exhibit significant differences in the time spent exhibiting the subcategory of social investigatory behaviors towards the familiar or different intruders, and thus would be considered to exhibit a 24-hour-duration social recognition memory, this effect did not reach statistical significance for the category of social behaviors, which would then lead to the conclusion that rats do not exhibit such a social recognition memory. Since most studies using the intruder-resident paradigm adopt a general "social behaviors" category (Thor and Holloway, 1982; Dantzer et al., 1987; Popik et al., 1991b; Popik et al., 1991a; Sekiguchi et al., 1991a; Gheusi et al., 1994a; Engelmann et al., 1995; Burman and Mendl, 1999, 2000; Squires et al., 2006), which includes a diversity of behaviors which may be characterized as social, but not necessarily related with social investigation (e.g., mild aggression consisting of rolling/standing over the juvenile and/or pushing it away, following or chasing the conspecific, dominance, social grooming and sniffing different parts of the intruder's body), their potential to detect social recognition memory may have been limited, as exemplified by those different statistical results when comparing social behaviors and social investigatory behaviors. 
Thus, it seems preferable to use of social investigatory behaviors instead of a general category of social behaviors that also include non-investigatory social behaviors, to study memory using the intruder-resident paradigm.

\section{Operational Definition of Social Recognition Memory}

Another important issue about relative to the use of the intruder-resident paradigm relates to the definition of social recognition memory. For instance, when discussing their results, Sekiguchi et al. (1991b) stated that social recognition of adults may be "defined as a decrease of social investigation during a second encounter session with the same juvenile" (p. 1255). Despite the fact that these authors included the presentation of a different intruder in their experimental design for comparing their social investigation with that seen towards the familiar intruder, the significant increase in social investigation towards the different intruder, even though detected and reported, did not receive any attention. That is, the Sekiguchi et al.'s Experiment 1 included groups of resident rats which first encounter lasted 30 minutes and that were subjected to the second encounter with either the familiar or a different intruder 60 minutes later. The authors reported no decrease of social investigation towards the familiar juvenile; however, "a small but significant increase of social investigation behavior was found when a different juvenile was exposed to the adults during the second encounter session" (p. 1254). This result could be suggesting that their resident rats did identified the intruders in this experimental condition, increasing their social investigation towards the identified novel intruder; however, because the resident rats exposed to the familiar intruder did not show a significant decrease of social investigation, this effect was not discussed in their article. 
As exemplified by data of the present study involving both social behaviors and social investigatory behaviors (see above), one can not rely exclusively in the decrease of social investigation towards the familiar intruder to make conclusions about social recognition memory.

Thor and Holloway (1982) properly addressed this issue in the introduction to their Experiment 2: "if the decrease in social investigation that occurs on repeated presentations of the same social stimulus can be attributed to habituation or fatigue,... then the decrease may be demonstrated as generalizing to other social stimuli of the same class" (p. 1002). This rationale emphasized the importance of including different intruders in the experimental design in order to reach conclusions about the social recognition memory. After such testing in their Experiment 2, Thor and Holloway (1982) did conclude that "the more satisfactory interpretation is that the data describe a gain in familiarity of recognition memory for the individual conspecific" (p. 1002). This conclusion, however, does not imply that one can completely exclude the participation of habituation processes in the behavioral outcomes (see below); in fact, it emphasizes the importance of the increased social investigation towards the different intruder, and particularly the existence of a significant difference between social investigation towards the familiar intruder as compared to that seen towards a different intruder, in order to conclude about the occurrence of social recognition memory.

The second encounter in the present study lasted 10 minutes; the behavioral scores in this session were recorded along four time bins of $150 \mathrm{~s}$ each. Therefore, it was possible to show that most of the social investigation by the resident rats towards the intruders occurred in the first time bin, and then decreased along time bins (Figure 2). In general, longer first encounter durations produced smaller social investigation towards the familiar intruder rat in the first time bin, associated with faster decrease in the time spent exhibiting social investigatory behaviors along time bins (Figure 2, left panels). In addition, the time spent by 
the resident rats exhibiting social investigatory behaviors towards the familiar and the different intruders were similar along all time bins when their first encounters lasted 0.083 (Figure 2A) and 0.5 hour (Figure 2C), indicating that they did not recognize the previously met intruder; even though, when the first encounter lasted 0.5 hour the rate of decrease in social investigatory behaviors was faster as compared to that seen when the first encounter lasted 0.083 hour (Figures $1 \mathrm{C}$ and 1A, respectively). This indicates that longer first encounters accelerates the rate of reduction of social investigation along time bins towards both the familiar and the different intruders, in spite of the lack social recognition, as if there was a transfer of habituation of the social investigatory activity from the first to the second encounters and this habituation was sensitive to the first encounter duration.

It is likely that this effect also occurred for the resident rats which first encounters lasted 2 (Figure 2E), 24 (Figure 2G) and 168 hours (Figure 2I); in fact, the stronger reduction of social investigatory behaviors towards the familiar intruders associated with longer first encounters give support to this interpretation. However, since first encounters lasting 2 hours or longer allow gathering enough information for social recognition memory, the resulting increased of social investigation towards a different intruder would have overcome that habituation effect, masking it.

This interpretation also allows to explain why the resident rats which first encounters lasted 168 hours (Figure 2I) exhibited both smaller times exhibiting social investigatory behaviors and faster reduction of social investigation towards the different intruders when compared to the groups which first encounters lasted 2 and 24 hours; that is, resident rats which first encounter lasted 168 hours would exhibit a greater transfer of habituation to the second encounter, which contributes to the reduction of the time spent exhibiting social investigatory behaviors. 


\section{Intruder Rats Exhibit Social Recognition Memory?}

The adult intruder rats involved in the present study did not show any significant differences in the amount of social investigatory behaviors towards a familiar as compared to a different intruder (Figure 1E); these data could be interpreted as reflecting a lack of social recognition memory by the intruder rats. Thor and Holloway (1982) described that intruder juveniles exhibit a reduction of social investigation towards the familiar resident as compared to that seen towards a different resident, indicating that the intruder juveniles also exhibited social recognition memory; this social recognition by the juveniles was evident only when the time interval between the first and the second encounters was smaller than 4 min. It would be tempting to ascribe that apparent lack of social recognition memory by our intruder rats to the 24-hour time interval between the first and the second encounters. However, this would be odd since the intruder rats involved in the present experiment were as old as the resident rats which, as shown above, unequivocally exhibited social recognition memory that lasted at least 24 hours (see below).

The major differences between the resident and the intruder rats of the present study refer to the fact that the resident rats (1) were introduced in the testing chamber 20 min before the intruders, (2) were maintained in the testing chamber during the 24-hour interval between the first and the second encounters, while the intruder rats were transferred to a novel cage, and (3) were maintained in the same testing chamber for the second encounter while the intruder rats were transferred to this chamber which could be either the familiar as the previous one when they were exposed to the familiar resident, or different from the previous one when they were exposed to a different resident. It is possible that these differences rendered a more disturbing experimental condition for the intruder rats as compared to the 
resident rats, thus interfering with their social recognition memory (Burman and Mendl, 2000).

As a matter of fact, Moura et al. C (in preparation) showed that the transportation of resident rats from the experimental room to the animal facilities 0.5 , but not 6 hours, after the first encounter strongly interfered with social recognition memory tested in a second encounter occurring 24 hours later.

However, it was noticeable that exposure to the testing chamber twenty minutes before the beginning of the first encounter was enough to determine that those rats would assume a behavioral pattern that characterizes them as "residents". It is possible that this 20minutes opportunity to explore the novel environment prior to the first encounter with an intruder conferred advantages to the so called "resident rats". First, they had the opportunity to urinate in the clean testing chamber and in the novel bedding, thus giving to this environment its individual signature scent (Sawyer et al., 1984); since these animals are territorial, it is not unlikely that this occurred and thus modulated both the resident rat's reaction towards the intruder, and the intruder rat's reaction towards the resident. Second, because they had the opportunity to explore the chamber previously to the introduction of the conspecific, the only novelty they had to deal with during the first encounter was the intruder conspecific, in which they concentrated their investigation thus gathering relatively more social information; note that this was not possible for the intruder rats that had to deal with the novel environment and the novel conspecific concurrently; this could have led to a less extensive gathering of social information. The relative contribution of each of these factors to the amount of social and non-social investigation in the second encounter is not clear. It is possible that because of the second possibility discussed above the amount of social information gathered by the resident rat in the first encounter was greater rendering a better social recognition memory as compared to that of the intruder rats. This could help to 
understand why the resident rats exhibited relatively more social behaviors (compare Figures 1A and 1D, and Figures 1B and 1E; Figure 5), and why the intruder exhibited relatively more non-social behaviors (compare Figures 1F and 1C; Figure 5). However, while this explanation seems plausible for subjects having relatively short first encounters, it does not seem sustainable for subjects which first encounters were longer. More studies would be required to evaluate these possibilities (see below).

In this context, it is interesting to emphasize that the intruder rats of the present study exhibited significantly longer times exhibiting non-social behavioral as compared to the resident rats (Figures $1 \mathrm{~F}$ and $1 \mathrm{C}$, respectively, and Figures 4 and 5) and that $76.8 \%$ of the non-social behaviors correspond to sniffing the environment (Table 2). To a certain extent, this is not surprising since the amount of prior exposure of the intruder rats with the testing environment was smaller when compared to that of the resident rats; thus, it seems plausible that they exhibit more non-social behaviors (that include investigation of the environment). However, contrary to this interpretation, this effect was stronger when the intruder rats were exposed to a different resident rat as compared to exposure to the familiar resident rat (Figures $1 \mathrm{~F}$ and 4 ). Thus, these results seem to suggest that the intruder rats were also capable of identifying the resident conspecific they had been exposed to; however, differently from the resident rats because of territoriality reasons, they would express this recognition memory by way of a smaller investigation (including mostly sniffing) of the cage walls and bedding where the familiar resident rat was maintained as compared to the corresponding behaviors directed to where the different resident was. Contrary to this interpretation, however, there was no significant influence of the first encounter duration on this difference. Interestingly, resident rats exhibited a gradual increase of the time spent exhibiting non-social behaviors along time bins (Figure 4); this result may reflect the investigative priorities of the resident rat when exposed to an intruder rat; that is, after investigating the intruder at the beginning of the 
encounter, the resident rat investigates the environment in order to evaluate to which extent the intruder introduced any changes in "his territory". Similar effects were not seen in the intruder rats; they spent longer times exhibiting non-social behaviors along the complete second encounter (Figure 4, right panels). The present data do not allow further evaluation of these hypotheses.

\section{The Intruder-Resident Paradigm Critical Scores}

The PCA included in the present study revealed two relevant and independent subcategories of social behaviors, one of them named "social investigatory behaviors", related to social information gathering, and another named "social agonistic behaviors", related to the establishment of social hierarchies. The most critical social investigatory behaviors scored in this study were anogenital and body sniffing, which corresponded to about $50 \%$ and $18 \%$ of the total social behaviors, respectively (Table 2). On the other hand, the most critical social agonistic behavior scored refers to dominance display that corresponded to about $24 \%$ of the total social behaviors. Note that this latter behavior, while relevant for the organization of the social group, does not seem relevant for social identification of the conspecific.

As a matter of fact, previous studies emphasized the critical importance of anogenital investigation for social recognition memory. For instance, (Ferguson et al., 2002) reported that male rodents not only closely sniff the anogenital region but also lick it. These authors called attention to the fact that male rodents usually do not sniff conspecifics at a distance, which would imply that the male is utilizing pheromonal, nonvolatile odorants for recognizing the conspecific (Wysocki et al., 1980; Halpern, 1987). Apparently, the rat's urine exhibits chemical compounds important for social recognition; supposedly, when the rat performs self-grooming it spreads olfactory cues along the body and head (Popik and van 
Ree, 1998), rendering itself identifiable to its conspecifics. This would explain why sniffing the anogenital region and the body strongly contributed for social investigatory behaviors in the present study.

While sniffing the environment (ENV) was responsible for about $77 \%$ of the nonsocial behaviors, rearing (REA) was responsible for about 14\%. Most of the environmental sniffing was directed towards the cage walls and bedding. It is not completely clear to which extent sniffing the bedding could also bring social information about conspecifics. It is known that dirt bedding has volatile putative odorants and nonvolatile compounds, mostly urinary proteins, that have been suggested to be involved in intra-specific communication (Jemiolo et al., 1985; Hurst et al., 2001). The fact revealed by the PCA, that ENV was positively correlated with REA, and negatively correlated with ANO, BOD and FOL, may suggest that the subjects exhibiting ENV were only gathering environmental information and not social information. This would help to explain why intruders did not exhibit different amounts of non-social behaviors when exposed to familiar or different residents. However, the present data do not allow to formulate a clear picture about this; more studies would be required to evaluate these hypotheses.

\section{Conclusions}

The major conclusions the present data allow include (1) that rats do exhibit long-term social recognition memory that lasts at least 24 hours, (2) that this long-term social recognition memory was consistently revealed by increasing the duration of the first

encounter of the resident rat with the intruder for 2 hours or longer, (3) that the subcategory of social investigatory behaviors correspond to a more appropriate index for studies on social recognition memory as compared to the usually adopted that correspond to a general category 
of social behaviors that also include social agonistic behaviors, (4) that social recognition memory can be indentifyed by the increase of the amount of social investigatory behaviors when met an different intruder in a second meeting, and also the difference between the amount of social investigatory behaviors toward the same and the different intruder in the second encounter, (5) that the PCA represents an helpful statistical tool for analyzing data generated by the intruder-resident paradigm, that usually includes a diversity of both social and non-social behavioral scores.

The present demonstration, for the first time to our knowledge, that the social recognition memory may be increased to at least 24 hours, opens several possibilities of studies involving the identification of the mechanisms involved in this type of memory store.

These results shade lights to the fact that increasing the time length of the first encounter leaded to long-term social memory in rats and that the precise analyses of each social and non-social behaviors may contribute to the better understanding of the complex social relationship in rodents as well as allow a carefully analyses about the consequences of manipulation of genes, neurotransmissors and brain regions on social memory.

\section{References}

Bluthe RM, Dantzer R (1992) Chronic intracerebral infusions of vasopressin and vasopressin antagonist modulate social recognition in rat. Brain Res 572:261-264.

Bluthe RM, Dantzer R (1993) Role of the vomeronasal system in vasopressinergic modulation of social recognition in rats. Brain Res 604:205-210.

Bluthe RM, Schoenen J, Dantzer R (1990) Androgen-dependent vasopressinergic neurons are involved in social recognition in rats. Brain Res 519:150-157.

Bluthe RM, Koob GF, Dantzer R (1991) Hypertonic saline mimics the effects of vasopressin and social recognition in rats. Behav Pharmacol 2:513-516. 
Burman OH, Mendl M (1999) The effects of environmental context on laboratory rat social recognition. Anim Behav 58:629-634.

Burman OH, Mendl M (2000) Short-term social memory in the laboratory rat: its susceptibility to disturbance. Appl Anim Behav Sci 67:241-254.

Carr EJ, Yee L, Gable D, Marasco E (1976) Olfactory recognition of conspecifics by domestic Norway rats. J Comp Physiol Psychol 90:821-828.

Castner SA, Goldman-Rakic PS, Williams GV (2004) Animal models of working memory: insights for targeting cognitive dysfunction in schizophrenia. Psychopharmacology (Berl) 174:111-125.

Cohen J (1988) Statistical power analysis for the behavioral sciences Hillsdale, NJ: Lawrence Erlbaum Associates.

Dantzer R, Bluthe RM, Koob GF, Le Moal M (1987) Modulation of social memory in male rats by neurohypophyseal peptides. Psychopharmacology (Berl) 91:363-368.

Dantzer R, Koob GF, Bluthe RM, Le Moal M (1988) Septal vasopressin modulates social memory in male rats. Brain Res 457:143-147.

Engelmann M, Landgraf R (1994) Microdialysis administration of vasopressin into the septum improves social recognition in Brattleboro rats. Physiol Behav 55:145-149.

Engelmann M, Wotjak CT, Landgraf R (1995) Social discrimination procedure: an alternative method to investigate juvenile recognition abilities in rats. Physiol Behav 58:315-321.

Engelmann M, Ebner K, Wotjak CT, Landgraf R (1998) Endogenous oxytocin is involved in short-term olfactory memory in female rats. Behav Brain Res 90:89-94.

Erickson CA, Barnes CA (2003) The neurobiology of memory changes in normal aging. Exp Gerontol 38:61-69.

Ferguson JN, Young LJ, Insel TR (2002) The neuroendocrine basis of social recognition. Front Neuroendocrinol 23:200-224.

Ferguson JN, Aldag JM, Insel TR, Young LJ (2001) Oxytocin in the medial amygdala is essential for social recognition in the mouse. J Neurosci 21:8278-8285.

Ferguson JN, Young LJ, Hearn EF, Matzuk MM, Insel TR, Winslow JT (2000) Social amnesia in mice lacking the oxytocin gene. Nat Genet 25:284-288.

Garau A, Marti MA, Sala J, Balada F (2000) Age effects on the social interaction test in early adulthood male rats. Depress Anxiety 12:226-231.

Gheusi G, Bluthe RM, Goodall G, Dantzer R (1994a) Social and individual recognition in rodents: methodological aspects and neurobiological bases. Behavioural Process $33: 59-88$. 
Gheusi G, Bluthe RM, Goodall G, Dantzer R (1994b) Ethological study of the effects of tetrahydroaminoacridine (THA) on social recognition in rats. Psychopharmacology (Berl) 114:644-650.

Halpern M (1987) The organization and function of the vomeronasal system. Annu Rev Neurosci 10:325-362.

Hurst JL, Payne CE, Nevison CM, Marie AD, Humphries RE, Robertson DH, Cavaggioni A, Beynon RJ (2001) Individual recognition in mice mediated by major urinary proteins. Nature 414:631-634.

Jemiolo B, Alberts J, Sochinski-Wiggins S, Harvey S, Novotny M (1985) Behavioral and endocrine responses of female mice to synthetic analogues of volatile compounds in male urine. Animal Behavior 33:1114-1118.

Le Moal M, Dantzer R, Michaud B, Koob GF (1987) Centrally injected arginine vasopressin (AVP) facilitates social memory in rats. Neurosci Lett 77:353-359.

Marin JC, Moura PJ, Cysneiros RM, Colugnati DB, Cavalheiro EA, Scorza FA, Xavier GF, Zilbovicius M, Mercadante MT (2008) Temporal lobe epilepsy and social behavior: An animal model for autism? Epilepsy Behav.

Popik P, Van Ree JM (1992) Long-term facilitation of social recognition in rats by vasopressin related peptides: a structure-activity study. Life Sci 50:567-572.

Popik P, van Ree JM (1998) Neurohypophyseal peptides and social recognition in rats. Prog Brain Res 119:415-436.

Popik P, Vetulani J, van Ree JM (1992) Low doses of oxytocin facilitate social recognition in rats. Psychopharmacology (Berl) 106:71-74.

Popik P, Wolterink G, De Brabander H, van Ree JM (1991a) Neuropeptides related to [Arg8] vasopressin facilitates social recognition in rats. Physiol Behav 49:1031-1035.

Popik P, Vetulani J, Bisaga A, van Ree JM (1991b) Recognition cue in the rat's social memory paradigm. J Basic Clin Physiol Pharmacol 2:315-327.

Prediger RD, Takahashi RN (2003) Ethanol improves short-term social memory in rats. Involvement of opioid and muscarinic receptors. Eur J Pharmacol 462:115-123.

Prediger RD, Takahashi RN (2005) Modulation of short-term social memory in rats by adenosine A1 and A(2A) receptors. Neurosci Lett 376:160-165.

Prediger RD, Batista LC, Miyoshi E, Takahashi RN (2004) Facilitation of short-term social memory by ethanol in rats is mediated by dopaminergic receptors. Behav Brain Res 153:149-157.

Roman FS, Alescio-Lautier B, Soumireu-Mourat B (1996) Age-related learning and memory deficits in odor-reward association in rats. Neurobiol Aging 17:31-40. 
Sawyer TF, Hengehold AK, Perez A (1984) Chemosensory and hormonal mediation of social memory in male rats. Behavioral Neuroscience 98:908-913.

Sekiguchi R, Wolterink G, van Ree JM (1991a) Analysis of the influence of vasopressin neuropeptides on social recognition of rats. Eur Neuropsychopharmacol 1:123-126.

Sekiguchi R, Wolterink G, van Ree JM (1991b) Short duration of retroactive facilitation of social recognition in rats. Physiol Behav 50:1253-1256.

Squires AS, Peddle R, Milway SJ, Harley CW (2006) Cytotoxic lesions of the hippocampus do not impair social recognition memory in socially housed rats. Neurobiol Learn Mem 85:95-101.

Thor DH, Holloway WR (1982) Social memory of the male laboratory rat. Journal of Comparative and Physiological Psychology 96:1000-1006.

Wysocki CJ, Wellington JL, Beauchamp GK (1980) Access of urinary nonvolatiles to the mammalian vomeronasal organ. Science 207:781-783.

Young LJ (2002) The neurobiology of social recognition, approach, and avoidance. Biol Psychiatry 51:18-26. 
CAPÍTULO 4 


\section{O PARADIGMA INTRUSO-RESIDENTE: ROTINAS LABORATORIAIS IGNORADAS QUE PODEM INTERFERIR NA MEMÓRIA DE RECONHECIMENTO SOCIAL}

Observação: Uma descrição detalhada do presente experimento é apresentada no anexo III (página 142).

Moura et al. (B, em preparação) mostraram que a memória de reconhecimento social de longa duração de ratos residentes pode durar pelo menos 24 horas quando seu primeiro encontro com um intruso adulto tem duração de 2 horas ou mais. Esse resultado conflita com observações prévias descritas na literatura da área. Hipotetizou-se que uma das possíveis razões para essa discrepância esteja relacionada com processos de interferência retroativa promovidos pelo transporte dos ratos residentes da sala de experimentação para o biotério, depois da experiência com o intruso. $\mathrm{O}$ presente trabalho foi desenhado para avaliar essa hipótese.

Ratos adultos machos foram transportados do biotério para a sala de experimentação 1h30min antes do início dos testes, realizados durante a fase inativa dos animais (Moura et al. (A), submetido). O residente foi introduzido na câmara de testes 20 minutos antes do intruso também adulto, para um encontro que teve duração de 2 horas. Metade dos residentes foi transportada para o biotério 0,5 horas depois do término desse encontro. A outra metade foi transportada para o biotério 6 horas depois do término do encontro. Vinte e quarto horas depois, os residentes foram expostos a um segundo encontro com intrusos familiares ou diferentes, ao longo de 10 minutos. Ambos os encontros sociais foram filmados; posteriormente, o comportamento dos residentes e dos intrusos foi analisado por um pesquisador treinado. O tempo investido por cada animal exibindo comportamentos sociais e não-sociais foi individualmente mensurado. Os resultados foram analisados com o auxílio da PCA complementada por uma ANOVA envolvendo os escores da PCA, e também pela ANOVA tradicional. 
A PCA revelou que mais de $50 \%$ da variância dos resultados pode ser explicada pelos dois primeiros componentes principais. No primeiro encontro, o primeiro componente foi caracterizado por comportamentos de coleta de informações que englobam os comportamentos sociais investigativos no pólo positivo (ANO1, BOD1, HEA1 e FOL1), que parcialmente se opõem à comportamentos de busca de informações ambientais (REA1 e ENV1). Já o segundo componente foi determinado por AGR1 e DOM1, i. e., comportamentos agonísticos, possivelmente vinculados ao estabelecimento de hierarquias sociais. No segundo encontro, o primeiro componente foi novamente determinado pelos comportamentos sociais investigativos no lado positivo (ANO2, BOD2, HEA2, FOL2), com uma pequena contribuição de AGR2, opondo-se aos comportamentos ENV2 and REA2, que também contribuem para a determinação do segundo componente. Desta forma, o segundo componente foi determinado por ENV2 e REA2 parcialmente oposto por AGR2, e também GRO2 oposto por DOM2. Assim, o segundo componente foi determinado pela associação da busca por pistas ambientais e comportamentos relacionados a conflito provavelmente associados ao estabelecimento de hierarquias. Confirmando as observações de Moura et al. (B) (in preparation), os comportamentos sociais investigativos parecem refletir mais claramente os efeitos vinculados à familiaridade em relação a um intruso previamente encontrado e também em relação a um intruso diferente. A ANOVA tradicional confirmou essas observações.

Os resultados confirmaram as observações de Moura et al. (B, em preparação) no sentido de que ratos exibem memória de reconhecimento social que se mantém por pelo menos 24 horas; porém, isso ocorreu apenas quando o intervalo de tempo entre o término do primeiro encontro e o transporte dos animais para o biotério foi 6 horas, mas não 0,5 horas. Assim, o transporte dos animais da sala de experimentos para o biotério, se realizada 0,5 
horas após o primeiro encontro, prejudica a memória de reconhecimento social dos animais, o que não ocorre quando o transporte é realizado 6 horas depois.

Assim, esses resultados indicam que deve haver cautela no planejamento de experimentos envolvendo a memória de reconhecimento social que requerem o transporte dos animais; como esse tipo de procedimento faz parte da rotina da maioria dos laboratórios que realizam estudos comportamentais, deve-se ter em mente que esse transporte pode influenciar o desempenho dos animais. 
ANEXO III

ב. ANEXO III




\title{
On the intruder-resident paradigm: unattended laboratory routines that may interfere with social recognition memory
}

\author{
Paula J. Moura ${ }^{1,2}$, Deepa V. Venkitaramani ${ }^{1}$, Roman Tashev ${ }^{1}$, Paul Lombroso ${ }^{1}$, Gilberto F. \\ Xavier $^{2}$ \\ ${ }^{1}$ Child Study Center, Yale University, New Haven, CT, USA \\ ${ }^{2}$ Department of Physiology, Biosciences Institute, University of São Paulo, SP, Brazil.
}

Running title: Interference on Social Recognition Memory

Corresponding author: Gilberto F. Xavier, Ph D, Department of Physiology, Biosciences Institute, University of São Paulo, Rua do Matão, Travessa 14, 101, São Paulo, SP, Brazil, 05508-900.

E-mail: gfxavier@usp.br / pjmoura@usp.br

Phone: (55) 113091 7504, Fax: (55) 1130917568.

Pages: 24

Figures: 3

Table: 1

Grant sponsor: Coordenação de Aperfeiçoamento de Pessoal de Nível Superior (CAPES), National Institute of Health (NIH), Conselho Nacional de Desenvolvimento Científico e Tecnológico (CNPQ), Brazil, and Fundação de Amparo à Pesquisa do Estado de São Paulo (FAPESP), Brazil.

Key-words: social memory, animal transportation, social recognition, stress, long-term social memory, rat, social behavior, mammal, rat, rodent, handling, memory disruption, memory disturbance 


\begin{abstract}
In this study was investigated the occurrence of possible interference effects of the animals' transportation between the experimental room and the animal facilities, a procedure commonly employed in several laboratories as part of their experimental protocols, either 0.5 or 6 hours after a first 2-hour-duration encounter, on performance in the intruder-resident paradigm; after being transported to the animal facilities, the rats stayed there until the following day, when they were again transported to the experimental room for the second encounter (thus, the intertrial interval was 24 hours). While half of the resident rats of each group was exposed, in the second encounter, to the same conspecific, the other half was exposed to a novel conspecific. Social investigatory, agonistic and non-social behaviors of both the resident and intruder rats were individually scored. The results showed that residents transported 0.5 hours after the 2-hour first encounter fail during the social recognition memory task after 24-hours; however, resident rats maintained undisturbed for 6 hours after the first encounter exhibited, in the second encounter, both a significant decrease of social investigation towards a familiar intruder and a significant increase of social investigation towards the different intruder. Together, these results suggest that unusually unattended laboratory routines may interfere with social recognition memory.
\end{abstract}




\section{Introduction}

Social behaviors play a remarkable role for group formation in mammals. Several approaches have been used to investigate how social information is processed; studies involving rodents have attempted to identify brain regions, neuropeptides and genes involved in this processing (Kogan et al., 2000; Ferguson et al., 2001; Young, 2002).

A substantial amount of studies on sociability use behavioral tasks such as the intruder-resident paradigm (Dantzer et al., 1987; Sekiguchi et al., 1991; Popik and van Ree, 1998; Burman and Mendl, 2000; Ferguson et al., 2000; Bannerman et al., 2001; Ferguson et al., 2001). In a typical procedure of this behavioral task an intruder conspecific is introduced within a resident animal's homecage for a 5-min trial; this latter animal exhibits intense social investigation activity towards the intruder conspecific. In a second 5-min trial, the introduction of the same intruder within the resident's home cage elicits far less investigation as compared to that seen both (1) when a novel intruder is presented and (2) during the first encounter; however, this effect is only seen when the intertrial interval is about 30-60 min, but not when it is about $2 \mathrm{~h}$ (Dantzer et al., 1987; Dantzer et al., 1988; Burman and Mendl, 2000; Garau et al., 2000; Ferguson et al., 2001; Young, 2002; Prediger and Takahashi, 2003; Castner et al., 2004; Prediger et al., 2004; Prediger and Takahashi, 2005). Because of these temporal effects, social recognition memory in rats has been considered a kind of short-term memory (Dantzer et al., 1987; Kogan et al., 2000; Richter et al., 2005).

For more than 20 years the intruder-resident paradigm has been extensively used to investigate social memory. This popularity seems to be related to (1) the consistency and reproducibility of the results, (2) the fact that it is based on the natural social exploratory behavior of rodents towards novel conspecifics, (3) the fact that acquisition of the critical information occurs after a single and relatively short trial, (4) how easy it is to test animals in 
this behavioral paradigm, and (5) the low costs to perform this type of experiments, among other reasons. Despite of this wide use, there is quite few information on both the social recognition memory of the intruder animals and on manipulations that may interfere with performance of the resident animals (Burman and Mendl, 2000, 2002, 2003).

\section{Manipulations that may interfere with performance}

Memory studies involving one-trial learning in inhibitory avoidance tasks have shown that essential biochemical changes on the brain takes place on the first 6 hours after the training phase suggesting and that the use of protein inhibitors disturb performance of the task when the testing session is run 24 hours after the initial acquisition (see (Izquierdo et al., 2006). These results are taken as evidence that the information is susceptive to disturbance during these phase and that interferences on these processes can impair long-term memory consolidation.

Social recognition memory in rodents is considered a kind of one-trial acquisition short-term memory There have been demonstrations that social recognition memory in mice may be disrupted by manipulations related to the housing conditions; for instance, while group-maintained mice are capable of retaining social recognition memory for at least seven days after an initial encounter with a conspecific, isolate-maintained mice do not retain social recognition memory for so long (Kogan et al., 2000; Richter et al., 2005). After a 2-min first meeting, grouped mice are able to retain information about an conspecific up to 7 days while single-housed mice retain the same information only for $30 \mathrm{~min}$ but not for even 1 day (Kogan et al., 2000).This suggests that interference may also occur for this kind of long-term social recognition memory, even though the mechanisms involved remain to be clarified. 
Similarly, there have been reports that social recognition memory in rats may be changed by husbandry, housing conditions and manipulations performed between encounters (Dantzer et al., 1987; Burman and Mendl, 1999, 2000, 2002, 2003). For instance, Dantzer et al. (1987) showed that resident rats receiving an additional exposure to the same intruder conspecific, after a first encounter, exhibit enhancement of the social recognition memory in a third session, run 2 hours after the second encounter; however, when the second encounter involves a different intruder, it impairs social recognition memory to the intruder 30-min later.

The resident rat's social recognition memory is also impaired when it is exposed to another cage, handled or exposed to a different intruder during the interval between encounter (Burman and Mendl, 2000).

It is tempting to interpret this interference effect on the rats' social recognition memory following the guidelines of studies involving interference in avoidance learning; another reason is related to the fact that both social recognition memory and inhibitory avoidance are acquired after a single trial. Note, however, that while inhibitory avoidance tasks are usually considered to involve long-term memory processes, social recognition memory in rats is usually considered to involve short-term, but not long-term, memory. In addition, it is widely known that short-term memory is more labile, being thus more susceptible to interference.

Moura et al. (B), (in preparation) recently showed that social recognition memory in rats endures at least 24 hours when the duration of the first encounter with the conspecific lasts 2 hours or longer.

The present study investigated the occurrence of possible interference effects of the animals' transportation between the experimental room and the animal facilities, a procedure commonly employed in several laboratories as part of their experimental protocols, either 0.5 or 6 hours after a first 2-hour-duration encounter, on performance in the intruder-resident 
paradigm; after being transported to the animal facilities, the rats stayed there until the following day, when they were again transported to the experimental room for the second encounter (thus, the intertrial interval was 24 hours). While half of the resident rats of each group was exposed, in the second encounter, to the same conspecific, the other half was exposed to a novel conspecific. Social and non-social behaviors of both the resident and intruder rats were individually scored.

The rationale for this experimental design was as it follows. If transportation in fact interferes with social recognition memory, it seems more likely to do it in relation to performance of rats transported to the animal facilities 0.5 hours, but not 6 hours, after the first (acquisition trial) encounter (see time course of avoidance learning studies, (see, (Izquierdo et al., 2006); therefore, while resident rats transported to the animal facilities 6 hours after the first encounter should exhibit a typical social recognition memory, expressed by a decreased social investigation towards the familiar intruder as compared to the social investigation towards the different intruder, resident rats transported 0.5 hours after the first encounter should not exhibit such a decrease in social investigation.

\section{Methods}

Animals. Fifty four naïve, male, Wistar rats (Rattus norvegicus), 3 months old, were purchased from Charles River Laboratories (Wilmington, MA) two weeks before the beginning of the experiments; they arrived at the laboratory in groups of 3-4 rats per cage and this group was maintained within the same home cage. Light was provided from 6:00-18:00h and temperature was set at $21 \pm 3^{\circ}$.C. Food and water were available ad libitum. Water was provided both via the animal facilities water system available at the back wall of the cage and via a water bottle; this guaranteed that all animals would have access to water even during the 
experimental procedures when they were transported to the experimental room. The animals were individually handled for 5 minutes per day along 2 days before the beginning of the experiments, in order to habituate to manipulation. Since rats usually exhibit greater social investigation of the intruder when tested during their inactive phase (Moura et al. (A), submitted), all experiments were run from 9:00 to 11:30h. A random schedule was used to ascribe animals to the (1) groups being transported from the experimental room to the animal facilities either 0.5 or $6 \mathrm{~h}$ after the first encounter, (2) groups exposed either to the familiar or to a novel intruder in the second encounter, and (3) function of either resident or intruder. Residents and intruders in these experiments were never originated from the same home cage. All procedures were conducted in accordance to the NIH Guide for the Care and Use of Experimental Animals and were approved by the Yale University Animal Care and Use Committee.

Test Chamber. The behavioral tests were run in a standard transparent polypropylene cage, placed in an open field chamber (Med Associates Inc.) in order to attenuate external cues that could distract the animals. Two cages were fit in an open field chamber in order to attenuate external cues that could distract the animals. On the chamber, one cage was placed in the floor while the other one was placed in a shelf in the way that there was no visual or physical contact between cages. The open field chamber was illuminated by fluorescent lamps (200300 lux at the polypropylene cage level); the chamber's doors were maintained closed during the experimental sessions providing a quiet environment for testing. A camera JVC (GZMG37) positioned on a tripod $40 \mathrm{~cm}$ besides the polypropylene testing cage allowed to tape record both the intruder and the resident social interaction in each encounter. 
Behavioral procedure. Social recognition memory testing was evaluated by using a modified version of the intruder-resident paradigm (Thor and Holloway, 1982), as adapted by Moura et al.(B), (in preparation). Briefly, rats were transported from the animal facilities to the experimental room ninety minutes before the beginning of the experiments, in order to get habituated to the environment.

As the animals were housed in the animal facilities located on the ground floor of the building, they were transported to the experimental room located on the third floor of the same building before the experimental sessions and returned back to the animal facilities after these sessions. The rats were transported within their own home cages, on a plastic car; 4 cages were transported per trip During the trips, the cages were covered with a white towel paper to reduce the impact of external cues on the animals. In a trip towards the experimental room, the car was conducted for about 30-m distance corridors, then 3 floors up using an elevator and for an additional 10-m distance corridor, until the experimental room. The trip back to the animal facilities followed the reverse pathway.

Animals ascribed to the "resident" groups were individually placed into the polypropylene cage located in the testing chamber, 20 min before the introduction of an adult intruder rat; since resident and intruder rats were adults with similar age, these social roles were defined by random, $i$. e., resident rats corresponded to those introduced within the testing chamber 20 min before. This first encounter lasted for 2 hours (see Moura et al. (B), in preparation). Then, the intruder rat was removed from the polypropylene cage and individually housed in another cage; differently, the resident rat was maintained within the same testing cage until the second encounter. While thirteen resident rats were transported back to the animal facilities 30 minutes after the end of the first encounter, fourteen resident rats were transported back to the animal facilities 6 hours after the end of the first encounter. 
During these time intervals, the animals remained undisturbed in the experimental room; thus, these time periods will be referred to as "time undisturbed".

The time interval between the first and the second encounters was $24 \mathrm{~h}$; thus, during the time period that both the resident and the intruder rats were not in the experimental room, they were maintained within their individual cages, located in opposite sides of the animal facilities.

Similar to the first encounter, ninety minutes before the second encounter the animals were transported from the animal facility to the experimental room. Then, while within their individual cages, the resident rats were placed in the open field for their second encounter with an intruder rat. Among the resident rats that had been transported to the animal facilities 30 minutes after the first encounter, six were exposed to the familiar intruder, $i$. e., the intruder that had been met during the first encounter; the remaining seven resident rats were exposed to a novel intruder rat. Among the resident rats that had been transported to the animal facilities' 6 hours after the first encounter, seven were exposed the familiar intruder rat and the remaining seven were exposed to novel intruder rats. The second encounter lasted 10 minutes. Our experimental design had planned the exclusion of rats that exhibited aggressive behavior such as biting; thus, an experimenter monitored all trials. However, there were no rats exclusion because such behaviors never occurred.

The initial 10 minutes of the first encounter and the complete second encounter were tape recorded such that it was possible to score the behaviors exhibited by both the resident and the intruder rats. The social behaviors scored included (1) sniffing anogenital area (ANO), (2) sniffing the head (HEA), (3) sniffing the body (BOD), (4) following the conspecific (FOL), (5) dominance behaviors (DOM) (corresponding to handling the conspecific which back is either on the floor or on the wall), and (6) aggression (AGR) (to beat using the legs); non-social behaviors included (7) sniffing the environment (ENV), (8) self-grooming (GRO) 
and (9) rearing (REA) (see Table 1 for details) (Dantzer et al., 1987; Gheusi et al., 1994;

Garau et al., 2000; Ferguson et al., 2001) A computer-assisted data acquisition system allowed an experimenter blind to the treatments to score the time spent by each rat performing the above mentioned behaviors.

Table 1. Description of the behaviors scored

\begin{tabular}{|c|c|c|}
\hline Social Behaviors & Code & Description \\
\hline $\begin{array}{l}\text { sniffing the anogenital } \\
\text { region }\end{array}$ & ANO & $\begin{array}{l}\text { Rat's nose is } 1 \mathrm{~cm} \text { or less from the anogenital area of the con-specific. The animal may } \\
\text { hold the con-specific during sniffing. }\end{array}$ \\
\hline sniffing the head & HEA & $\begin{array}{l}\text { Rat's nose is } 1 \mathrm{~cm} \text { or less from the head of the conspecific. The animal may hold the con- } \\
\text { specific during sniffing. }\end{array}$ \\
\hline sniffing the body & BOD & $\begin{array}{l}\text { Rat's nose is } 1 \mathrm{~cm} \text { or less from the body of the conspecific with exception of the anogenital } \\
\text { and the head areas. The animal may hold the con-specific during sniffing. }\end{array}$ \\
\hline following the conspecific & FOL & The animal walks behind the con-specific approaching it. \\
\hline dominance behavior & DOM & The animal holds the conspecific against the floor with its back or ventral part on the floor. \\
\hline aggression & AGR & The animal hits the con-specific with the posterior paws or exhibits an aggressive posture. \\
\hline Non-social Behaviors & Code & Description \\
\hline sniffing the environment & ENV & $\begin{array}{l}\text { The animal sniffs the cage walls standing either on two or four paws (touching the cage } \\
\text { walls with its anterior paws) or sniffs the bedding. }\end{array}$ \\
\hline self-grooming & GRO & $\begin{array}{l}\text { The animal performs movements including wiping, licking, and scratching the fur, towards } \\
\text { its own head and body. }\end{array}$ \\
\hline rearing & REA & $\begin{array}{l}\text { The animal stands in its posterior limbs without touch the cage and performs up and down } \\
\text { movement, usually sniffing. }\end{array}$ \\
\hline
\end{tabular}

\section{Data analysis}

An initial exploratory analysis of the data was performed by using a Principal Component Analysis (PCA) as described in Moura et al. (B), (in preparation). Briefly, the procedure was run after standardizing and applying a square root transformation to homogenize and reduce the dispersion of data in the original matrix. Individual PCAs were performed for data from the first and the second encounters. Each matrix contained 9 
observed variables (ANO, HEA, BOD, FOL, DOM, AGR, REA, GRO, ENV) and 54 units that represented each individual animal, including both resident and intruder rats. To distinguish the variables from the first and second encounters, they were added a number (either 1 or 2) after the variable code; thus, while ANO1, HEA1, BOD1, FOL1, DOM1, AGR1, REA1, GRO1 and ENV1 refer to the variables of the first encounter, ANO2, HEA2, BOD2, FOL2, DOM2, AGR2, REA2, GRO2 and ENV2 refer to the variables of the second encounter. The analysis was applied to the correlation matrix. No further rotation procedure was applied. The resulting loading vectors and individuals PCA scores were represented on a Euclidian biplot.

Two principal components (or axes) considered relevant were further analyzed using a ANOVA (General Linear Model - GLM) to test the hypotheses for segregation of the variables applied in each encounter; the first two principal component axes were further analysed because they allowed to explain more than $50 \%$ of the data variance. The analysis design included "familiarity" (familiar and different intruders"), "social role" (resident and intruder) and "time undisturbed" (0.5 and 6 hours) as the between, and each component axis as the within-subjects factors. Post hoc Tukey HSD tests were used when applicable. All statistical procedures were run using Statistical Package for the Social Sciences (SPSS) and $A$ MultiVariate Statistical Package (MVSP). As the PCA revealed that the major interesting results related to the behavior of the resident rats, only scores of these subjects were further analyzed.

Moura et al. (B), (in preparation), relying on a PCA analysis, suggested that there are advantages in subdividing social behaviors in two subcategories, including the total time each rat spent performing (1) social investigatory behaviors, which corresponded to the sum of times spent performing ANO, HEA, BOD and FOL, and (2) social agonistic behaviors, which 
corresponded to the sum of times spent performing DOM and AGR, because these behavioral subcategories express different aspects of the social interaction.

In addition, the sum of (total) social and non-social behaviors, and of the amount of social investigatory and social agonistic behaviors were subjected to a repeated measures analysis of variance (ANOVA) having (1) "familiarity" and (2) "time undisturbed" as the between-, and (3) "encounter" (first and second) as the within-subjects factors; one independent analysis was run for each variable. The Post hoc Tukey's Test was used to identify specific differences; the $p$-values were smaller (less) than 0.05 were considered significant.

\section{Results}

Figure 1 shows the total time spent by the resident rats performing social (Figure 1A), non-social (Figure 1B), social investigatory (Figure 1C) and social agonistic (Figure 1D) behaviors in the first and second encounters as a function of the time undisturbed and of the presentation of either the same or a novel conspecific (note that since the critical treatments were actually implemented after the first encounter, the data relative to the first encounter refer to a retrospective analysis of the groups later exposed to the familiar and novel intruders, and to different times undisturbed; this retrospective analysis was included to show that the groups did not differ among each other before the treatments). 

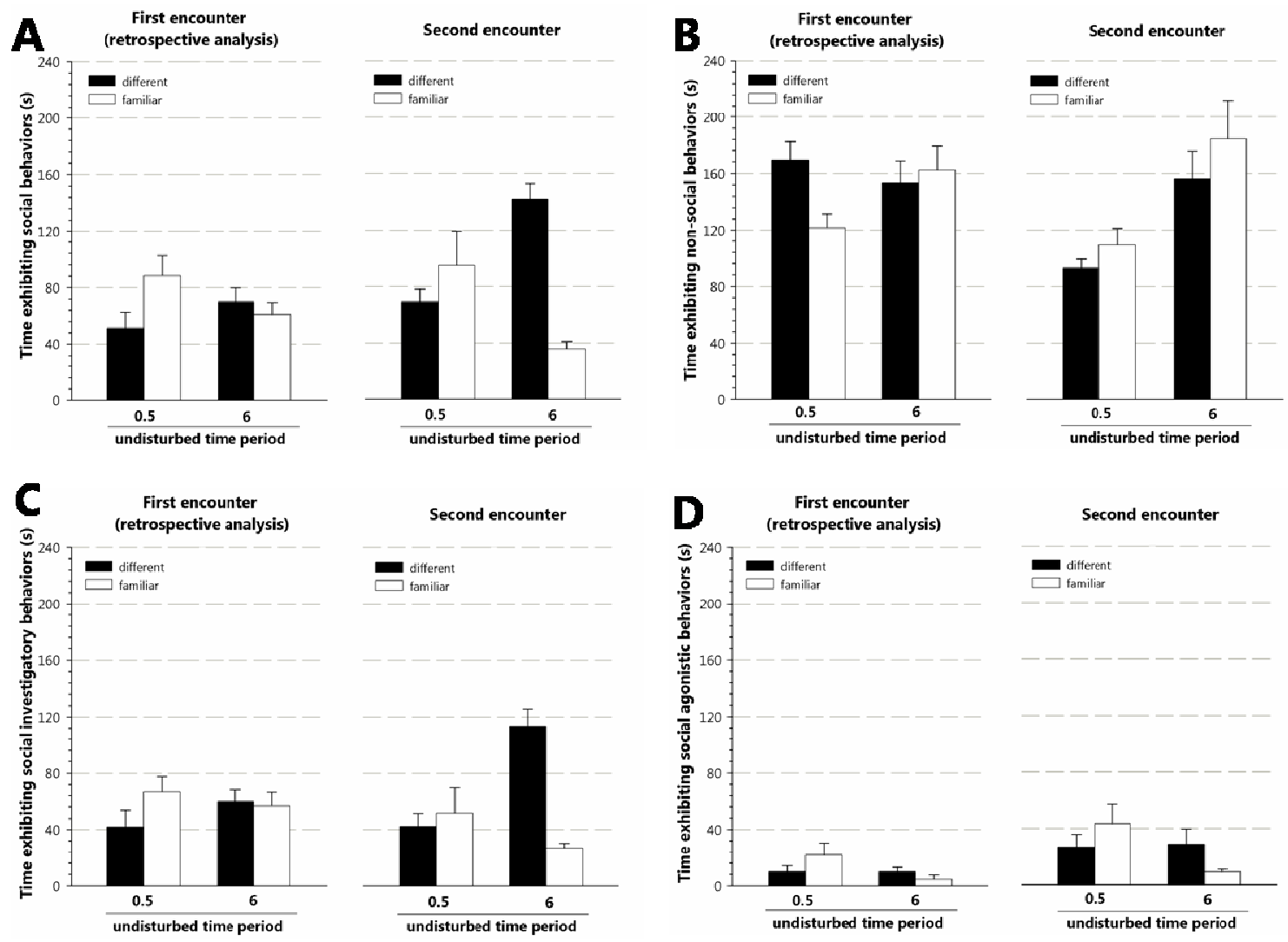

Figure 1. Time spent by residents transported 0.5 or 6 hours after the first encounter. Both social encounters are represented on the figure. Note that on the first encounter the residents were not under influence of the undisturbed time period representing (see explanation on the text). (A) Time exhibiting (total) social behaviors. There were no differences during the first encounter. On the second encounter residents that were transported after 0.5 hours showed similar levels of social behaviors toward the familiar (white bar) or an different (black bar). However, residents that were transported after 6 hours showed high levels of social investigation toward the different intruder, and low levels toward the familiar suggesting long-term social recognition memory. (B) Time exhibiting non-social behaviors. Similar amount of non-social behaviors are seem on the first encounter. During the second day, residents transported after 0.5 hours exposed to a different intruder in the second meeting showed a decrease of time spent exhibiting non-social behaviors. Also, residents transported after 6 hours showed an increase of non-social behaviors when exposed to the familiar intruder on the second encounter. (C) Time exhibiting social investigatory behaviors. Similarly to the results found on the (total) social behaviors clearly showing long-term social recognition memory, and (D) Time exhibiting social agonistic behaviors. Residents clearly showed that there was a general increase in the amount of agonistic behaviors exhibited in the second encounter as compared to that seen in the first encounter; this effect, however, was not seen for resident rats transported to the animal facilities 6 hours after the first encounter, and exposed to the familiar intruder in the second encounter. $(n=6$ or 7 , mean \pm S.E., $p<0.05$.

\section{$\underline{\text { First encounter }}$}

In the first encounter the only actual independent variable was the social role; the resident rats were introduced within the testing chamber 20 min before the intruder. Even 
though, the analysis was run as if the subjects had been exposed to different times undisturbed and the familiar and novel intruders, for comparisons reasons.

The PCA revealed two main components (or axes) explaining more than $50 \%$ of the variance matrix, being the first component responsible for $32 \%$ and the second component responsible for $21 \%$ percent of this variance. Figure 2 shows that the first component of the PCA includes the behaviors ANO1, BOD1, HEA1 and FOL1, partially opposing to REA1 and ENV1. These behaviors may be characterized as gathering information, being that in the positive side of the axis it corresponds to gathering social information and in the negative side of the axis it corresponds to gathering environmental information.

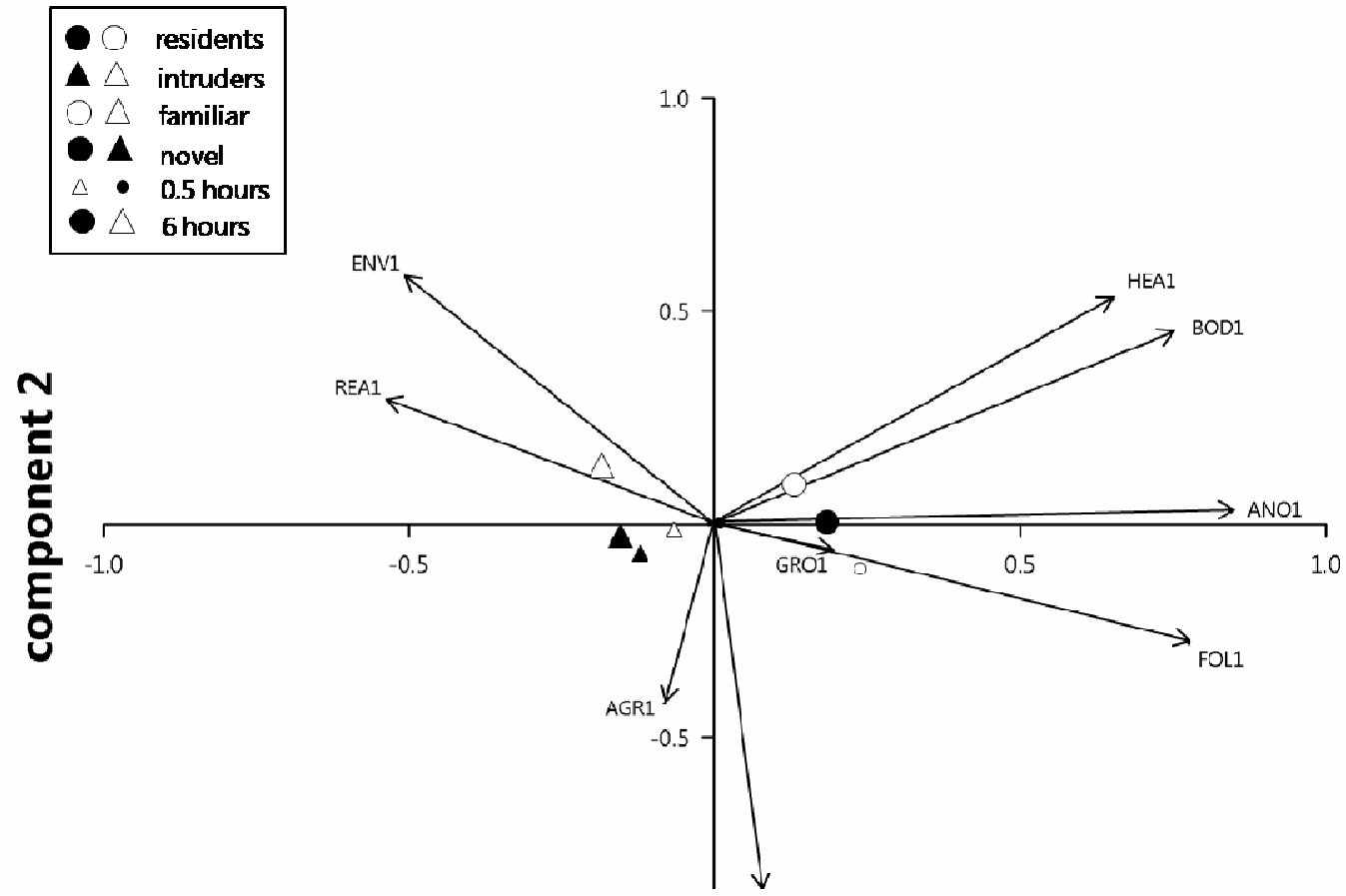

Figure 2. Principal component analysis of the first encounter: loading variables and average of the groups. The first two principal components represent more than $50 \%$ of the data variability. The component 1 formed by ANO1, BOD1, HEA1 and FOL1 on the positive side and ENV1 and REA1 on the negative side. Mainly residents are positioned on the positive side of the figure (circles) corresponding to gathering social information while intruders (triangles) are in the opposite side corresponding to gathering environmental information. The component 2 has BOD1, HEA1 and ENV1 sits on the positive side opposing to AGR1 and DOM1; this component is related to agonistic behaviors.

Figure 2 also shows that the second component of the PCA includes AGR1 and DOM1, behaviors that may be characterized as agonistic behaviors, possibly related to the 
establishment of hierarchies. Interestingly, the ANOVA of the PCA scores revealed significant differences for the first component $(F(1,53)=25.839 ; p<0.000005)$, but not for the second component, indicating that the amount of either social or environmental exploration depends on the social role; in fact, while the resident rats exhibit greater social investigation (Figure 2, circles on the positive side of the axis), the intruder rats exhibit greater investigation of the environment (Figure 2, triangles on the negative side of the axis) [note that the mean squares of the residents appear on the positive side of the first component, thus exhibiting strong correlation social investigatory behaviors (ANO1, HEA1, BOD1 and FOL1) and that the intruders' mean squares appear on the negative side of the first component, thus exhibiting strong correlation with investigation of the environment by way of REA1 and ENV1).

\section{$\underline{\text { Second encounter }}$}

In the second encounter there were three actual independent variables, that is, (1) "social role", (2) "familiarity" and (3) "time undisturbed". Once more, two principal components explain more than $50 \%$ of the variance matrix being $34 \%$ in the first component and $19 \%$ in the second component. Figure 3 shows that the first principal component is mainly determined by ANO2, BOD2, HEA2, FOL2 and, to a lesser extent, by AGR2, partially opposing to ENV2 and REA2; these latter behaviors also strongly influenced the second component. Thus, even more strikingly than in the first encounter, in the second encounter the positive axis of the first component refers unequivocally to social investigation. Figure 3 also shows that the second component is mainly determined by ENV2 and REA2 partially opposed by AGR2, and by GRO2 opposed by DOM2. 


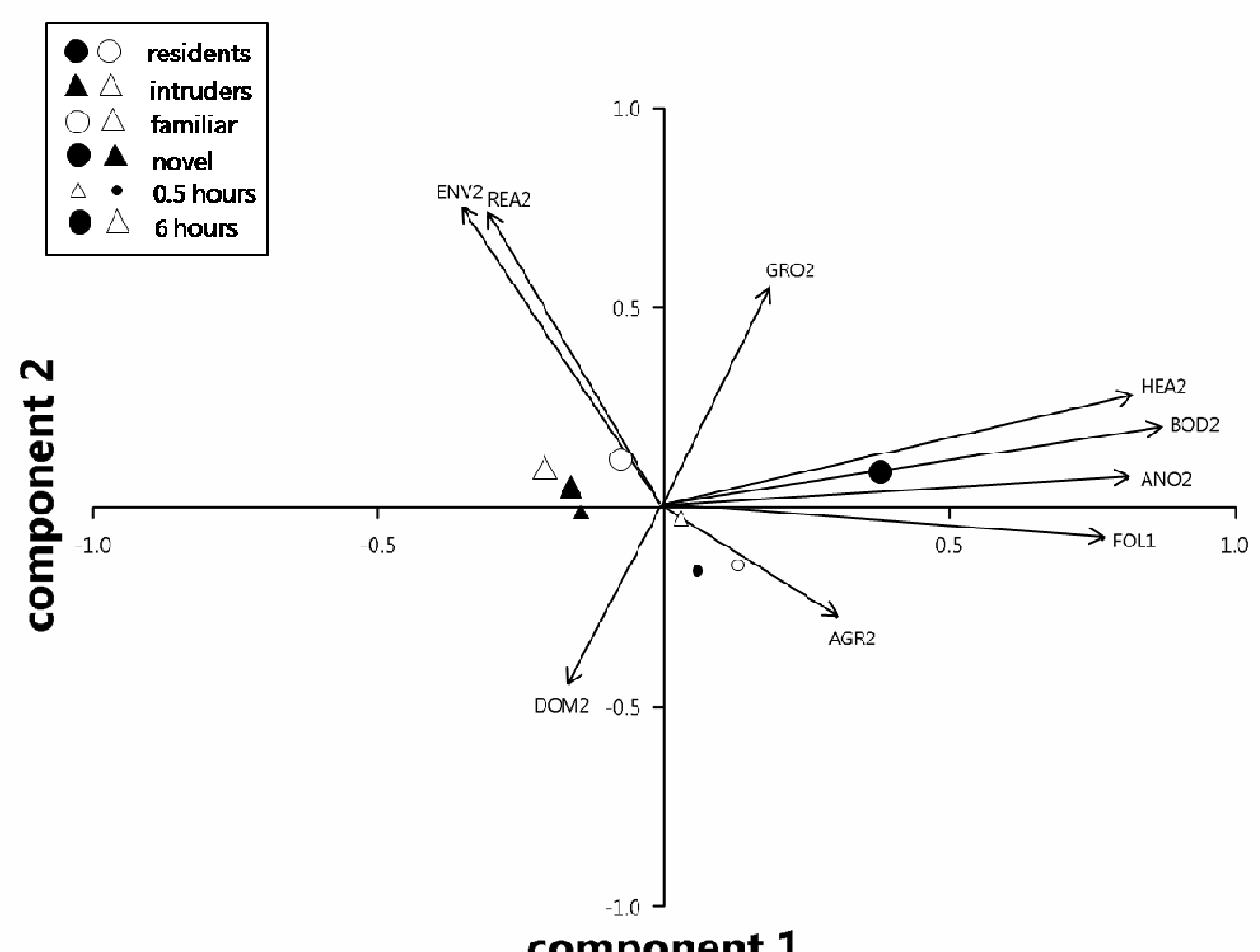

\section{component 1}

Figure 3. Principal component analysis of the second encounter: loading variables and average the groups. The first two principal components represent more than $50 \%$ of the data variability. The component 1 or first principal component is formed by ANO2, BOD2, HEA2 and FOL2 on the positive side and ENV2 and REA2 on the negative side. Residents that stayed longer on the experimental room and were exposed to a different intruder (great black circle) showed more social investigatory behaviors in comparison to residents that were left undisturbed during the same amount of time to the experimental room, but that were exposed to the same intruder (great white circle) or the other groups as well. Residents that were left undisturbed in the experimental room during only $0.5 \mathrm{~h}$ did not showed significant differences when they were exposed to the same (small white circle) or to a different (small black circle) intruder suggesting disruption of the long-term social recognition memory. The component 2 has GRO2, HEA2 and ENV2 sits on the positive side opposing to AGR2 and DOM2 suggesting an association between environmental investigation with a self-conflict-related behavior, and also an component of agonistic behaviors.

Thus, the second component is mainly determined by investigation driven towards the environment associated with a self-conflict-related behavior (manifested by GRO2), being this latter in opposition to DOM2, possibly indicating agonistic behaviors related to the establishment of hierarchies (Grant, 1963; Ades, 1968). The ANOVA of the PCA scores revealed significant differences related to (1) the "time undisturbed" $(F(1,53)=29.836 ; p<$ $0.000002)$ and to the interaction between (2) the "social role" and "time undisturbed" $(F(1,53)$ 
$=4.327 ; p<0.043)$, (3) the "social role" and "familiarity" $(F(1,53)=8.226 ; p<0.006)$, and (4) the "time undisturbed" and "familiarity" $(F(1,53)=17.316 ; p<0.00013)$. The ANOVA including the second principal component scores revealed a "time undisturbed" significant effect $(F(1,53)=15.164 ; p<0.0003)$. As a matter of fact, inspection of Figure 3 clearly shows that the resident rats transported to the animal facilities 6 hours after the first encounter and exposed to a different intruder exhibited more social behaviors (particularly social investigatory behaviors) as compared to the remaining groups (Figure 3, greater circle black). Differently, intruder rats exhibited more non-social behaviors, particularly those related to gathering environmental information; this effect was stronger for subjects transported do the animal facilities 6 hours after the first encounter (Figure 3, great white circle and great triangles). In addition, subjects (particularly the resident rats) transported to the animal facilities 0.5 hours after the first encounter exhibited more aggression (Figure 3, small black and white circles) relative to subjects transported 6 hours after the first encounter.

ANOVA

As shown by the PCA, most of the social investigation effects of interest seem to be related to the behaviors of the resident rats; thus, only data of the resident rats were subjected to further analysis.

The ANOVA involving (total) social behaviors (Figure 1A) revealed significant effects for the factor (1) "encounter" $[F(1,23)=6.11 ; p<0.03]$, and significant interaction effects for (2) "time undisturbed" and "familiarity" $[F(1,23)=18.44 ; p<0.0003]$, (3) "encounter" and "familiarity" $[F(1,23)=14.16 ; p<0.001]$, and (4) "encounter", "time undisturbed" and "familiarity" $[F(1,23)=8.96 ; p<0.007]$. Similarly, the ANOVA involving 
social investigatory behaviors (Figure 1C) revealed significant interaction effects for (1) "time undisturbed" and "familiarity" $[F(1,23)=9.70 ; p<0.005]$, (2) "encounter" and "familiarity" $[F(1,23)=14.96 ; p<0.0009]$, and (3) "encounter", "time undisturbed" and "familiarity" $[F(1,23)=7.01 ; p<0.02]$.

Inspection of Figures $1 \mathrm{~A}$ and $1 \mathrm{C}$ reveals that resident rats maintained undisturbed for 0.5 hours after the first encounter and later exposed to either a familiar or a different intruder adult rat did not show any decrease of social investigation towards the intruder rats in the second encounter relative to the first encounter; in addition, their social investigation towards the familiar and the different intruders did not differ. Differently, resident rats maintained undisturbed for 6 hours after the first encounter exhibited, in the second encounter, both a significant decrease of social investigation towards a familiar intruder and a significant increase of social investigation towards the different intruder (Figures 1A and 1C). Together, these data clearly show that when the transport of the resident rats to the animal facilities occurred 6 hours after the 2-hour first encounter, their social recognition memory was intact 24 hours after this encounter; differently, however, when the transport of the resident rats occurred 0.5 hours after the 2-hour first encounter, social recognition memory was disturbed and the animals behaved as if they had had not social contact, at all, in the previous day.

The ANOVA involving the non-social behaviors (Figure 1B) revealed significant effects for the factor (1) "time undisturbed" $[F(1,23)=7.41 ; p<0.02]$, and significant interaction effects for (2) "encounter" and "time undisturbed" $[F(1,23)=8.31 ; p<0.009]$ and (3) "encounter" and "familiarity" $[F(1,23)=4.45 ; p<0.05]$. As illustrated in Figure 1B, these effects are related to a decrease of time spent exhibiting non-social behaviors by resident rats transported to the animal facilities 0.5 hours after the first encounter, particularly for the subjects exposed to a different intruder in the second encounter, and by an increase in these 
scores for resident rats transported to the animal facilities 6 hours after the first encounter and exposed to the familiar intruder rat in the second encounter. In order to understand precisely the nature of these results, the relative percentage of each behavioral score included in the category of non-social behaviors was calculated. This revealed that about $76 \%$ of the nonsocial behaviors related to sniffing the environment (ENV). In this context, the increased environmental investigation in the second encounter, relative to the first encounter, by resident rats transported 6 hours after the first encounter may be seen as related to their smaller investigation towards the familiar intruder (see Figure 1C); that is, because they recognized this intruder, they did not explore it so extensively, thus releasing time to investigate the environment. However, this interpretation does not deal with the decreased environmental investigation in the second encounter, relative to the first, by resident rats transported to the animals facilities 0.5 hours after the first encounter. More studies would be required to clarify this issue.

The ANOVA involving social agonistic behaviors (Figure 1D) revealed (1) almost significant effects for the factor "time undisturbed" $[F(1,23)=4.08 ; p<0.06],(2)$ significant effects for the factor "encounter" $[F(1,23)=10.38 ; p<0.004]$ and (3) significant interaction effects for "time undisturbed" and "familiarity" $[F(1,23)=4.64 ; p<0.05]$. Figure 1D clearly shows that there was a general increase in the amount of agonistic behaviors exhibited by the resident rats in the second encounter as compared to that seen in the first encounter; this effect, however, was not seen for resident rats transported to the animal facilities 6 hours after the first encounter, and exposed to the familiar intruder in the second encounter (Figure 1D). Together, these results indicate that when the resident rat recognizes a previously encountered intruder, it exhibits a smaller amount of agonistic behaviors as compared to that seen in 
resident rats which second encounter involved either a unrecognized intruder or a different intruder.

\section{Discussion}

The results of the present study clearly showed that the transportation of the resident rats to the animal facilities 0.5 , but not 6 hours, after a 2-hour first encounter with an adult intruder rat had a profound impact on social recognition memory as evaluated in a second encounter occurring 24 hours after the first encounter. That is, resident rats maintained undisturbed for 6 hours after the first encounter, showed, in the second encounter realized 24 hours after the first, both a significant decrease in social investigation towards a familiar adult intruder rat and a significant increase in social investigation towards a different adult intruder rat; in addition, social investigation towards the familiar and the intruder rats in the second encounter did differ significantly among each other. Together, there results revealed that social recognition memory was spared in these rats, in spite of the transportation (Figures 1A and 1C). Conversely, resident rats maintained undisturbed for only 0.5 hours after the first encounter, showed, in the second encounter 24 hours later, no significant decrease in social investigation towards the familiar intruder and no significant increase in social investigation towards a different intruder (Figures 1A and 1C); in addition, social investigation towards the adult familiar and the intruder rats in the second encounter did not differ significantly among each other. These results indicate that social recognition memory was disturbed when transportation occurred 0.5 hours after the first encounter.

Behavioral experiments usually involve testing in special rooms where stimuli are controlled and the behavioral apparatus, testing chambers, recording equipments, and other required instruments are properly installed. Therefore, not rarely, running the experiments 
requires transportation of the subjects from the animal facilities to these experimental rooms and, after testing, transportation back to the animal facilities. This study showed that the selection of the time interval the animals are left undisturbed after behavioral testing before they are transported, may be critical for the behavioral outcomes.

Prior studies on memory consolidation after one-trial learning tasks have emphasized that memory do not consolidate immediately after acquisition and that different processes take place in brain regions involved in memory (McGaugh, 1966). For instance, there have been demonstrations that the processes underlying consolidation of a labile short-term memory into a more stable long-term memory requires protein synthesis and gene transcription (McGaugh, 2000; Izquierdo et al., 2006). In addition, it has been shown that these processes occur between 3 and 6 hours after the acquisition of the critical information (McGaugh, 2000; Kandel, 2001; Dudai, 2002). Congruent with these evidence, it has been shown that the infusion of protein synthesis inhibitors into the CA1 hippocampal subfield immediately after the acquisition of information about one object impairs long-term memory, but not short-term memory, to it; interestingly, the infusion of this protein synthesis inhibitor 6 hours after the acquisition did not interference with long-term memory for that object (Rossato et al., 2007)

In this context, one may hypothesize that when transportation of the resident rats in this study occurred 0.5 hours after the first encounter, the processes required to establish a long-term memory for the social experience were in course and thus disrupted by transportation. Differently, in resident rats which transportation occurred 6 hours after the social experience, these processes had been already completed, thus, preventing any interference.

It is also possible that the stimuli to which the animals are exposed during transportation are stressing and/or anxiety eliciting. It is well known that these types of events 
may interfere with memory; one possible way for this interference relates to protein synthesis inhibition (Cohen et al., 2006).

In conclusion, the results of the present study emphasize that usually unattended laboratory routines that may interfere with social recognition memory.

\section{References}

Ades C (1968) A resposta de levantar-se no rato branco. Ciência e Cultura 20:59-71.

Bannerman DM, Lemaire M, Beggs S, Rawlins JN, Iversen SD (2001) Cytotoxic lesions of the hippocampus increase social investigation but do not impair social-recognition memory. Exp Brain Res 138:100-109.

Burman OH, Mendl M (1999) The effects of environmental context on laboratory rat social recognition. Anim Behav 58:629-634.

Burman OH, Mendl M (2000) Short-term social memory in the laboratory rat: its susceptibility to disturbance. Appl Anim Behav Sci 67:241-254.

Burman OH, Mendl M (2002) Recognition of conspecific odors by laboratory rats (Rattus norvegicus) does not show context specificity. J Comp Psychol 116:247-252.

Burman OH, Mendl M (2003) The influence of preexperimental experience on social discrimination in rats (Rattus norvegicus). J Comp Psychol 117:344-349.

Castner SA, Goldman-Rakic PS, Williams GV (2004) Animal models of working memory: insights for targeting cognitive dysfunction in schizophrenia. Psychopharmacology (Berl) 174:111-125.

Cohen H, Kaplan Z, Matar MA, Loewenthal U, Kozlovsky N, Zohar J (2006) Anisomycin, a protein synthesis inhibitor, disrupts traumatic memory consolidation and attenuates posttraumatic stress response in rats. Biol Psychiatry 60:767-776.

Dantzer R, Bluthe RM, Koob GF, Le Moal M (1987) Modulation of social memory in male rats by neurohypophyseal peptides. Psychopharmacology (Berl) 91:363-368.

Dantzer R, Koob GF, Bluthe RM, Le Moal M (1988) Septal vasopressin modulates social memory in male rats. Brain Res 457:143-147.

Dudai Y (2002) Molecular bases of long-term memories: a question of persistence. Curr Opin Neurobiol 12:211-216. 
Ferguson JN, Aldag JM, Insel TR, Young LJ (2001) Oxytocin in the medial amygdala is essential for social recognition in the mouse. J Neurosci 21:8278-8285.

Ferguson JN, Young LJ, Hearn EF, Matzuk MM, Insel TR, Winslow JT (2000) Social amnesia in mice lacking the oxytocin gene. Nat Genet 25:284-288.

Garau A, Marti MA, Sala J, Balada F (2000) Age effects on the social interaction test in early adulthood male rats. Depress Anxiety 12:226-231.

Gheusi G, Bluthe RM, Goodall G, Dantzer R (1994) Social and individual recognition in rodents: methodological aspects and neurobiological bases. Behavioural Process $33: 59-88$.

Grant EC (1963) An analysis of the social behaviour of the male laboratory rat Behaviour $21: 260-281$.

Izquierdo I, Bevilaqua LR, Rossato JI, Bonini JS, Medina JH, Cammarota M (2006) Different molecular cascades in different sites of the brain control memory consolidation. Trends Neurosci 29:496-505.

Kandel ER (2001) The molecular biology of memory storage: a dialogue between genes and synapses. Science 294:1030-1038.

Kogan JH, Frankland PW, Silva AJ (2000) Long-term memory underlying hippocampusdependent social recognition in mice. Hippocampus 10:47-56.

McGaugh JL (1966) Time-dependent processes in memory storage. Science 153:1351-1358.

McGaugh JL (2000) Memory--a century of consolidation. Science 287:248-251.

Popik P, van Ree JM (1998) Neurohypophyseal peptides and social recognition in rats. Prog Brain Res 119:415-436.

Prediger RD, Takahashi RN (2003) Ethanol improves short-term social memory in rats. Involvement of opioid and muscarinic receptors. Eur J Pharmacol 462:115-123.

Prediger RD, Takahashi RN (2005) Modulation of short-term social memory in rats by adenosine A1 and A(2A) receptors. Neurosci Lett 376:160-165.

Prediger RD, Batista LC, Miyoshi E, Takahashi RN (2004) Facilitation of short-term social memory by ethanol in rats is mediated by dopaminergic receptors. Behav Brain Res 153:149-157.

Richter K, Wolf G, Engelmann M (2005) Social recognition memory requires two stages of protein synthesis in mice. Learn Mem 12:407-413.

Rossato JI, Bevilaqua LR, Myskiw JC, Medina JH, Izquierdo I, Cammarota M (2007) On the role of hippocampal protein synthesis in the consolidation and reconsolidation of object recognition memory. Learn Mem 14:36-46. 
Sekiguchi R, Wolterink G, van Ree JM (1991) Short duration of retroactive facilitation of social recognition in rats. Physiol Behav 50:1253-1256.

Thor DH, Holloway WR (1982) Social memory of the male laboratory rat. Journal of Comparative and Physiological Psychology 96:1000-1006.

Young LJ (2002) The neurobiology of social recognition, approach, and avoidance. Biol Psychiatry 51:18-26. 
CAPÍTULO 5 
Em conjunto, os resultados do presente trabalho mostram que (1) a expressão de comportamentos sociais, assim como a memória de reconhecimento social, em ratos está sujeita à modulação temporal (Capítulo 2), (2) a duração do primeiro encontro no paradigma intruso-residente envolvendo ratos é crucial para o estabelecimento da memória de reconhecimento social de "longa duração"; isto é, quando o primeiro encontro tem duração de 2 horas ou mais, a memória de reconhecimento social dura pelo menos 24 horas (Capítulo 3), e (3) o transporte dos animais residentes para o biotério 30 minutos após o primeiro encontro, mas não 6 horas depois, prejudica a memória de reconhecimento social no paradigma intrusoresidente, indicando que deve-se estar atento para esse tipo de rotina laboratorial durante a realização de experimentos envolvendo esse paradigma comportamental.

O paradigma intruso-residente vem sendo empregado como modelo experimental pela facilidade do seu emprego, rapidez na realização dos testes e consistência dos resultados. Ademais, trata-se de um teste que permite avaliar memória adquirida após uma única tentativa, facultando o acompanhamento do curso temporal de seu arquivamento e também a realização de manipulações e intervenções no sistema nervoso, para avaliar seu impacto nesses processos. Ademais, esse paradigma comportamental vem sendo empregado para identificar determinados tipos de disfunções do sistema nervoso central. Os resultados do presente estudo indicam claramente que variáveis experimentais não raramente negligenciadas podem influenciar marcadamente os resultados.

Por exemplo, a maioria dos estudos acerca da memória de reconhecimento social é realizada na fase ativa do animal, ou seja, na fase escura do ciclo circadiano em roedores (Dantzer et al., 1987; Dantzer et al., 1988; Popik et al., 1991a; Sekiguchi et al., 1991a,b; Engelmann e Landgraf, 1994; Popik e Van Ree, 1998). Os resultados do presente estudo 
mostram que a expressão de comportamentos sociais comumente empregados na avaliação da memória de reconhecimento social é mais pronunciada na fase inativa dos animais; ademais, observou-se que quando testados nessa fase, intervalos de 60 minutos entre sessões de 5 minutos de duração não levam ao usualmente observado desvanecimento da memória de reconhecimento social (Moura et al. (A), submitted - ver Capítulo 2). Essa observação estimulou a realização dos demais experimentos com ratos em sua fase inativa, particularmente em decorrência do interesse em se demonstrar que a memória de reconhecimento social não corresponde apenas a um sistema de memória de curta duração, mas também um sistema de memória de longa duração. Essa estratégia revelou-se bem sucedida (Moura et al. (B), em preparação - ver Capítulo 3; Moura et al. (C), em preparação ver Capítulo 4).

Relatos anteriores postulavam que a memória de reconhecimento social corresponde a um mecanismo que permite a retenção temporária de informações (Dantzer et al., 1987; Dantzer et al., 1988; Popik et al., 1991a; Sekiguchi et al., 1991a,b; Engelmann e Landgraf, 1994; Popik e Van Ree, 1998). Por exemplo, diversos estudos mostram que a memória de reconhecimento social se desvanece quando o intervalo entre os encontros varia entre 30 e 60 minutos. Contudo, evidências geradas em estudos sócio-biológicos parecem conflitar com esse postulado, dado que ratos são identificados como animais sociais e que vivem em grupos (Barnett, 1958; Bolles e Woods, 1964; Latane e Glass, 1968). Caldweel (1985), por exemplo, defendeu que do ponto de vista sociobiológico, é crucial a existência de uma habilidade para reter lembranças sobre um outro indivíduo dada a possibilidade do mesmo encontrado posteriormente. Essas concepções conflitantes parecem estar relacionadas aos procedimentos utilizados para se avaliar a duração da memória de reconhecimento social em ratos de labotório. 
Esse tipo de raciocínio levou à proposta de se aumentar a duração do primeiro encontro como forma de induzir a uma memória de reconhecimento social (mais) duradoura. Os resultados descritos por Moura et al. (B, em preparação - ver Capítulo 3), confirmados por Moura et al. (C, em preparação - ver Capítulo 4), sustentam enfaticamente a noção de que o aumento da duração do encontro social inicial leva à formação de uma memória de reconhecimento social cuja duração é de pelo menos 24 horas. Isto é, o intrusos devem permanecer com os residentes por pelo menos 2 horas no primeiro encontro para que este último seja capaz de identifica-lo e distingui-lo de um intruso diferente. Por outro lado, e confirmando a literatura da área, encontros com duração de 30 minutos ou menos não levam à formação de uma memória de reconhecimento social que se manifeste 24 horas depois (Sekiguchi et al., 1991a).

Estudos sobre a memória de reconhecimento social baseiam suas conclusões na análise da quantidade de comportamentos sociais apresentados pelos roedores durante encontros; é comum que se ignore a contribuição singular de cada comportamento registrado (Thor e Holloway, 1982; Dantzer et al., 1987; Popik et al., 1991b; Popik et al., 1991a; Sekiguchi et al., 1991b; Gheusi et al., 1994; Engelmann et al., 1995; Burman e Mendl, 1999, 2000; Ferguson et al., 2000; Ferguson et al., 2001); isto é, usualmente adota-se como parâmetro de análise o conjunto de atividades direcionadas pelo animal ao co-específico. Nos experimentos apresentados no presente trabalho, os comportamentos sociais individuais foram registrados; sua escolha baseou-se na literatura da área (Thor e Holloway, 1982; Dantzer et al., 1987; Popik et al., 1991b; Popik et al., 1991a; Sekiguchi et al., 1991b; Gheusi et al., 1994; Engelmann et al., 1995) e também nas observações desta autora. Na maioria dos experimentos, cerca de $50 \%$ dos comportamentos sociais dos residentes corresponderam à investigação anogenital. Por outro lado, dentre os comportamentos não-sociais, mais do que $75 \%$ corresponde à investigação do ambiente. 
A Análise de Componentes Principais utilizada nestes estudos (Sekiguchi et al., 1991a) revelou que ao invés de agrupar os comportamentos sociais em uma única categoria, deve-se optar pela sua organização em duas sub-categorias cujas naturezas são distintas. A primeira, denominada comportamentos sociais investigatórios, incluindo ANO, HEA, BOD e FOL, e a segunda denominada comportamentos sociais agonísticos, incluindo DOM e AGR (ver Moura et al. (B), em preparação - ver Capítulo 3; Moura et al. (C), em preparação - ver Capítulo 4). Os resultados do presente estudo mostraram também que a sub-categoria de comportamentos sociais investigativos é suficiente (e mais eficiente) para revelar a memória de reconhecimento social de ratos em relação a intrusos encontrados anteriormente e em relação a intrusos diferentes dos anteriormente encontrados.

Outro aspecto que requer especial atenção no estudo da memória de reconhecimento social em ratos envolve a escolha do co-específico apresentado como intruso durante os testes. Desconhecemos estudos que tenham utilizado intrusos adultos machos em testes de memória de reconhecimento social, em ratos. Os relatos disponíveis na literatura dessa área de conhecimento referem-se à utilização de filhotes entre 21 e 30 dias, ou de fêmeas adultas ovarectomizadas como intrusos; pensa-se que esses intrusos minimizam o aparecimento de comportamentos agressivos e sexuais por parte dos residentes (Thor e Holloway, 1982; Engelmann et al., 1995; Ferguson et al., 2000; Ferguson et al., 2001). Contudo, parece plausível pensar que filhotes não representam grande desafio ou risco para residentes adultos; assim, é possível que o encontro com filhotes ou fêmeas ovariectomizadas seja uma experiência menos "memorável" do que com um adulto macho de mesmo tamanho. Assim, é possível que parte do sucesso do presente estudo em revelar a memória de reconhecimento social com duração de pelo menos 24 horas seja decorrente da utilização de adultos machos como intrusos (Moura et al. (B), em preparação - ver Capítulo 3; Moura et al. (C), em preparação - ver Capítulo 4). Ressalte-se, porém, que não se pode ser assertivo ou definitivo 
em relação a essa conclusão, uma vez que não foram utilizados intrusos juvenis com exposição contínua e prolongada (de pelo menos 2 horas) ao residente, testado 24 horas depois desse encontro. Mais estudos seriam necessários para se poder concluir acerca dessa questão.

Existem relatos na literatura de que o tipo de acondicionamento dos animais influencia a memória de reconhecimento social em roedores, além da quantidade de comportamentos agressivos (Thor e Holloway, 1982; Dantzer et al., 1987; Dantzer et al., 1988; Popik et al., 1991a; Sekiguchi et al., 1991a,b; Engelmann e Landgraf, 1994; Engelmann et al., 1995; Popik e Van Ree, 1998). Nos experimentos descritos por Moura et al. (A, submetido - ver Capitulo 2) os residentes foram mantidos socialmente isolados por cerca de 30 dias, enquanto nos experimentos descritos por Moura et al. (B, em preparação - ver Capítulo 3) e Moura et al. (C, em preparação - ver Capítulo 4) os residentes foram isolados na câmara de testes por apenas 20 minutos antes do primeiro encontro; nestes últimos estudos tanto intrusos como residentes foram mantidos agrupados antes do primeiro encontro. Assim, diferentemente do proposto na literatura, não há necessidade alguma de isolar ratos socialmente antes da realização dos testes no paradigma intruso-residente. Por outro lado, é possível que a manutenção dos animais agrupados antes do primeiro encontro social tenha contribuído para a memória de reconhecimento social de longa duração. De fato, a literatura da área inclui relatos de que animais mantidos isolados exibem comprometimento no desempenho em testes de memória (Gentsch et al., 1988; Wilkinson et al., 1994; Rudy, 1996; Wongwitdecha e Marsden, 1996a,b,c; Coudereau et al., 1997; Coventry et al., 1997; Weiss et al., 2004). Essa questão permanece sem resposta, mas poderia ser facilmente examinada experimentalmente, submetendo-se co-específicos a diferentes períodos de isolamento social antes dos testes.

Uma questão interessante gerada por essas estratégias experimentais refere-se ao estabelecimento dos papéis sociais assumidos pelos animais nos experimentos envolvendo 
intrusos adultos. Isto é, os animais residentes e intrusos foram ambos adultos machos, e exibiam a mesma idade; do ponto de vista da execução do experimento, a escolha de qual animal seria manipulado como residente ou intruso foi completamente casual. E a principal distinção entre esses animais refere-se à introdução do residente na caixa de testes 20 minutos antes da introdução do intruso e sua posterior manutenção no mesmo ambiente, até o segundo encontro. Como vimos, esse período de 20 minutos foi suficiente para a definição dos papéis sociais assumidos pelos animais, que se manifestaram já no primeiro encontro. É possível que a introdução dos residentes na câmara experimental 20 minutos da introdução dos intrusos confira aos primeiros a vantagem de conhecer e demarcar o ambiente como seu território antes da chegada do possível competidor. Um estudo potencialmente interessante seria introduzir ambos os adultos concomitantemente na câmara experimental. Supostamente, isso geraria uma competição pela demarcação do ambiente e pelo estabelecimento de uma hierarquia que poderia ter reflexos no estabelecimento da memória de reconhecimento social em ambos os animais.

Finalmente, outro fator que prejudicou os indicadores de memória de reconhecimento social dos residentes foi o transporte desses animais para o biotério 0,5 horas, mas não 6 horas, depois do primeiro encontro (Moura et al. (C), (em preparação - ver Capítulo 4). É provável que na maioria dos estudos em que o intervalo de tempo entre os encontros foi pequeno, os animais nem sequer tenham sido transportados ou mesmo retirados da sala de experimentos. Porém, em estudos que envolvem treinamento e/ou testes em pelo menos dois dias, é provável que o transporte tenha sido necessário; o procedimento habitual da maioria dos laboratórios em que se realiza testes comportamentais nestes casos é que esse transporte seja realizado entre 30 minutos e 2 horas, antes e/ou após a realização dos testes. Assim, os resultados do presente estudo (Moura et al. (C), (em preparação - ver Capítulo 4) representam um alerta no sentido de que deve-se ser cauteloso em relação às rotinas laboratoriais, já que as 
mesmas podem influenciar o desempenho dos animais se realizadas um curto período de tempo depois do teste comportamental. Os fatores que levaram a esse prejuízo da memória de reconhecimento social nos animais transportados 0,5 horas após o primeiro encontro não estão claros. É possível que eles estejam relacionados a algum tipo de interferência nos processos de síntese protéica que se seguem após uma experiência significativa. Por exemplo, Richter et al. (2005) mostraram que a síntese protéica que se segue ao primeiro encontro entre camundongos da mesma espécie ocorre em duas etapas, a primeira entre 1 e 2 horas após o encontro 2, e a segunda entre 5 e 6 horas após o encontro; como o desenvolvimento da segunda etapa parece depender do completamento da primeira, interferência na primeira pode comprometer todo o processo. A avaliação dessa hipótese requer experimentos adicionais que poderiam envolver, inclusive, a administração de inibidores de síntese protéica sistemicamente, em diferentes momentos após a aquisição da informação social que ocorre no primeiro encontro. Outra possibilidade também interessante envolveria a identificação das estruturas nervosas envolvidas nesses processos. 


\section{Referências}

BARNETT, S.A. An analysis of social behavior in Wild rats. Proc Zool Soc Lond, v. 130, p. 107-52, 1958.

BOLLES, R.C.; WOODS, P.J. The ontogeny of behavior in the albino rat. Anim Behav, v. 427-41, 1964.

BURMAN, O.H.; MENDL, M. The effects of environmental context on laboratory rat social recognition. Anim Behav, v. 58, p. 629-34, 1999.

BURMAN, O.H.; MENDL, M. Short-term social memory in the laboratory rat: its susceptibility to disturbance. Appl Anim Behav Sci, v. 67, p. 241-54, 2000.

CALDWEEL, R.L. A test of individual recognition in the stomatopod Gonodactylus festae. Animal Behavior, v. 33, p. 101-6, 1985.

COUDEREAU, J.P.; DEBRAY, M.; MONIER, C.; BOURRE, J.M.; FRANCES, H. Isolation impairs place preference conditioning to morphine but not aversive learning in mice. Psychopharmacology (Berl), v. 130, p. 117-23, 1997.

COVENTRY, T.L.; D'AQUILA, P.S.; BRAIN, P.; WILLNER, P. Social influences on morphine conditioned place preference. Behav Pharmacol, v. 8, p. 575-84, 1997.

DANTZER, R.; BLUTHE, R.M.; KOOB, G.F.; LE MOAL, M. Modulation of social memory in male rats by neurohypophyseal peptides. Psychopharmacology (Berl), v. 91, p. 363-68, 1987.

DANTZER, R.; KOOB, G.F.; BLUTHE, R.M.; LE MOAL, M. Septal vasopressin modulates social memory in male rats. Brain Res, v. 457, p. 143-47, 1988.

ENGELMANN, M.; LANDGRAF, R. Microdialysis administration of vasopressin into the septum improves social recognition in Brattleboro rats. Physiol Behav, v. 55, p. 145-49, 1994.

ENGELMANN, M.; WOTJAK, C.T.; LANDGRAF, R. Social discrimination procedure: an alternative method to investigate juvenile recognition abilities in rats. Physiol Behav, v. 58, p. 315-321, 1995.

FERGUSON, J.N.; ALDAG, J.M; INSEL, T.R.; YOUNG, L.J. Oxytocin in the medial amygdala is essential for social recognition in the mouse. J Neurosci, v. 21, p. 8278-85, 2001.

FERGUSON, J.N.; YOUNG, L.J.; HEARN, E.F.; MATZUK, M.M.; INSEL, T.R.; WINSLOW, J.T. Social amnesia in mice lacking the oxytocin gene. Nat Genet, v. 25, p. $284-$ $88,2000$. 
GENTSCH, C.; LICHTSTEINER, M.; FRISCHKNECHT, H.R.; FEER, H.; SIEGFRIED, B. Isolation-induced locomotor hyperactivity and hypoalgesia in rats are prevented by handling and reversed by resocialization. Physiol Behav, v. 43, p. 13-16, 1988.

GHEUSI, G.; BLUTHE, R.M.; GOODALL, G.; DANTZER, R. Social and individual recognition in rodents: methodological aspects and neurobiological bases. Behavioural Process, v. 33, p. 59-88, 1994.

LATANE, B.; GLASS, D.C. Social and nonsocial attraction in rats. J Pers Soc Psychol, v. 9, p. 142-46, 1968.

MOURA, P.J.; MEIRELLES, S.T.; XAVIER, G.F. (B, in preparation). Social recognition memory in rats may last at least 24 hours: a parametric study.

MOURA, P.J.; VENKITARAMANI, D.V.; TASHEV, R.; LOMBROSO, P.; XAVIER, G.F. On the intruder-resident paradigm: unattended laboratory routines that may interfere with SRM.

POPIK, P.; VAN REE, J.M. Neurohypophyseal peptides and social recognition in rats. Prog Brain Res, v. 119, p. 415-36, 1998.

POPIK, P.; VETULANI, J.; BISAGA, A.; VAN REE, J.M. Recognition cue in the rat's social memory paradigm. J Basic Clin Physiol Pharmacol, v. 2, p. 315-27, 1991a.

POPIK, P.; WOLTERINK, G.; DE BRABANDER, H.; VAN REE, J.M. Neuropeptides related to [Arg8]vasopressin facilitates social recognition in rats. Physiol Behav, v. 49, p. 1031-35, $1991 b$.

RUDY, J.W. Postconditioning isolation disrupts contextual conditioning: an experimental analysis. Behav Neurosci, v. 110, p. 238-46, 1996.

SEKIGUCHI, R.; WOLTERINK, G.; VAN REE, J.M. Analysis of the influence of vasopressin neuropeptides on social recognition of rats. Eur Neuropsychopharmacol, v. 1, p. 123-26, 1991a.

SEKIGUCHI, R.; WOLTERINK, G.; VAN REE, J.M. Short duration of retroactive facilitation of social recognition in rats. Physiol Behav, v. 50, p. 1253-56, $1991 \mathrm{~b}$.

THOR, D.; HOLLOWAY, W.R. Social memory of the male laboratory rat. Journal of Comparative and Physiological Psychology, v. 96, p. 1000-1006, 1982.

WEISS, I.C.; PRYCE, C.R.; JONGEN-RÊLO, A.L.; NANZ-BAHR, N.I.; FELDON, J. Effect of social isolation on stress-related behavioural and neuroendocrine state in the rat. Behavioral Brain Research, v. 152, p. 279-95, 2004.

WILKINSON, L.S.; KILLCROSS, S.S.; HUMBY, T.; HALL, F.S.; GEYER, M.A.; ROBBINS, T.W. Social isolation in the rat produces developmentally specific deficits in prepulse inhibition of the acoustic startle response without disrupting latent inhibition. Neuropsychopharmacology, v. 10, p. 61-72, 1994. 
WONGWITDECHA, N.; MARSDEN, C.A. Effect of social isolation on the reinforcing properties of morphine in the conditioned place preference test. Pharmacol Biochem Behav, v. 53, p. 531-34, 1996a.

WONGWITDECHA, N.; MARSDEN, C.A. Effects of social isolation rearing on learning in the Morris water maze. Brain Res, v. 715, p. 119-24, $1996 \mathrm{~b}$.

WONGWITDECHA, N.; MARSDEN, C.A. Social isolation increases aggressive behaviour and alters the effects of diazepam in the rat social interaction test. Behav Brain Res, v. 75, p. 27-32, $1996 \mathrm{c}$. 